\title{
Alkyl halides via visible light mediated dehalogenation
}

Manjula D. Rathnayake, and Jimmie D. Weaver III*

Department of Chemistry, Oklahoma State University, Stillwater, OK 74078

¡immie.weaver@okstate.edu

Supporting information

Table of contents:

$\begin{array}{ll}\text { General experimental } & \mathrm{S} 2\end{array}$

$\begin{array}{ll}\text { Synthesis of substrates } & \text { S3 }\end{array}$

$\begin{array}{ll}\text { Optimization of reaction conditions } & \text { S10 }\end{array}$

$\begin{array}{ll}\text { Mechanistic experiments } & \text { S12 }\end{array}$

$\begin{array}{ll}\text { Light mediated dehalogenation } & \text { S31 }\end{array}$

$\begin{array}{lr}\text { References } & \text { S39 }\end{array}$

$\begin{array}{ll}\text { NMR and MS spectra } & \text { S41 }\end{array}$ 


\section{General Experimental:}

All reagents were obtained from commercial suppliers (Aldrich, VWR, TCI Chemicals, and Oakwood Chemicals) and used without further purification unless otherwise noted. Acetonitrile $\left(\mathrm{CH}_{3} \mathrm{CN}\right)$ was dried for $48 \mathrm{~h}$ over activated $3 \mathrm{~A}^{\circ}$ molecular sieves. Distilled diisopropylethylamine was stored over $\mathrm{KOH}$ pellets with air tight light resistant container.

Reactions were monitored by a combination of thin layer chromatography (TLC), (obtained from sorbent technologies Silica XHL TLC Plates, w/UV254, glass backed, $250 \mu \mathrm{m}, 20$ x $20 \mathrm{~cm}$ ) and were visualized with ultraviolet light, potassium permanganate stain, GC-MS (QP 2010S, Shimadzu equipped with auto sampler) and 1H NMR (vide infra). Isolations were carried out using Teledyne Isco Combiflash Rf 200i flash chromatograph with Redisep Rf normal phase silica (4 g, 12 g, 24 g, 40 g) with product detection at 254 and $288 \mathrm{~nm}$ and by ELSD (evaporative light scattering detection). NMR spectra were obtained on a $400 \mathrm{MHz}$ Bruker Avance III spectrometer and Neo $600 \mathrm{MHz}$. 1H and 13C NMR chemical shifts are reported in ppm relative to the residual protio solvent peak $(1 \mathrm{H}, 13 \mathrm{C})$. Photophysical properties were studied on Varian Cary Eclipse spectrophotometer. Mass spectra (HRMS) analysis was performed on LTQOrbitrapXL by Thermo Scientific ltd using a Heatedelectrospray ionization (H-ESI) source.

Reactions were set up in a light bath which consists of Blue LEDs ( $\lambda$ max emission $\sim 450 \mathrm{~nm}$ ) or purple LEDs ( $\lambda_{\max }$ emission $\sim 410 \mathrm{~nm}$ ) as described below. Blue LEDs (200 LEDs)/ purple LEDs (240 LEDs) were wrapped around the walls of glass crystallization dish and secured with masking tape and then wrapped with aluminum foil. A lid which rest on the top was fashioned from cardboard and holes were made such that reaction tubes were held firmly in the cardboard lid which was placed on the top of bath. Water was added to the bath such that the tubes were submerged in the water which was at $28{ }^{\circ} \mathrm{C}$. (Temperature of the bath was maintained at $28^{\circ} \mathrm{C}$ using a fan).

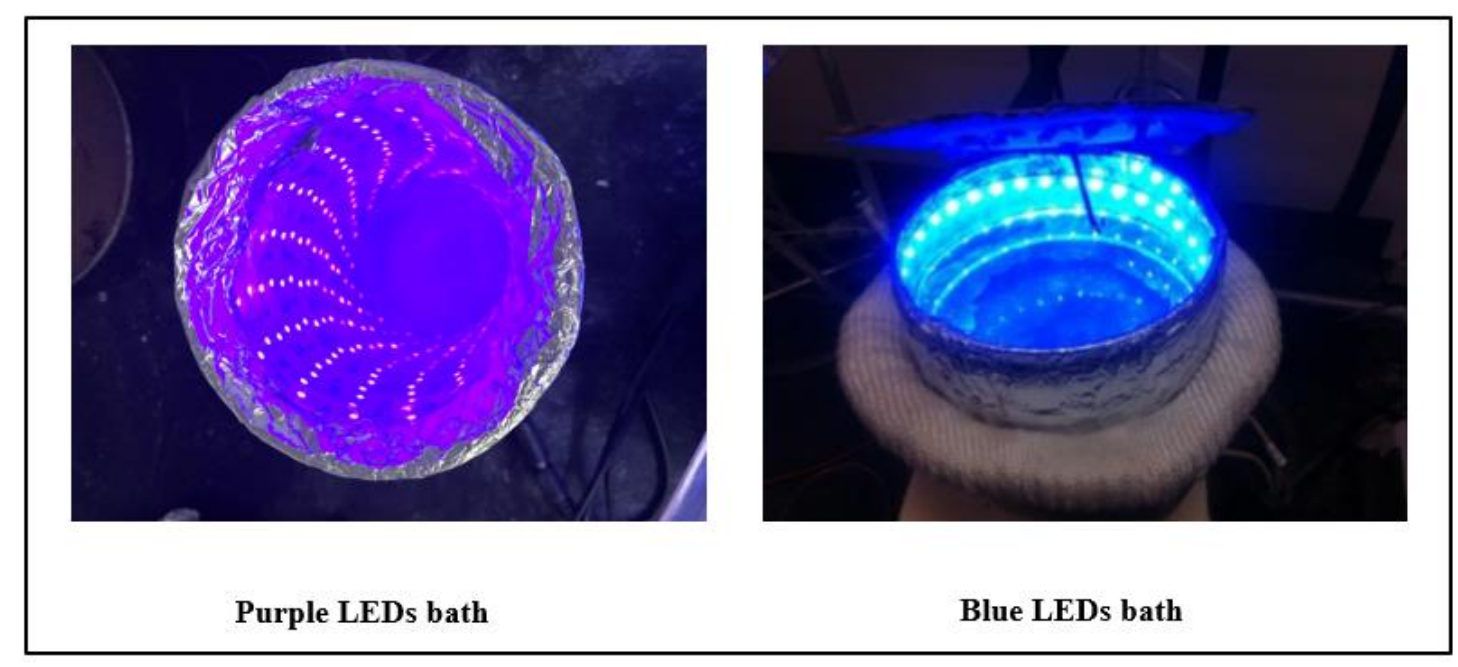




\section{Synthesis of alkyl bromide/chloride substrates:}

Alkyl bromides and alkyl chlorides were synthesized according to the literature procedures and some procedures were modified slightly to increase the yield of alkyl bromides and chlorides. ${ }^{1}$

Ethyl 2,2-dibromo-2-((2,6-difluorophenyl)sulfonyl)acetate

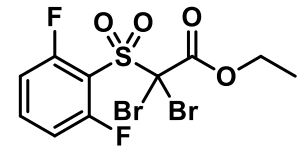

$1 \mathrm{~b}$

Ethyl 2-((2,6-difluorophenyl)sulfonyl)acetate (1.0 g, $3.9 \mathrm{mmol}, 1$ equiv) and triethylamine (1.2 g, $11.7 \mathrm{mmol}, 3$ equiv) in $25 \mathrm{~mL}$ of DCM was stirred for $20 \mathrm{~min}$. Bromine (2.5 g, $15.6 \mathrm{mmol}, 4$ equiv) was added in to the reaction. The progress of the reaction was monitored by TLC. The reaction was stirred at room temperature for 15 h. After consumption of the starting material, the mixture was diluted with $\mathrm{H}_{2} \mathrm{O}(15 \mathrm{~mL})$ and then extracted with EtOAc $(3 \times 15 \mathrm{~mL})$. The organic layers were combined and washed with brine then dried with $\mathrm{MgSO}_{4}$. The crude product was concentrated in vacuo and purified via automated flash chromatography using EtOAc in hexanes ( $0 \%$ to $100 \%)$ with product eluting at $19 \%$ on a $40 \mathrm{~g}$ silica column to afford $\mathbf{1 b}$ in $95 \%$ yield (3.7 mmol, $1.6 \mathrm{~g}$ ). ${ }^{1 \mathrm{a}}{ }^{1} \mathrm{H} \mathrm{NMR}\left(400 \mathrm{MHz}, \mathrm{CDCl}_{3}\right) \delta 7.72$ (tt, $J=8.4,5.7 \mathrm{~Hz}, 1 \mathrm{H}$ ), 7.11 (ap t, $J=8.4$ $\mathrm{Hz}, 2 \mathrm{H}), 4.39(\mathrm{q}, J=7.2 \mathrm{~Hz}, 2 \mathrm{H}), 1.36(\mathrm{t}, J=7.2 \mathrm{~Hz}, 3 \mathrm{H}) .{ }^{19} \mathrm{~F} \mathrm{NMR}\left(376 \mathrm{MHz}, \mathrm{CDCl}_{3}\right) \delta-98.4--98.5(\mathrm{~m})$. ${ }^{13} \mathrm{C}$ NMR $\left(101 \mathrm{MHz}, \mathrm{CDCl}_{3}\right) \delta 163.4,161.4-160.5(\mathrm{dd}), 138.8(\mathrm{qd}, J=9.7,8.2,4.6 \mathrm{~Hz}), 114.1(\mathrm{~d}, J=4.6$ $\mathrm{Hz}), 113.9(\mathrm{~d}, J=5.8 \mathrm{~Hz}), 71.0,66.6,14.1$. HRMS (ESI) calcd. for $\left[\mathrm{C}_{10} \mathrm{H}_{8} \mathrm{Br}_{2} \mathrm{~F}_{2} \mathrm{O}_{4} \mathrm{SNa}\right]^{+}[\mathrm{M}+\mathrm{Na}]^{+}: \mathrm{m} / \mathrm{z}$, 444.8355 found 444.8355 .

\section{Ethyl 2,2-dibromo-2-(phenylsulfonyl)acetate}

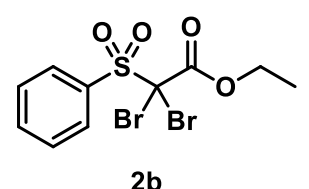

Ethyl 2-(phenylsulfonyl)acetate (0.9 g, $3.9 \mathrm{mmol}, 1$ equiv) and triethylamine (1.2 g, $11.7 \mathrm{mmol}, 3$ equiv) in $25 \mathrm{~mL}$ of DCM was stirred for $20 \mathrm{~min}$. Bromine (2.5 g, 15.6 mmol, 4 equiv) was added in to the reaction. The progress of the reaction was monitored by TLC. The reaction was stirred at room temperature for $17 \mathrm{~h}$. After consumption of the starting material, the mixture was diluted with $\mathrm{H}_{2} \mathrm{O}(15 \mathrm{~mL})$ and then extracted with EtOAc $(3 \times 15 \mathrm{~mL})$. The organic layers were combined and washed with brine then dried with $\mathrm{MgSO}_{4}$. The crude product was concentrated in vacuo and purified via automated flash chromatography using EtOAc in hexanes ( $0 \%$ to $100 \%)$ with product eluting at $21 \%$ on a $40 \mathrm{~g}$ silica column to afford $\mathbf{2 b}$ in $93 \%$ yield (3.6 mmol, $1.4 \mathrm{~g}) .{ }^{1 \mathrm{a}}{ }^{1} \mathrm{H}$ NMR $\left(400 \mathrm{MHz}, \mathrm{CDCl}_{3}\right) \delta 8.12(\mathrm{dd}, 2 \mathrm{H}), 7.75(\mathrm{t}, 1 \mathrm{H}), 7.60(\mathrm{t}, J=7.9 \mathrm{~Hz}, 2 \mathrm{H}), 4.35(\mathrm{q}$, $J=7.1 \mathrm{~Hz}, 2 \mathrm{H}), 1.33(\mathrm{t}, J=7.1 \mathrm{~Hz}, 3 \mathrm{H}) .{ }^{13} \mathrm{C} \mathrm{NMR}\left(101 \mathrm{MHz}, \mathrm{CDCl}_{3}\right) \delta 161.8,135.9,133.1,132.9,129.1$, 69.2, 66.0, 14.1. HRMS (ESI) calcd. for $\left[\mathrm{C}_{10} \mathrm{H}_{10} \mathrm{Br}_{2} \mathrm{O}_{4} \mathrm{SNa}\right]^{+}[\mathrm{M}+\mathrm{Na}]^{+}: \mathrm{m} / \mathrm{z}, 408.8544$ found 408.8541. 
Ethyl 2,2-dibromo-2-(methylsulfonyl)acetate

Ethyl 2-(methylsulfonyl)acetate $(0.7 \mathrm{~g}, 3.9 \mathrm{mmol}, 1$ equiv) and triethylamine $(1.2 \mathrm{~g}, 11.7$
mmol, 3 equiv) in $25 \mathrm{~mL}$ of DCM was stirred for $20 \mathrm{~min}$. Bromine $(2.5 \mathrm{~g}, 15.6 \mathrm{mmol}, 4$ The reaction was stirred at room temperature for $20 \mathrm{~h}$. After consumption of the starting material, the mixture was diluted with $\mathrm{H}_{2} \mathrm{O}(15 \mathrm{~mL})$ and then extracted with EtOAc $(3 \times 15 \mathrm{~mL})$. The organic layers were combined and washed with brine then dried with $\mathrm{MgSO}_{4}$. The crude product was concentrated in vacuo and purified via automated flash chromatography using EtOAc in hexanes (0\% to 100\%) with product eluting at $27 \%$ on a $40 \mathrm{~g}$ silica column to afford $\mathbf{3 b}$ in $90 \%$ yield $(3.5 \mathrm{mmol}, 1.1 \mathrm{~g}) .{ }^{1 \mathrm{a}}{ }^{1} \mathrm{H} \mathrm{NMR}(400 \mathrm{MHz}$, $\left.\mathrm{CDCl}_{3}\right) \delta 4.42(\mathrm{q}, J=7.1 \mathrm{~Hz}, 2 \mathrm{H}), 3.50(\mathrm{~s}, 3 \mathrm{H}), 1.39(\mathrm{t}, J=7.1 \mathrm{~Hz}, 3 \mathrm{H}) .{ }^{13} \mathrm{C} \mathrm{NMR}\left(101 \mathrm{MHz}, \mathrm{CDCl}_{3}\right) \delta$ 162.4, 67.1, 66.2, 37.3, 14.1. HRMS (ESI) calcd. for $\left[\mathrm{C}_{5} \mathrm{H}_{8} \mathrm{Br}_{2} \mathrm{O}_{4} \mathrm{SNa}\right]^{+}[\mathrm{M}+\mathrm{Na}]^{+}: \mathrm{m} / \mathrm{z}, 346.8387$ found 346.8385 .

Diethyl 2,2-dibromomalonate

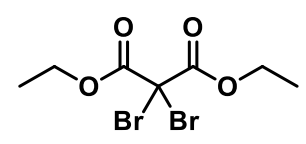

4b

Bromine (2 g, 12.5 mmol, 4 equiv) was added into a solution of diethyl malonate $(0.5$ $\mathrm{g}, 3.12 \mathrm{mmol}, 1$ equiv) in $30 \mathrm{~mL}$ DCM. Then, the reaction was stirred at room temperature for $20 \mathrm{~h}$. The progress of the reaction was monitored by TLC. After consumption of the starting material, the mixture was diluted with $\mathrm{H}_{2} \mathrm{O}(20 \mathrm{~mL})$ and then extracted with EtOAc $(3 \times 15 \mathrm{~mL})$. The organic layers were combined and washed with brine then dried with $\mathrm{MgSO}_{4}$. The crude product was concentrated in vacuo and purified via automated flash chromatography using EtOAc in hexanes ( $0 \%$ to $100 \%$ ) with product eluting at $7 \%$ on a $24 \mathrm{~g}$ silica column to afford $\mathbf{4 b}$ in $96 \%$ yield (3 mmol, $0.95 \mathrm{~g}) .{ }^{1 \mathrm{~g}, 2}$

\section{Ethyl 2,2-dibromo-2-cyanoacetate}

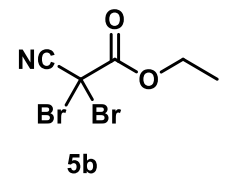

Bromine (2 g, $12.5 \mathrm{mmol}, 4$ equiv) was added into a solution of ethyl 2-cyanoacetate $(0.4$ $\mathrm{g}, 3.1 \mathrm{mmol}, 1$ equiv) in $30 \mathrm{~mL}$ DCM. The progress of the reaction was monitored by TLC. The reaction was stirred at room temperature for $20 \mathrm{~h}$. After consumption of the starting material, the mixture was diluted with $\mathrm{H}_{2} \mathrm{O}(20 \mathrm{~mL})$ and then extracted with EtOAc $(3 \times 15 \mathrm{~mL})$. The organic layers were combined and washed with brine then dried with $\mathrm{MgSO}_{4}$. The crude product was concentrated 
in vacuo and purified via automated flash chromatography using EtOAc in hexanes (0\% to 100\%) with product eluting at $9 \%$ on a $24 \mathrm{~g}$ silica column to afford $\mathbf{5 b}$ in $95 \%$ yield $(3 \mathrm{mmol}, 0.80 \mathrm{~g}){ }^{1 \mathrm{~g}, 3}$

\section{3,3-Dibromo-1,5-dioxaspiro[5.5]undecane-2,4-dione}

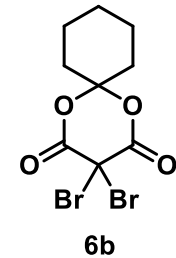

To a chilled $\left(0{ }^{\circ} \mathrm{C}\right) 2 \mathrm{M}$ solution of $\mathrm{NaOH}(5 \mathrm{~mL}), 1,5$-dioxaspiro[5.5] undecane-2,4-dione (0.9 g, 5 mmol, 1 equiv) was added and stirred for $15 \mathrm{~min}$ to get homogeneous reaction mixture. Then, bromine (1.6 g, $10 \mathrm{mmol}, 2$ equiv) was added dropwise at $0{ }^{\circ} \mathrm{C}$. After addition, the reaction was stirred for 45 minutes at $0{ }^{\circ} \mathrm{C}$ and solid crude was observed at the end of the reaction. Then, it was filtered and washed with distilled water and extracted with toluene $(3 \mathrm{x}$

$3 \mathrm{~mL}$ ). The organic layers were dried over $\mathrm{MgSO}_{4}$ and concentrated in vacuo to afford $\mathbf{6 b}$ in $75 \%$ yield (3.8 mmol, $1.3 \mathrm{~g}) .{ }^{1 \mathrm{~b}} \quad{ }^{1} \mathrm{H}$ NMR (400 MHz, CDCl $) \delta 2.05(\mathrm{t}, 4 \mathrm{H}), 1.77(\mathrm{p}, J=6.3 \mathrm{~Hz}, 4 \mathrm{H}), 1.52$ (p, J = 6.0 Hz, 2H). ${ }^{13} \mathrm{C}$ NMR $\left(101 \mathrm{MHz}, \mathrm{CDCl}_{3}\right) \delta 161.0,108.6,39.2,36.8,23.9,22.3$. HRMS (ESI) calcd. for $\left[\mathrm{C}_{9} \mathrm{H}_{10} \mathrm{Br}_{2} \mathrm{O}_{4} \mathrm{Na}\right]^{+}[\mathrm{M}+\mathrm{Na}]^{+}: \mathrm{m} / \mathrm{z}, 364.8823$ found 364.8822 .

\section{2,2-dibromo-1-phenylethan-1-one}

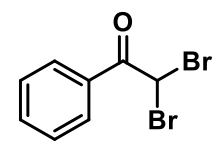

$7 \mathbf{b}$

Bromine (1.4 g, 9 mmol, 2 equiv) was added dropwise over a period of 20 minutes into 3 $\mathrm{mL}$ of anhydrous 1,4-dioxane at room temperature under a flow of Ar. Then, the reaction mixture was stirred for another 30 minutes. A solution of acetophenone (0.5 g, $4.2 \mathrm{mmol}, 1$ equiv) in $2 \mathrm{~mL}$ of dioxane was added into the reaction mixture at once and stirred for another $5 \mathrm{~h}$. At the end of the reaction, ice cold water ( $50 \mathrm{~mL}, 10$ volumes with respect to the dioxane) was added to the reaction flask causing the product to precipitate which was filtered from solution. The filtrate was washed with hexane to afford $\mathbf{7 b}$ in $92 \%$ yield $(3.9 \mathrm{mmol}, 1.1 \mathrm{~g}) .{ }^{1 \mathrm{c}, 4}$

\section{2,2-Dibromo-1-(4-(trifluoromethyl)phenyl)ethan-1-one}

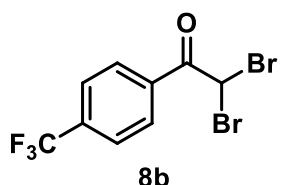

$8 b$

Bromine (1.4 g, 9 mmol, 2 equiv) was added dropwise over a period of 20 minutes into

$3 \mathrm{~mL}$ of anhydrous 1,4-dioxane at room temperature under a flow of Ar. Then, the reaction mixture was stirred for another 30 minutes. 1-(4(trifluoromethyl)phenyl)ethan-1-one ( $0.8 \mathrm{~g}, 4.2 \mathrm{mmol}, 1$ equiv) in $2 \mathrm{~mL}$ of dioxane was added into the reaction mixture at once and stirred for another $5 \mathrm{~h}$. At the end of the reaction, ice cold 
water (50 mL, 10 volumes with respect to the dioxane) was added to the reaction flask causing the product to precipitate which was filtered from solution. The filtrate was washed with hexane to afford $\mathbf{8 b}$ in $93 \%$ yield (3.9 mmol, $1.4 \mathrm{~g}) .^{1 \mathrm{c}, 5}$

\section{2,2,2-tribromo-1-(4-(trifluoromethyl)phenyl)ethan-1-one}

in $\mathrm{AcOH}(10 \mathrm{~mL})$ and $3 \mathrm{~mL}$ of water, $\mathrm{Br}_{2}(2.1 \mathrm{~g}, 13.5 \mathrm{mmol}, 5$ equiv) was added at 0
${ }^{\circ} \mathrm{C}$. Then, the reaction mixture was brought to reflux for $60 \mathrm{~h}$. The reaction mixture was diluted with water and extracted with ethylacetate $(3 \times 10 \mathrm{~mL})$. The organic layers were combined and washed with water, saturated aqueous $\mathrm{NaHCO}_{3}$ and brine. The organic layer was dried over $\mathrm{MgSO}_{4}$ and concentrated in vacuo. The crude product was purified via automated flash chromatography using DCM in hexanes $(0 \%$ to $100 \%)$ with product eluting at $0.2 \%$ on a $40 \mathrm{~g}$ silica column to afford $9 \mathrm{~b}$ in $45 \%$ yield $(1.2$ mmol, $0.5 \mathrm{~g}){ }^{6}$

\section{((1,1-Dibromoethyl)sulfonyl)benzene}

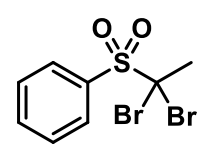

To (ethylsulfonyl)benzene $\left(0.4 \mathrm{~g}, 2.2 \mathrm{mmol}, 1\right.$ equiv) in anhydrous THF $(11 \mathrm{~mL})$ at $-78{ }^{\circ} \mathrm{C}$ was added n-BuLi (3 mL, $4.8 \mathrm{mmol}, 1.6 \mathrm{M}$ in hexane). Before addition of n-BuLi, it should $10 \mathrm{~b}$ be titrated to find the exact concentration of n-BuLi (as given below). After addition, the yellow mixture was allowed to warm to room temperature and then again cooled to $-78{ }^{\circ} \mathrm{C}$. Bromine $(1.1$ g, $6.6 \mathrm{mmol}, 3$ equiv) was added slowly, and the mixture was then warmed to room temperature. The reaction was stirred at room temperature for $13 \mathrm{~h}$. The reaction was diluted with $1 \mathrm{M} \mathrm{NaHSO}_{3}$, the mixture was extracted with diethyl ether $(3 \times 10 \mathrm{~mL})$ and the combined extracts were dried over $\mathrm{MgSO}_{4}$ and concentrated. The collected crude was purified via automated flash chromatography using EtOAc in hexanes ( $0 \%$ to $100 \%)$ with product eluting at $10 \%$ on a $24 \mathrm{~g}$ silica column to afford $10 \mathrm{~b}$ in $80 \%$ yield (1.8 mmol, $0.6 \mathrm{~g}) .{ }^{1 \mathrm{~d}, 7}$

General procedure for $\mathrm{n}-\mathrm{BuLi}$ titration:

An oven dried $25 \mathrm{ml}$ three neck flask equipped with an argon inlet adapter, a stirring bar and two rubber septa. The flask was charged with menthol (0.64 mmol, $100 \mathrm{mg}), 2,2^{\prime}$ '-dipyridyl (2.5 mg) and $10 \mathrm{~mL}$ of dry THF. To the resulting solution is added $\mathrm{n}-\mathrm{BuLi}$ via $1.0 \mathrm{~mL}$ syringe (graduated in $0.01 \mathrm{~mL}$ increments) in a 
dropwise fashion. During addition, it was observed that periodic quantities of a red colored complex appeared in the solution. It could be noted that in the early stage of the titration this red color dispersed rapidly. As one nears the endpoint, the red coloration required longer periods of time to disperse. At this point, it is necessary to slow the rate of addition. Eventually, the addition of a single drop of n-BuLi caused a persistent red coloration of the solution. Then, find the difference between initial and final volumes of $\mathrm{n}$ BuLi to get the used volume of n-BuLi in the titration. Finally, calculate the molarity of n-BuLi.

Calculation:

$100 \mathrm{mg}$ menthol $=0.64 \mathrm{mmol}$ which reacts with $0.64 \mathrm{mmol} \mathrm{n}-\mathrm{BuLi}$.

This amount of $\mathrm{n}-\mathrm{BuLi}$ is present in $\mathrm{V} \mathrm{ml}$ (used volume in the titration) of the analyte.

Since molarity equals $\mathrm{mol} / \mathrm{L}$, it also equals $\mathrm{mmol} / \mathrm{mL}$. Thus:

\section{$0.64 \mathrm{mmol} / \mathrm{V} \mathrm{mL}=$ Concentration of $\mathrm{n}-\mathrm{BuLi}$ solution}

\section{((Dibromo(phenyl)methyl)sulfonyl)benzene}

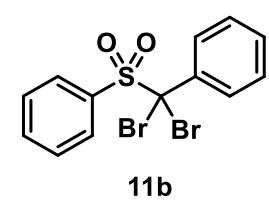

To (benzylsulfonyl)benzene $(0.5 \mathrm{~g}, 2.2 \mathrm{mmol}, 1$ equiv) in anhydrous THF (11 mL) at $78{ }^{\circ} \mathrm{C}$ was added $\mathrm{n}$-BuLi ( $3 \mathrm{~mL}, 4.8 \mathrm{mmol}, 1.6 \mathrm{M}$ in hexane). The yellow mixture was warmed to room temperature and then again cooled to $-78^{\circ} \mathrm{C}$. Bromine $(1.1 \mathrm{~g}, 6.6 \mathrm{mmol}$, 3 equiv) was added in a single portion, and the mixture was then warmed to room temperature. The reaction was stirred at room temperature for $10 \mathrm{~h}$. The reaction was diluted with $1 \mathrm{M}$ $\mathrm{NaHSO}_{3}$, the mixture was extracted with diethyl ether $(3 \times 10 \mathrm{~mL})$ and the combined extracts were dried over $\mathrm{MgSO}_{4}$ and concentrated. The crude was purified via automated flash chromatography using EtOAc in hexanes $(0 \%$ to $100 \%)$ with product eluting at $4 \%$ on a $24 \mathrm{~g}$ silica column to afford $\mathbf{1 1 b}$ in $65 \%$ yield $(1.43 \mathrm{mmol}, 0.55 \mathrm{~g}){ }^{1 \mathrm{~d}, 7}$

\section{2,2-Dibromo-6,6-dimethylcyclohexan-1-one}

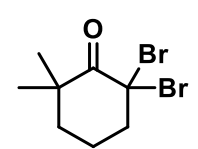

12b

A solution of 2,2-dimethylcyclohexan-1-one (0.5 g, 4 mmol, 1 equiv) in DCM (2 mL) was added dropwise to a solution of n-bromosuccinimide (1.6 g, $8.8 \mathrm{mmol}, 2.2$ equiv) and p$\mathrm{TsOH}\left(0.13 \mathrm{~g}, 0.8 \mathrm{mmol}, 0.2\right.$ equiv) in $\mathrm{DCM}(15 \mathrm{~mL})$ at $0{ }^{\circ} \mathrm{C}$. The reaction mixture was then brought to reflux for $15 \mathrm{~h}$. After addition of $\mathrm{H}_{2} \mathrm{O}(10 \mathrm{~mL})$, the organic layer was separated, and the aqueous layer was extracted with $\mathrm{CH}_{2} \mathrm{Cl}_{2}(3 \times 10 \mathrm{~mL})$. The combined organic layer was washed with saturated aqueous $\mathrm{NaHCO}_{3}$ and brine, dried over anhydrous $\mathrm{MgSO}_{4}$, and concentrated under reduced pressure. The 
residue was purified via automated flash chromatography using EtOAc in hexanes (0\% to 100\%) with product eluting at $0.1 \%$ on a $24 \mathrm{~g}$ silica column to afford $\mathbf{1 2 b}$ in $85 \%$ yield $(3.4 \mathrm{mmol}, 1.0 \mathrm{~g}) .^{1 \mathrm{e}, 8}$

\section{(Dibromomethyl)benzene}

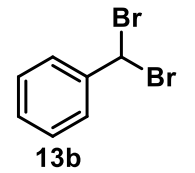

13b was synthesized according to a modified literature procedure. Benzyl bromide $(0.4 \mathrm{~g}, 2.3$ mmol, 1 equiv), N-bromosuccinimide $(0.5 \mathrm{~g}, 2.6 \mathrm{mmol}, 1.1$ equiv $)$ and azobis(isobutyronitrile) ( $3 \mathrm{mg}, 0.01 \mathrm{mmol}, 0.006$ equiv) in $10 \mathrm{~mL}$ of $\mathrm{CCl}_{4}$ was heated for 10 $\mathrm{h}$ under reflux. The mixture was cooled and the precipitate (succinimide) was filtered off and washed with $5 \mathrm{~mL}$ of $\mathrm{CCl}_{4}$, and the filtrate was washed in succession with a $5 \%$ solution of $\mathrm{Na}_{2} \mathrm{SO}_{3}$, a $10 \%$ solution of $\mathrm{Na}_{2} \mathrm{CO}_{3}$, and water and dried over $\mathrm{MgSO}_{4}$. The solvent was removed, and the residue was purified via automated flash chromatography using EtOAc in hexanes ( $0 \%$ to $100 \%)$ with product eluting at $0.1 \%$ on a $24 \mathrm{~g}$ silica column to afford $\mathbf{1 3 b}$ in $70 \%$ yield $(1.6 \mathrm{mmol}, 0.4 \mathrm{~g}){ }^{9}$

\section{Ethyl 2,2-dichloro-2-((2,6-difluorophenyl)sulfonyl)acetate}

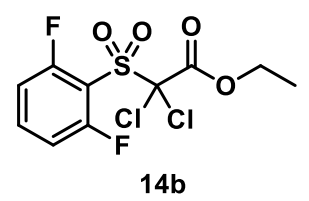

Ethyl 2-((2,6-difluorophenyl)sulfonyl)acetate (1 g, $3.9 \mathrm{mmol}, 1$ equiv) and triethylamine (1.18 g, $11.7 \mathrm{mmol}, 3$ equiv) in $25 \mathrm{~mL}$ of DCM was stirred for $20 \mathrm{~min}$. N-chlorosuccinimide (1.6 g, $11.7 \mathrm{mmol}, 3$ equiv) was added in to the reaction. The progress of the reaction was monitored by TLC. The reaction was stirred at room temperature for $21 \mathrm{~h}$. After consumption of the starting material, the mixture was diluted with $\mathrm{H}_{2} \mathrm{O}(15 \mathrm{~mL})$ and then extracted with EtOAc $(3 \times 10 \mathrm{~mL})$. The organic layers were combined and washed with brine then dried with $\mathrm{MgSO}_{4}$. The crude product was concentrated in vacuo and purified via automated flash chromatography using EtOAc in hexanes ( $0 \%$ to $100 \%$ ) with product eluting at $30 \%$ on a $40 \mathrm{~g}$ silica column to afford $\mathbf{1 4 b}$ in $80 \%$ yield $(3.1 \mathrm{mmol}, 1.01 \mathrm{~g}) .{ }^{1} \mathrm{H} \mathrm{NMR}\left(400 \mathrm{MHz}, \mathrm{CDCl}_{3}\right) \delta 7.74(\mathrm{tt}, J=8.5,5.7 \mathrm{~Hz}, 1 \mathrm{H})$, $7.11($ ap t, $J=16.8 \mathrm{~Hz}, 2 \mathrm{H}), 4.42(\mathrm{q}, J=7.2 \mathrm{~Hz}, 2 \mathrm{H}), 1.38(\mathrm{t}, J=7.2 \mathrm{~Hz}, 3 \mathrm{H}) .{ }^{19} \mathrm{~F} \mathrm{NMR}\left(376 \mathrm{MHz}, \mathrm{CDCl}_{3}\right)$ $\delta$-99.3 (ddd, $J=8.9,5.8,2.9 \mathrm{~Hz}) .{ }^{13} \mathrm{C} \mathrm{NMR}\left(151 \mathrm{MHz}, \mathrm{CDCl}_{3}\right) \delta 161.6(\mathrm{dd}, J=266.5,2.6 \mathrm{~Hz}), 160.4$, $138.4(\mathrm{t}, J=11.5 \mathrm{~Hz}), 113.6,113.4(\mathrm{~d}, J=4.6 \mathrm{~Hz}), 93.6,66.0,13.6$. HRMS (ESI) calcd. for $\left[\mathrm{C}_{10} \mathrm{H}_{8} \mathrm{Cl}_{2} \mathrm{~F}_{2} \mathrm{O}_{4} \mathrm{SNa}\right]^{+}[\mathrm{M}+\mathrm{Na}]^{+}: \mathrm{m} / \mathrm{z}, 354.9386$ found 354.9383 . 


\section{Ethyl 2,2,2-trichloroacetate}

$\begin{array}{cl}\mathrm{N}_{\mathbf{1 5 b}}^{\mathrm{Cl}} \mathrm{Cl} & \text { A mixture of trichloroacetic acid }(0.7 \mathrm{~g}, 4.3 \mathrm{mmol}, 1 \text { equiv), concentrated sulfuric acid }(0.1 \\ \mathrm{mL}) \text {, and ethanol }(5 \mathrm{~mL}) \text { was refluxed for } 7 \mathrm{~h} \text {. Then the flask was cooled to room }\end{array}$ extracted with diethyl ether $(3 \times 10 \mathrm{~mL})$. The organic layers were combined and washed with a $10 \%$ sodium carbonate solution and dried with anhydrous $\mathrm{MgSO}_{4}$. The solvent was removed, and the residue was purified via automated flash chromatography using EtOAc in hexanes (0\% to 100\%) with product eluting at $8 \%$ on a $24 \mathrm{~g}$ silica column to afford $\mathbf{1 5 b}$ in $85 \%$ yield $(3.7 \mathrm{mmol}, 0.70 \mathrm{~g}) .{ }^{1 \mathrm{f}, 10}$

\section{Benzyl 2,2,2-trichloroacetate}

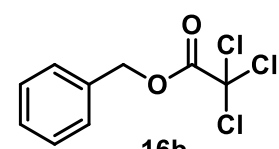

$16 b$

A mixture of trichloroacetic acid $(0.7 \mathrm{~g}, 4.3 \mathrm{mmol}, 1$ equiv), concentrated sulfuric acid (0.1 mL), and benzyl alcohol (1.4 g, $12.9 \mathrm{mmol}, 3$ equiv) in $10 \mathrm{~mL}$ of $\mathrm{MeCN}$ was refluxed for $5 \mathrm{~h}$. Then the flask was cooled to room temperature, water $(10 \mathrm{~mL})$ was added to the content of the flask, and the crude was extracted with diethyl ether $(3 \times 10 \mathrm{~mL})$. The combined organic extracts were washed with a $10 \%$ sodium carbonate solution and dried with anhydrous $\mathrm{MgSO}_{4}$. The solvent was removed, and the residue was purified via automated flash chromatography using EtOAc in hexanes ( $0 \%$ to $100 \%$ ) with product eluting at $0.5 \%$ on a $24 \mathrm{~g}$ silica column to afford $\mathbf{1 6 b}$ in $70 \%$ yield (3 mmol, $0.76 \mathrm{~g}) .{ }^{1 \mathrm{f}, 11}$ 


\section{Optimization of hydrodebromination:}

Optimization of amine structure:

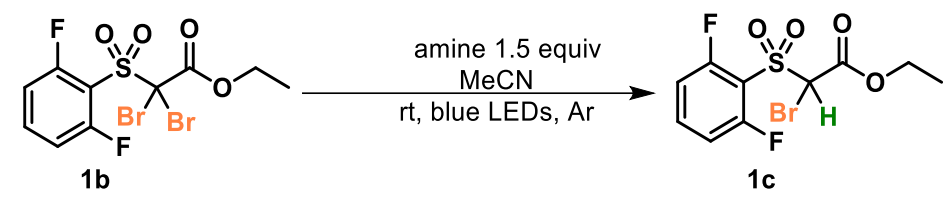

\begin{tabular}{lllll}
\hline entry & amine & time & ${\text { conv }{ }^{a}}^{a}$ & $\mathbf{1 c}^{a}$ \\
\hline 1 & $\mathrm{Et}_{3} \mathrm{~N}$ & $90 \mathrm{~min}$ & $78^{b}$ & 75 \\
2 & $\mathrm{Bu}_{3} \mathrm{~N}$ & $90 \mathrm{~min}$ & $98^{b}$ & 65 \\
\hline 3 & DIPEA & $45 \mathrm{~min}$ & 100 & 96 \\
\hline 4 & DABCO & $90 \mathrm{~min}$ & 47 & 2 \\
5 & DBU & $90 \mathrm{~min}$ & $94^{b}$ & 75 \\
6 & $4-m e t h o x y t r i p h e n y l a m i n e$ & $90 \mathrm{~min}$ & 3 & 3 \\
7 & $2,2,6,6$-tetramethylpiperidine & $90 \mathrm{~min}$ & 2 & 2 \\
\hline
\end{tabular}

${ }^{a}$ determined by ${ }^{19} \mathrm{~F} \mathrm{NMR} .{ }^{b}$ didebrominated product is $10-15 \%$.

Attempted hydrodebromination with other potential reductants:

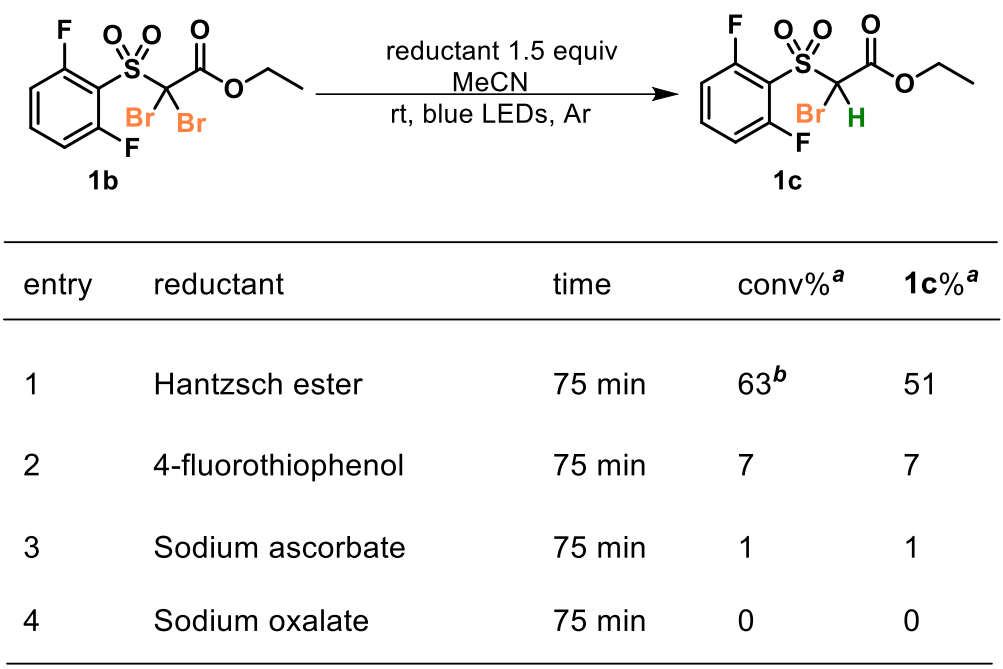

${ }^{a}$ determined by ${ }^{19} \mathrm{~F}$ NMR. ${ }^{b}$ didebrominated product is $12 \%$. 


\section{Solvent optimization:}

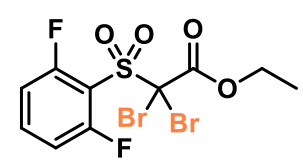

1b

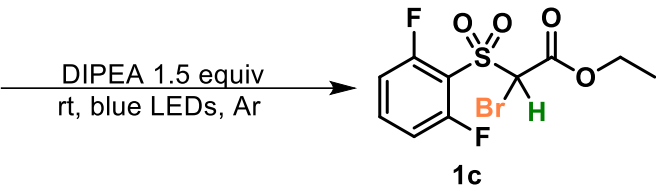

1c

\begin{tabular}{lllll}
\hline entry & solvent & time & conv $\%^{a}$ & $1 \mathbf{c}^{a}$ \\
\hline 1 & Toluene & $90 \mathrm{~min}$ & 37 & 37 \\
2 & THF & $90 \mathrm{~min}$ & 39 & 38 \\
3 & DCM & $90 \mathrm{~min}$ & 20 & 20 \\
4 & $\mathrm{NMP}$ & $60 \mathrm{~min}$ & 40 & 23 \\
\hline 5 & $\mathrm{MeCN}$ & $45 \mathrm{~min}$ & 100 & 96 \\
\hline 6 & $\mathrm{DMF}$ & $60 \mathrm{~min}$ & $100^{b}$ & 87 \\
7 & $\mathrm{DMSO}$ & $60 \mathrm{~min}$ & $100^{b}$ & 85 \\
8 & $\mathrm{MeOH}$ & $60 \mathrm{~min}$ & $100^{b}$ & 60 \\
\hline
\end{tabular}

${ }^{a}$ determined by ${ }^{19} \mathrm{~F} \mathrm{NMR} .{ }^{b}$ didebrominated product is $10-15 \%$

Temperature optimization:<smiles>CCOC(=O)C(Br)(Br)S(=O)(=O)c1c(F)cccc1F</smiles>

1b

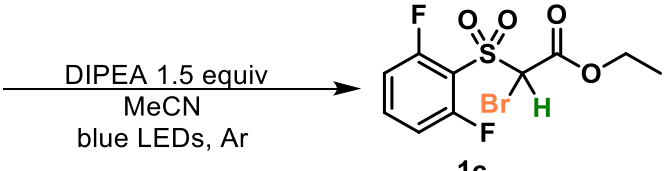

$1 \mathrm{c}$

\begin{tabular}{lllll}
\hline entry & temperature & time & conv\% ${ }^{a}$ & $1 \mathbf{c}^{a}$ \\
\hline 1 & $0^{\circ} \mathrm{C}$ & $90 \mathrm{~min}$ & 87 & 83 \\
\hline 2 & $28^{\circ} \mathrm{C}(\mathrm{rt})$ & $45 \mathrm{~min}$ & 100 & 96 \\
\hline 3 & $45^{\circ} \mathrm{C}$ & $30 \mathrm{~min}$ & 100 & 90 \\
\hline
\end{tabular}

${ }^{a}$ determined by ${ }^{19} \mathrm{~F}$ NMR. 


\section{Mechanistic experiments}

\section{UV-Vis experiments:}

Time-dependent UV/Vis spectra of hydrodebromination reaction of $\mathbf{1 b}$ :

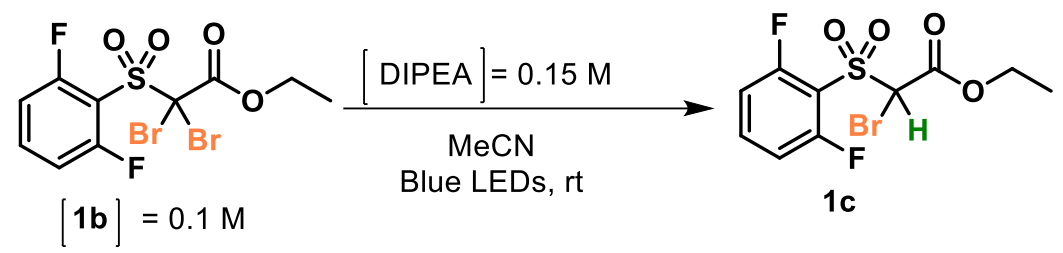

Brominated compound $\mathbf{1 b}(101.3 \mathrm{mg}, 0.24 \mathrm{mmol}, 1$ equiv) and $N, N$-diisopropylethylamine (62.8 $\mu \mathrm{L}, 0.36$ mmol, 1.5 equiv) was added into $1 \mathrm{~cm}$ path quartz cuvette and total volume was adjusted to $2.4 \mathrm{~mL}$ by adding MeCN to the cuvette. Then, the blue light on a fiber optic cable was dipped in the cuvette and reaction was irradiated. UV-Vis spectra were recorded for the reaction at different reaction times using Varian Cary Eclipse spectrophotometer. The appearance of an absorption band in the visible region as a function of time is consistent with the formation of a streptocyanine dye as the reaction progresses.

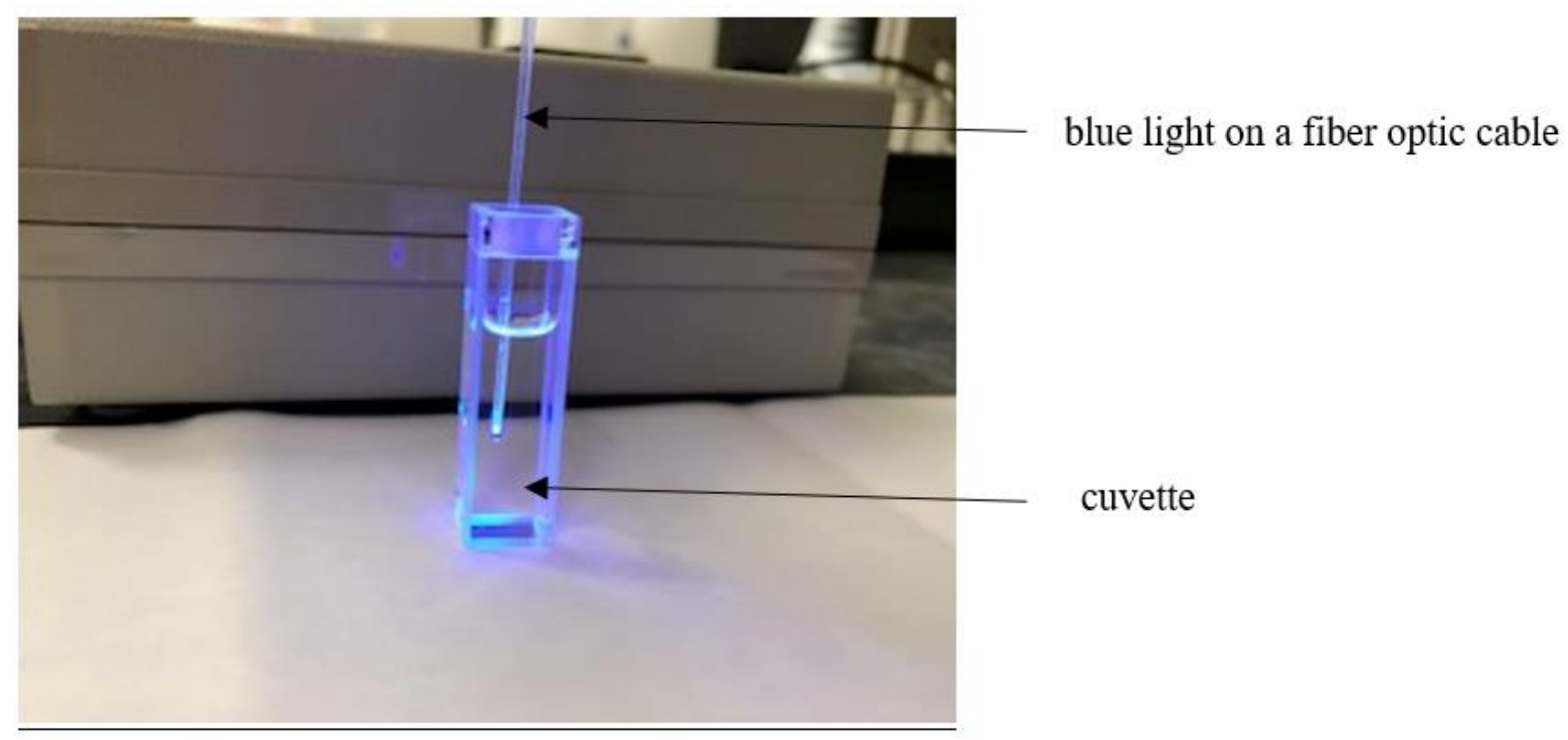


Time-dependent UV/Vis spectra of debromination reaction of $\mathbf{1 b}$

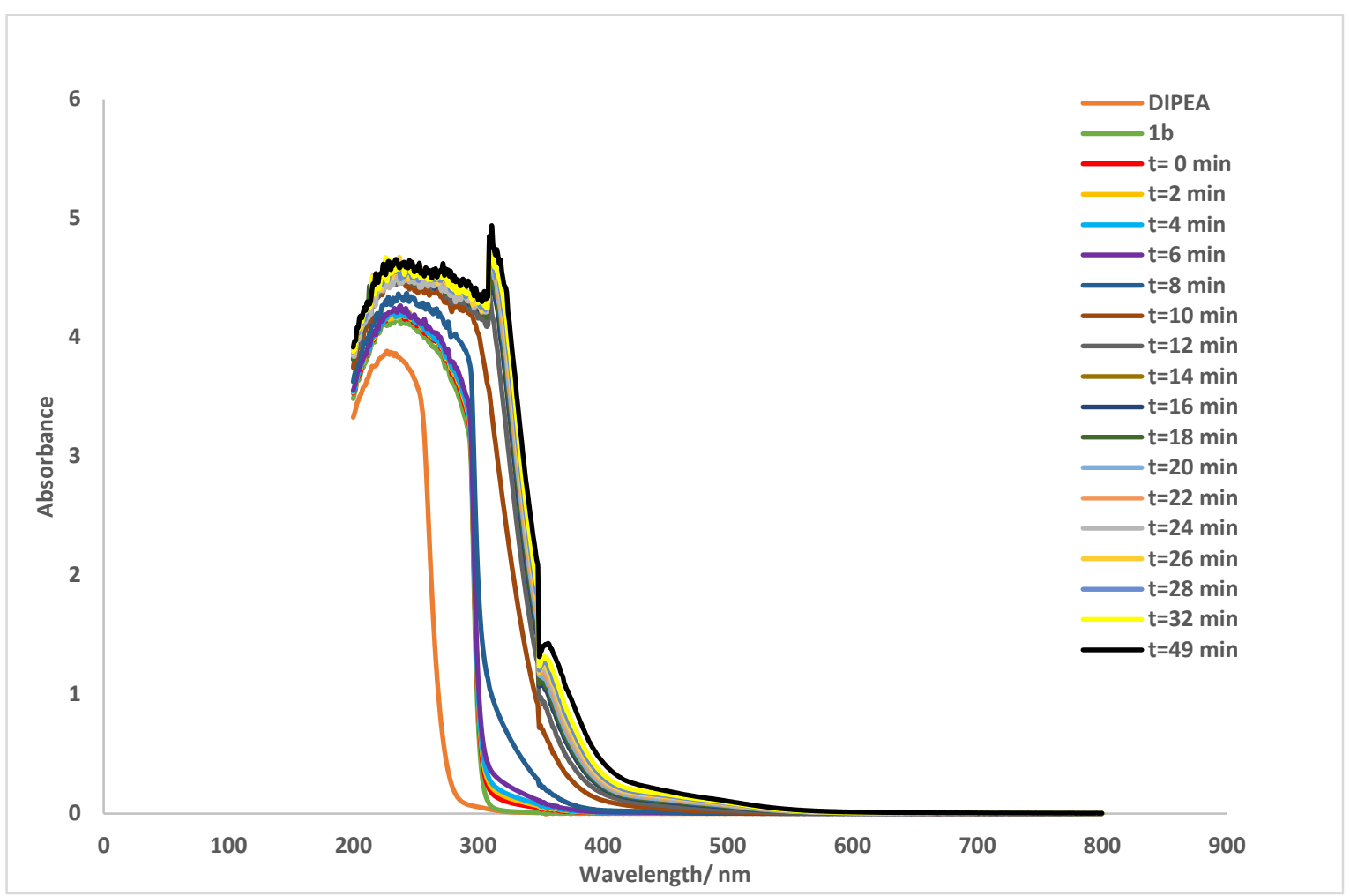

Expansion of the above spectrum:

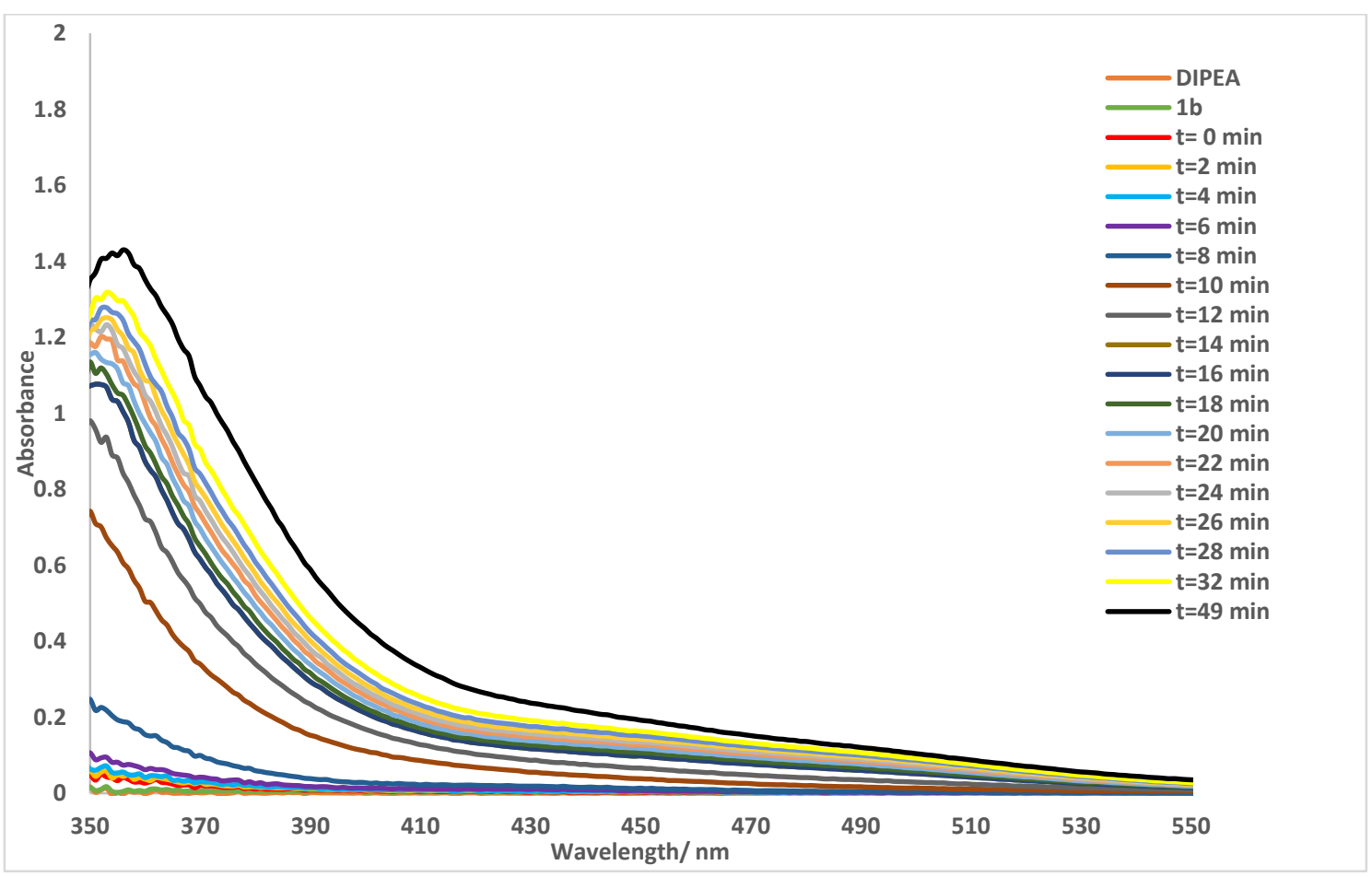




\section{$\operatorname{Exp~1:~}$}

Spiking experiment:

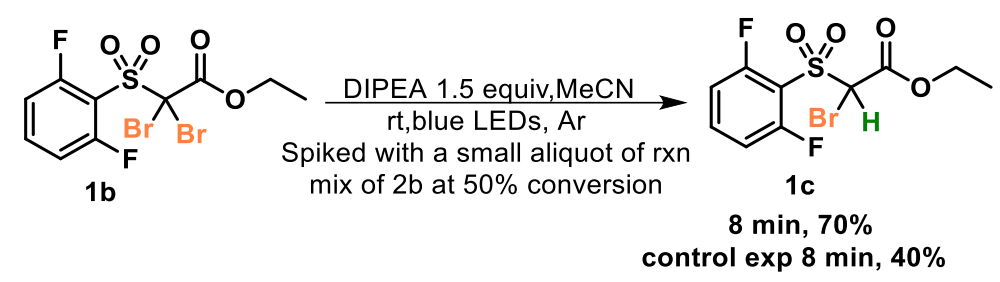

Reaction of $\mathbf{2 b}$ used for above spiking:

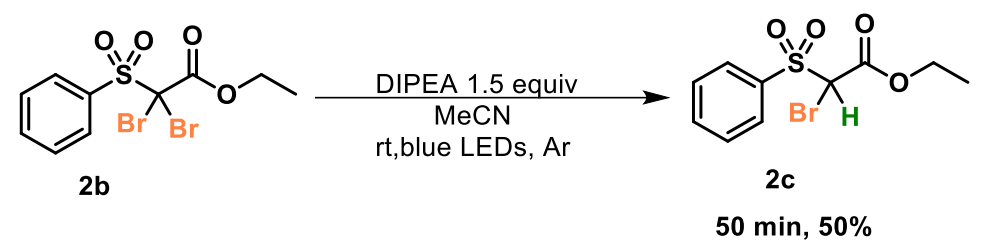

An NMR tube fitted with a rubber septum was charged with brominated sulfone $\mathbf{1 b}(50.6 \mathrm{mg}, 0.12 \mathrm{mmol}$, 1 equiv), $N, N$-diisopropylethylamine $(31.4 \mu \mathrm{L}, 0.18 \mathrm{mmol}, 1.5$ equiv) and $\mathrm{MeCN}(1.2 \mathrm{~mL})$. Then the reaction mixture was spiked with a $20 \mu \mathrm{L}$ aliquot of reaction mixture of $\mathbf{2 b}$ at $50 \%$ conversion. The reaction tube was covered with piece of aluminum foil to avoid ambient light and degassed via Ar bubbling for 10 min. Then the piece of aluminum foil was removed and the tube was placed in a blue LED bath. Meanwhile, a control experiment was set up without any reaction mixture of $\mathbf{2 b}$. The reactions were monitored by 19F NMR. After $8 \mathrm{~min}$, the spiked reaction showed 70\% conversion while the control experiment showed only $40 \%$ conversion, indicating that a species formed during the reaction of a different substrate was capable of accelerating the formation of a different product. This is suggestive that the postulated streptocyanine dye is capable of catalyzing this hydrodebromination reaction.

\section{$\operatorname{Exp} 2$ :}

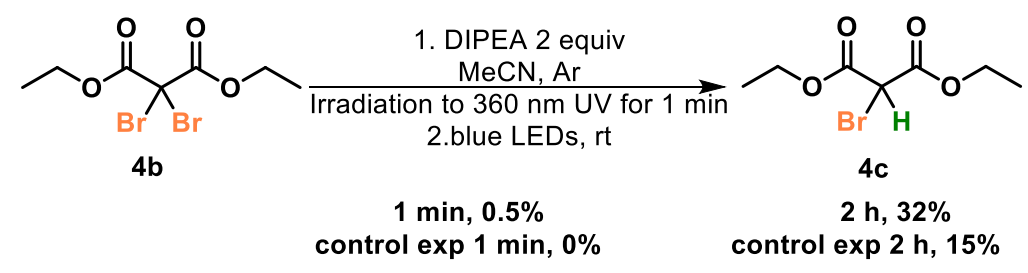

An NMR tube fitted with a rubber septum was charged with brominated compound $\mathbf{4 b}(38.15 \mathrm{mg}, 0.12$ mmol, 1 equiv), $N, N$-diisopropylethylamine (41.8 $\mu \mathrm{L}, 0.24 \mathrm{mmol}, 2$ equiv) and $\mathrm{MeCN}(01.2 \mathrm{~mL})$. The reaction tube was covered with piece of aluminum foil to avoid ambient light and degassed via Ar bubbling for $10 \mathrm{~min}$. The piece of aluminum foil was removed and the colorless reaction mixture was irradiated with 
the long wavelength UV light $(360 \mathrm{~nm}$ ) produced by a hand held TLC lamp, for $1 \mathrm{~min}$. Then, the tube was returned to a blue LED bath. Meanwhile, the control experiment was immediately placed in the same blue LED bath. The reactions were monitored by $1 \mathrm{H}$ NMR. After $2 \mathrm{~h}$, the UV-exposed reaction mixture showed $32 \%$ conversion while the control experiment showed only $15 \%$ conversion. This experiment suggests that UV light can initiate reaction faster than blue light.

$\operatorname{Exp}$ 3:

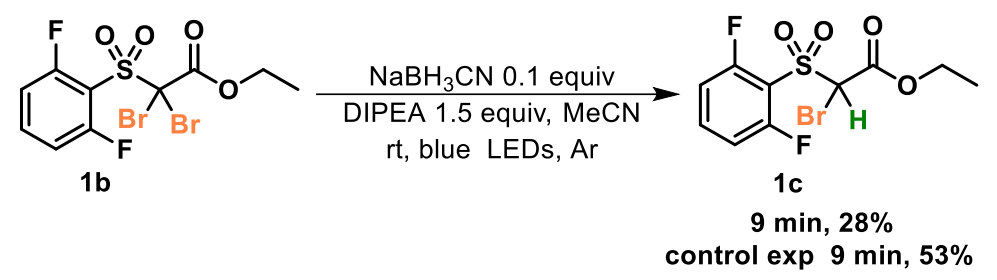

An NMR tube fitted with a rubber septum was charged with brominated compound $\mathbf{1 b}$ (50.6 mg, 0.12 mmol, 1 equiv), $N$, $N$-diisopropylethylamine (31.4 $\mu \mathrm{L}, 0.18 \mathrm{mmol}, 1.5$ equiv), $\mathrm{NaBH}_{3} \mathrm{CN}(0.8 \mathrm{mg}, 0.012$ mmol, 0.1 equiv) and $\mathrm{MeCN}(1.2 \mathrm{~mL})$. The reaction tube was covered with piece of aluminum foil to avoid ambient light and degassed via Ar bubbling for $10 \mathrm{~min}$. Then, the piece of aluminum foil was removed and the tube was placed in a blue LED bath. Meanwhile, a control experiment was set up containing no $\mathrm{NaBH}_{3} \mathrm{CN}$. The reactions were monitored by 19F NMR. After $9 \mathrm{~min}$, the reaction mixture containing $\mathrm{NaBH}_{3} \mathrm{CN}$ showed only $28 \%$ conversion, while the positive control experiment showed $53 \%$ conversion. Indicating the presence of the hydride source retarded the rate of the reaction. Importantly, a dark version of this reaction showed that the $\mathrm{NaBH}_{3} \mathrm{CN}$ did not reduce the substrate.

\section{$\operatorname{Exp}$ 4:}

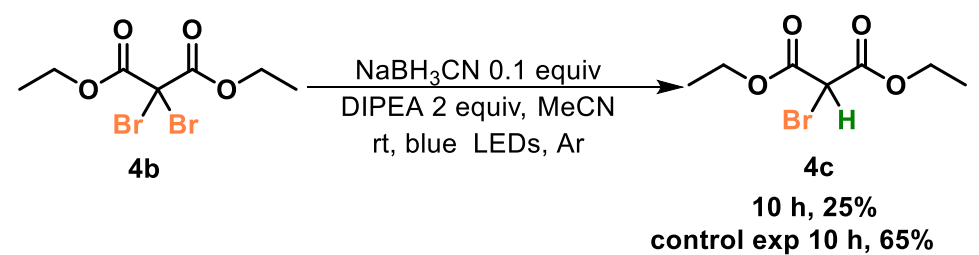

An NMR tube fitted with a rubber septum was charged with brominated compound $\mathbf{4 b}$ (38.15 $\mathrm{mg}, 0.12$ mmol, 1 equiv), $N, N$-diisopropylethylamine (41.8 $\mu \mathrm{L}, 0.24$ mmol, 2 equiv), $\mathrm{NaBH}_{3} \mathrm{CN}$ (0.8 mg, 0.012 mmol, 0.1 equiv) and $\mathrm{MeCN}(1.2 \mathrm{~mL})$. The reaction tube was covered with piece of aluminum foil to avoid ambient light and degassed via Ar bubbling for $10 \mathrm{~min}$. Then, the piece of aluminum foil was removed and the tube was placed in a blue LED bath. The control experiment was set up without adding $\mathrm{NaBH}_{3} \mathrm{CN}$. The 
reactions were monitored by $1 \mathrm{H}$ NMR. After $10 \mathrm{~h}$, the reaction containing the $\mathrm{NaBH}_{3} \mathrm{CN}$ showed only $25 \%$ conversion while the positive control experiment gave $65 \%$ conversion. Again, this experiment shows that the presence of the hydride source retarded the rate of the reaction. Importantly, a dark version of this reaction showed that the $\mathrm{NaBH}_{3} \mathrm{CN}$ did not reduce the substrate. A further observation concerning experiments 3 and 4 was the slowing of the formation of colored reaction mixture. These observations are consistent with a streptocyanine based dye in which the iminium functional group would be expected to be reduced by the $\mathrm{NaBH}_{3} \mathrm{CN}$.

Evidence for streptocyanine dye:

A $12 \times 75 \mathrm{~mm}$ borosilicate tube fitted with a rubber septum was charged with brominated compound $\mathbf{1 b}$ (50.6 mg, 0.12 mmol, 1 equiv), $N, N$-diisopropylethylamine (31.4 $\mu \mathrm{L}, 0.18 \mathrm{mmol}, 1.5$ equiv) and $\mathrm{MeCN}$ $(1.2 \mathrm{~mL})$. The reaction tube was covered with piece of aluminum foil to avoid ambient light and degassed via Ar bubbling for $10 \mathrm{~min}$. The tube was placed in a blue LED bath which was at $28{ }^{\circ} \mathrm{C}$. The reaction was monitored by the Expression Compact Mass Spectrometer (CMS)- Advion in the positive detection mode to detect the cyanine dyes. Mass spectrum of crude reaction when $\mathrm{t}=7 \mathrm{~min}$ has given below. It revealed masses of 255, 238 and 169 which could explain the following streptocyanine dye and its hydrolyzed products. Furthermore, after complete conversion of $1 \mathrm{~b}$, crude reaction was subjected to GCMS. It also showed hydrolyzed product of streptocyanine dye. Attempts to isolate the colored material failed as its quantity seemed to be very low.

\section{A $\quad \mathbf{m} / \mathbf{z}=\mathbf{2 5 5}$}

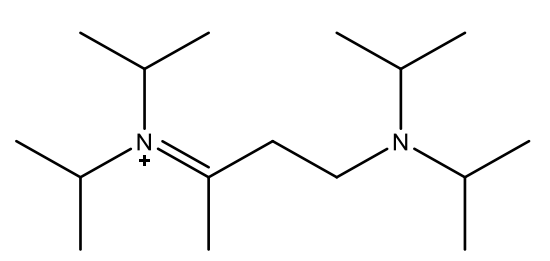

C $\quad \mathbf{m} / \mathbf{z}=\mathbf{1 6 9}$<smiles>CC(=O)/C=C/N(C(C)C)C(C)C</smiles>

B $\quad \mathbf{m} / \mathbf{z}=\mathbf{2 3 8}$<smiles>CCN(/C=C/C(C)=N\C(C)C)C(C)C</smiles>

D $m / z=86$

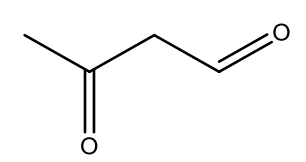


CMS- Mass spectrum of crude reaction of $1 \mathrm{~b}$ when $\mathrm{t}=7 \mathrm{~min}$

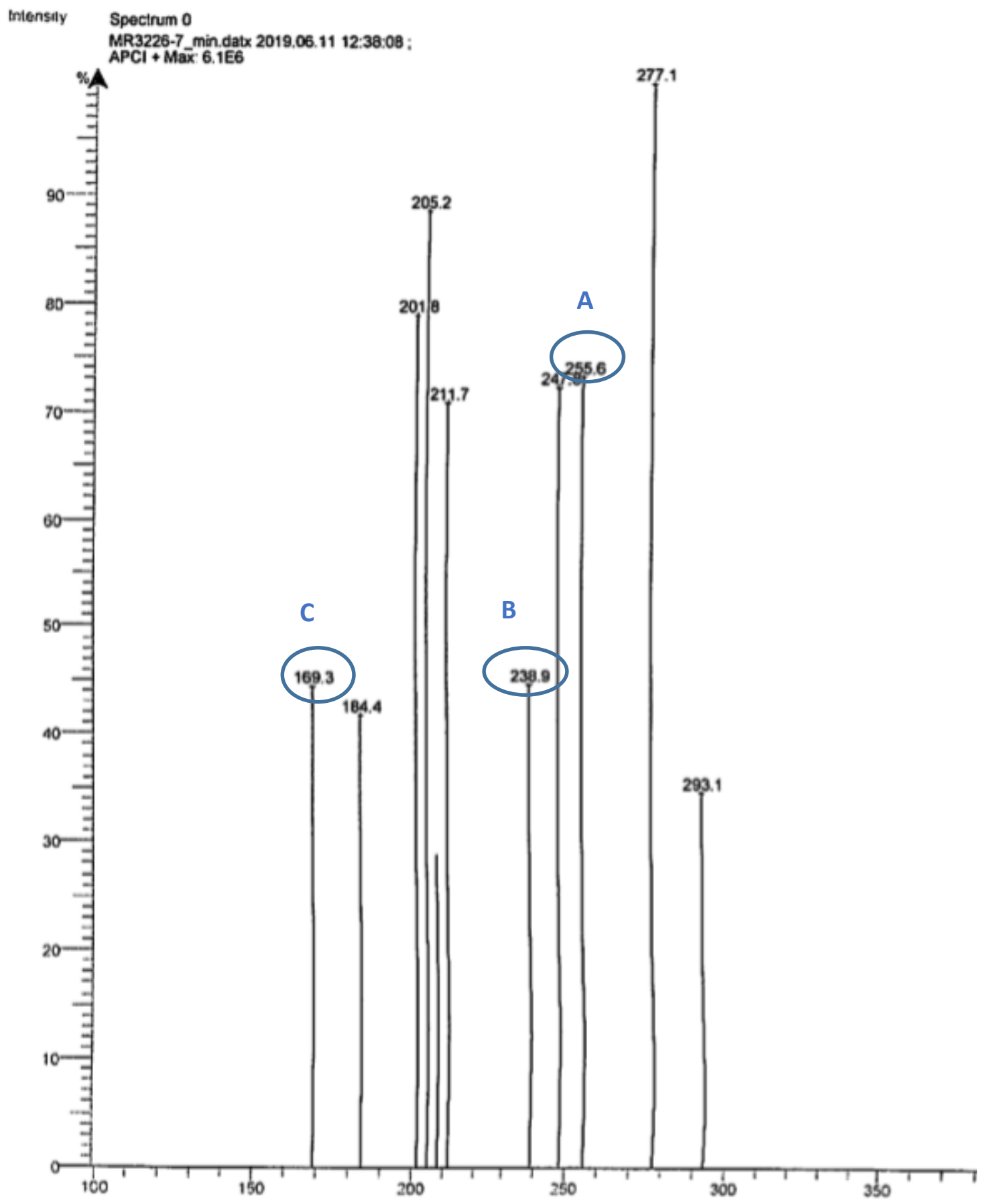




\section{GC- MS of crude reaction when $t=45 \mathrm{~min}$}

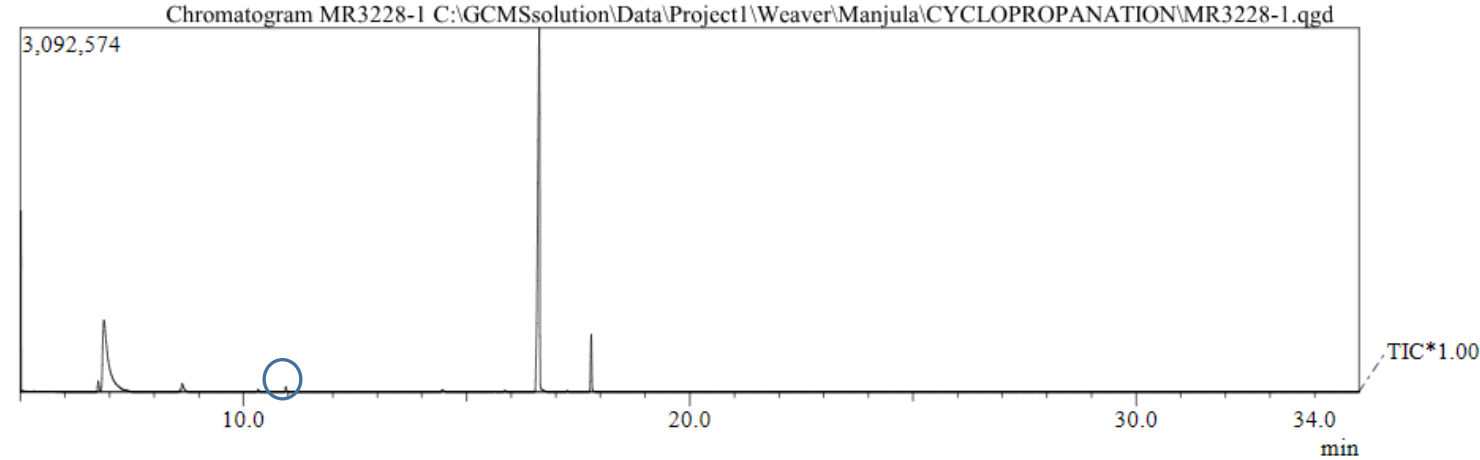

Spectrum

Line\#:1 R.Time:11.0(Scan\#:718)

MassPeaks:4

RawMode:Single 11.0(718) BasePeak:72(4103)

BG Mode:None

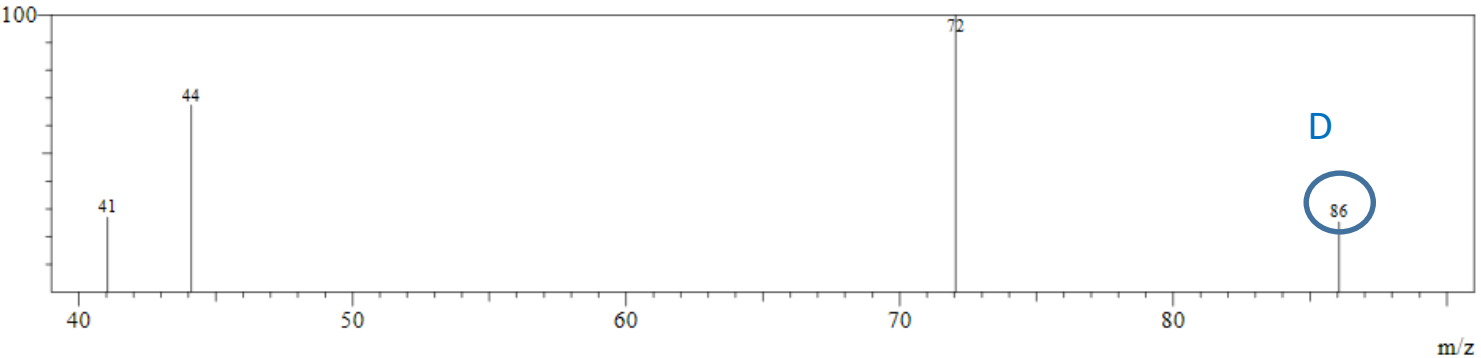




\section{Following experiments were set up to answer the reviewers' questions:}

1) Experiments related to streptocyanine dye

We postulate that a streptocyanine dye formed under the reaction conditions, and that it is responsible for photoinduced electron transfer process. We have performed several experiments that are consistent with our hypothesis. While the exact dye we believe to be involved was not commercially available, we were able to purchase the following related streptocyanine dye.

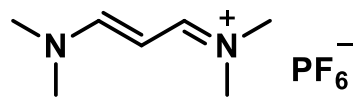

Methanaminium, N-[3-(dimethylamino)-2-propen-1-ylidene]-Nmethyl-, hexafluorophosphate

Following reaction was performed using a catalytic amount of this streptocyanine dye. This allowed to see if the reaction was accelerated by the presence of this dye.

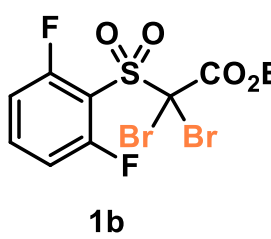

$1 \mathrm{~b}$

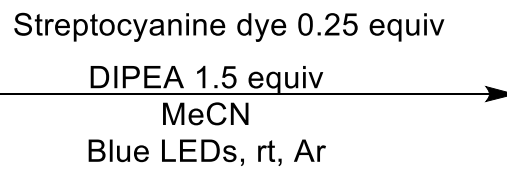

Blue LEDs, rt, Ar

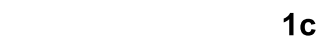

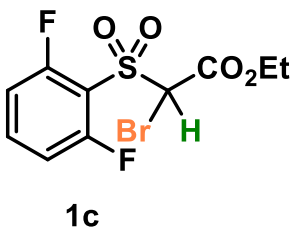

$20 \min , 91 \%$

control (without streptocyanine dye): $20 \mathrm{~min}, 67 \%$

An NMR tube fitted with a rubber septum was charged with brominated sulfone $\mathbf{1 b}(50.6 \mathrm{mg}, 0.12 \mathrm{mmol}$, 1 equiv), $N, N$-diisopropylethylamine $(31.4 \mu \mathrm{L}, 0.18 \mathrm{mmol}, 1.5$ equiv), streptocyanine dye (8.2 $\mathrm{mg}, 0.03$ mmol, 0.25 equiv) and $\mathrm{MeCN}(1.2 \mathrm{~mL})$. The reaction tube was covered with piece of aluminum foil to avoid ambient light and degassed via Ar bubbling for $10 \mathrm{~min}$. Then, the piece of aluminum foil was removed and the tube was placed in a blue LED bath. Meanwhile, a control experiment was set up without any streptocyanine dye in the reaction. The reactions were monitored by 19F NMR. After 20 min, streptocyanine dye contained reaction showed $91 \%$ conversion while the control experiment (without 
streptocyanine dye) showed only $67 \%$ conversion, indicating that having streptocyanine dye accelerates the rate of the reaction.

A control experiment showing that the streptocyanine dye itself does not serve as a stoichiometric reagent in the debromination was performed.

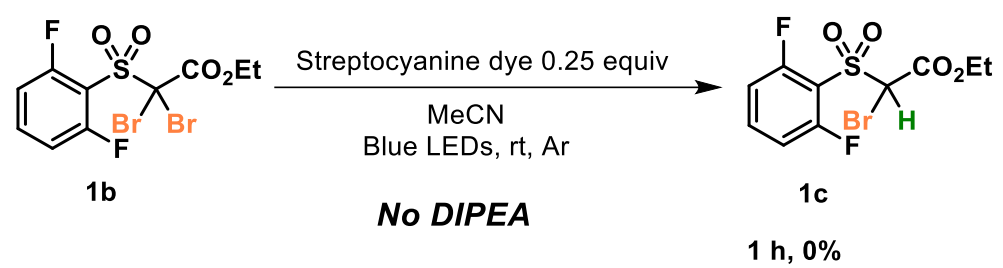

An NMR tube fitted with a rubber septum was charged with brominated sulfone $\mathbf{1 b}$ (50.6 $\mathrm{mg}, 0.12 \mathrm{mmol}$, 1 equiv), streptocyanine dye ( $8.2 \mathrm{mg}, 0.03 \mathrm{mmol}, 0.25$ equiv) and $\mathrm{MeCN}$ (1.2 mL). The reaction tube was covered with piece of aluminum foil to avoid ambient light and degassed via Ar bubbling for $10 \mathrm{~min}$. Then, the piece of aluminum foil was removed and the tube was placed in a blue LED bath. The reaction was monitored by $19 \mathrm{~F}$ NMR. After $1 \mathrm{~h}$, reaction showed $0 \%$ conversion indicating that having DIPEA is necessary for the reaction.

A similar experiment was performed on a second substrate. Again, a similar acceleration was seen. It should be noted that the inflection in the rate profile is still observed. We believe that this explained by the formation of the dye during the course of the reaction, which may be even more active than the commercially available dye.

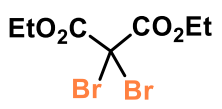

$4 b$

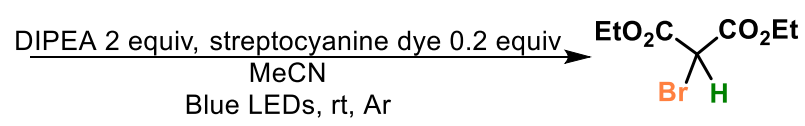

4c

An NMR tube fitted with a rubber septum was charged with diethyl 2,2-dibromomalonate $\mathbf{4 b}$ (19.1 $\mathrm{mg}$, $0.06 \mathrm{mmol}, 1$ equiv), $N, N$-diisopropylethylamine ( $21 \mu \mathrm{L}, 0.12 \mathrm{mmol}, 2$ equiv) streptocyanine dye (3.3 $\mathrm{mg}$, $0.012 \mathrm{mmol}, 0.2$ equiv) and $\mathrm{MeCN}(0.6 \mathrm{~mL})$. The reaction tube was covered with piece of aluminum foil to avoid ambient light and degassed via Ar bubbling for $10 \mathrm{~min}$. Then the piece of aluminum foil was removed and the tube was placed in a blue LED bath. Meanwhile, a control experiment was set up without any streptocyanine dye in the reaction. The reactions were monitored by $1 \mathrm{H}$ NMR. Different time points were collected to plot a graph time vs product conversion as below. It indicates that having streptocyanine dye accelerates the rate of the reaction. 


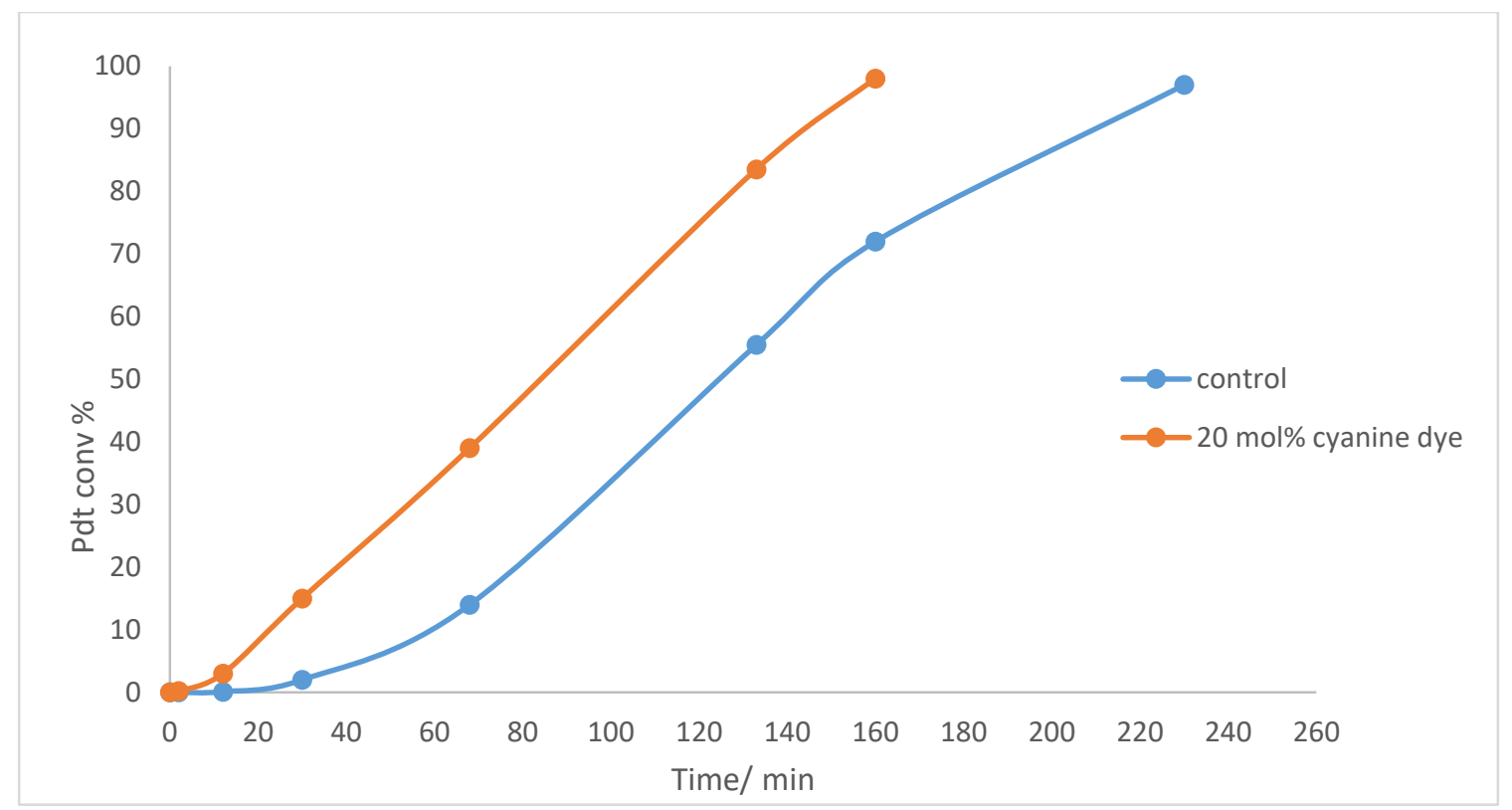

\section{UV-Vis experiments of streptocyanine dye:}

UV/Vis spectra were recorded using $1 \mathrm{~cm}$ path quartz cuvette and Varian Cary Eclipse spectrophotometer. $\mathrm{MeCN}$ was used as the solvent. UV/Vis spectra were recorded for following mixtures.

1. Streptocyanine dye $(0.012 \mathrm{mmol}$ of streptocyanine dye in $2.1 \mathrm{ml}$ total volume of $\mathrm{MeCN})$

2. DIPEA (0.06 mmol of DIPEA in $2.1 \mathrm{ml}$ total volume of $\mathrm{MeCN})$

3. Streptocyanine dye and DIPEA $(0.012 \mathrm{mmol}$ of streptocyanine dye and $0.06 \mathrm{mmol}$ of DIPEA in $2.1 \mathrm{ml}$ total volume of $\mathrm{MeCN}$ )

4. Reaction of $\mathbf{1 b}$ with $100 \%$ conversion

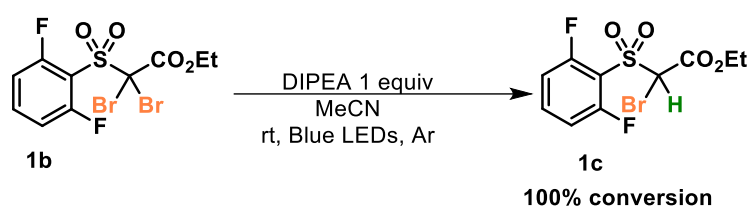

( 1b $0.12 \mathrm{mmol}$, DIPEA $0.06 \mathrm{mmol}$ in total volume of $2.1 \mathrm{~mL}$ of $\mathrm{MeCN}$ )

5. Reaction of $\mathbf{1 b}$ with $100 \%$ conversion and streptocyanine dye $(0.012 \mathrm{mmol})$ 

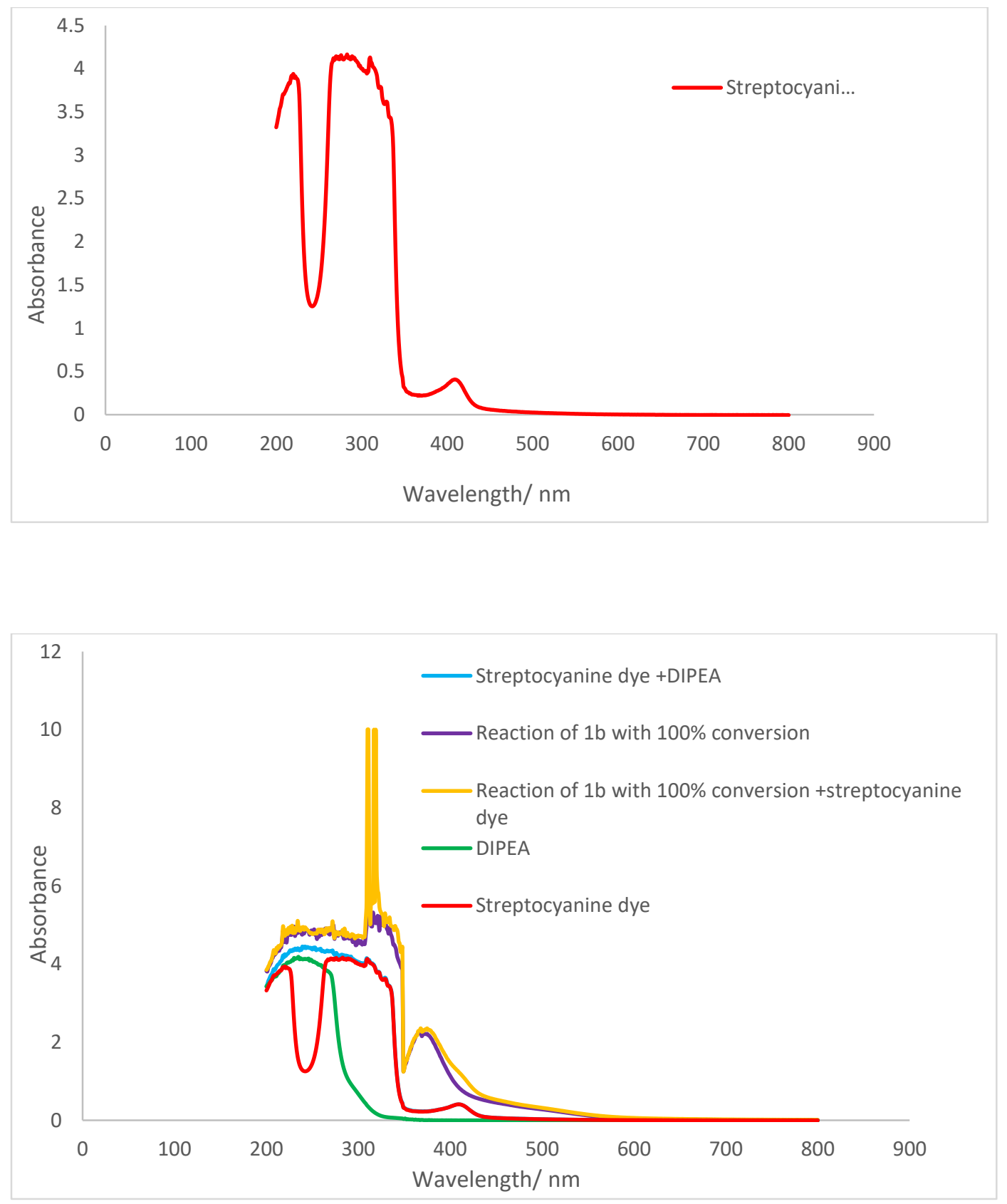

Commercial streptocyanine dye absorbs in the visible region with $\lambda=413 \mathrm{~nm}$. Reaction of $\mathbf{1 b}$ with $100 \%$ conversion also absorbs in the same visible region. 
Expansion of the above spectrum:

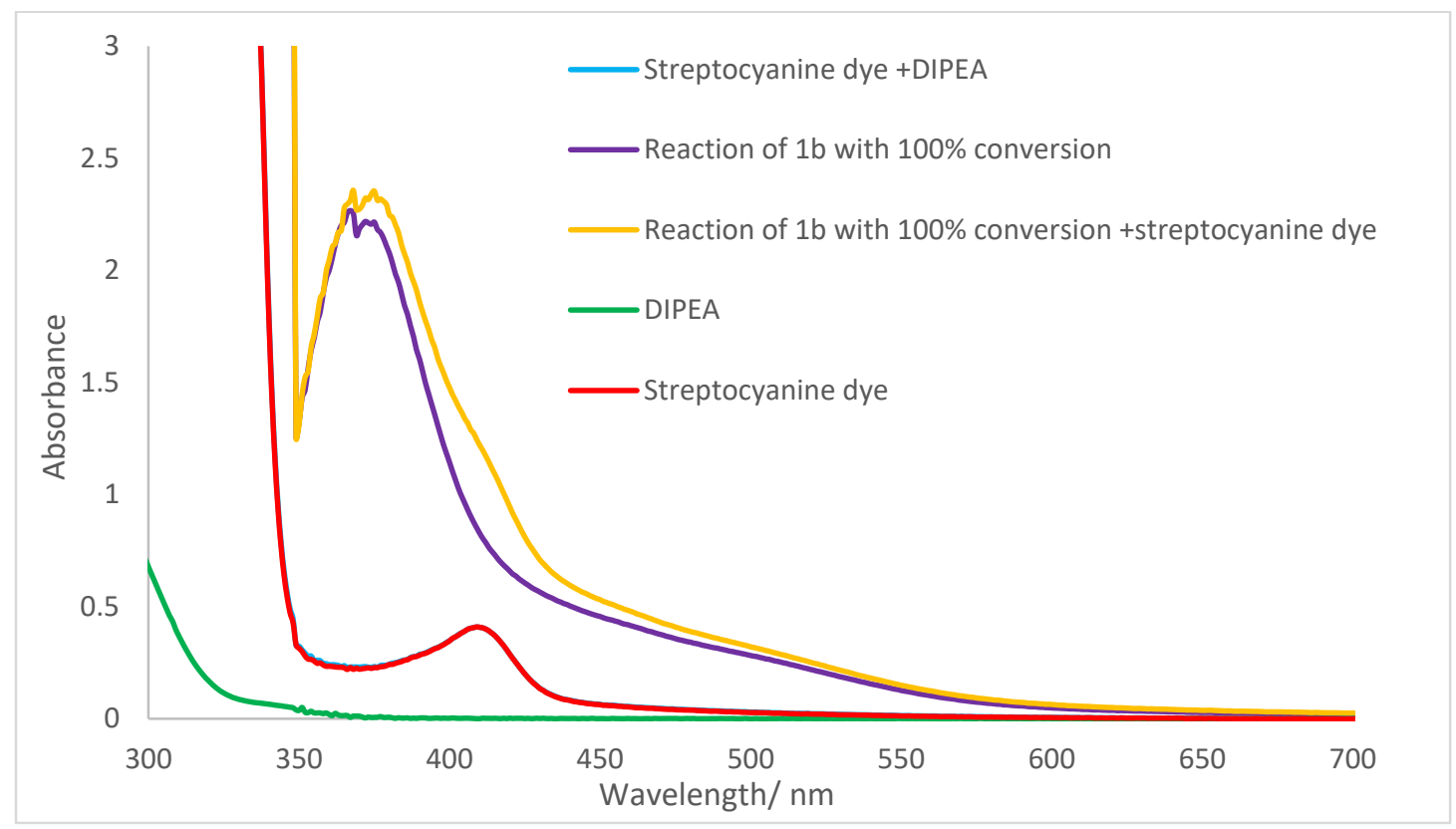

2) $\mathrm{Br}_{2}$ related experiments

During the debromination reactions, upon irradiation of the reaction mixture with blue LEDs, it was noted that the appearance of the reaction mixture changed from colorless to deep yellow and later to yellowish brown. It was suggested that the brownish color may result from the formation of $\mathrm{Br}_{2}$. The following experiments probed the formation of $\mathrm{Br}_{2}$.

Experiment 1: Addition of $\mathrm{Br}_{2}$ to the reaction

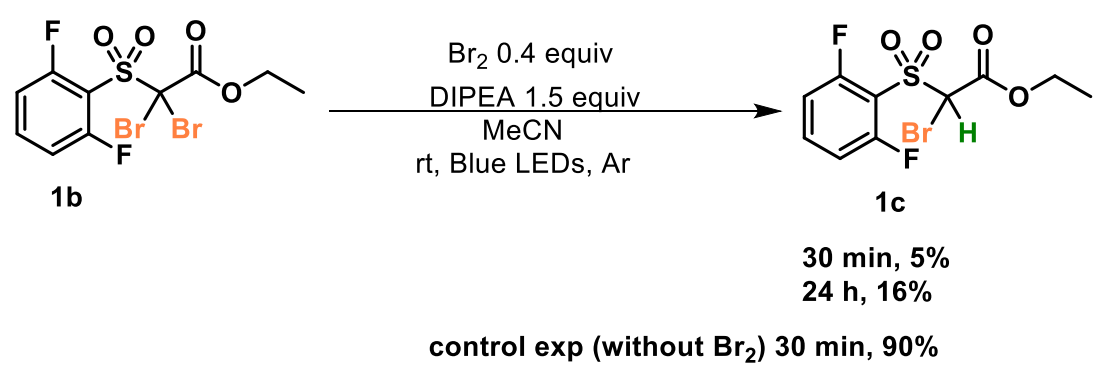

An NMR tube fitted with a rubber septum was charged with brominated sulfone $\mathbf{1 b}(50.6 \mathrm{mg}, 0.12 \mathrm{mmol}$, 1 equiv), $N, N$-diisopropylethylamine ( $31.4 \mu \mathrm{L}, 0.18 \mathrm{mmol}, 1.5$ equiv), bromine ( $2.5 \mu \mathrm{L}, 0.048 \mathrm{mmol}, 0.4$ equiv) and $\mathrm{MeCN}(1.2 \mathrm{~mL})$. The reaction tube was covered with piece of aluminum foil to avoid ambient 
light and degassed via Ar bubbling for $10 \mathrm{~min}$. Then the piece of aluminum foil was removed and the tube was placed in a blue LED bath. Meanwhile, a control experiment was set up without any bromine in the reaction. The reactions were monitored by 19F NMR. After $30 \mathrm{~min}$, the bromine contained reaction showed only 5\% conversion while the control experiment (normal conditions-no $\mathrm{Br} 2$ ) gave $90 \%$ conversion, indicating that bromine significantly retarded the rate of the reaction.

\section{Experiment 2: Addition of bromine scavenger to the reaction}

Bromination of (E)-1,2-diphenylethene is well known reaction in literature. ${ }^{12}$ If the reaction forms bromine in the reaction, (E)-1,2-diphenylethene would react with bromine and form the di-brominated product. Therefore, following reaction was set up.

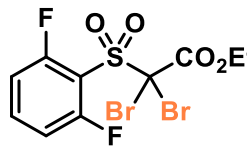

1 equiv $1 \mathrm{~b}$

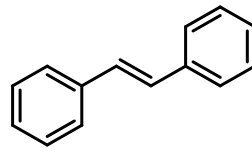

2 equiv

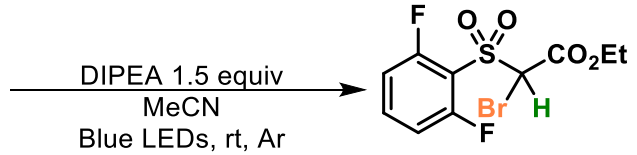

$1 \mathrm{c}$

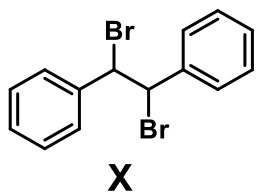

$X$

$50 \mathrm{~min}, 90 \%$

An NMR tube fitted with a rubber septum was charged with brominated sulfone $1 \mathbf{b}(50.6 \mathrm{mg}, 0.12 \mathrm{mmol}$, 1 equiv), $N, N$-diisopropylethylamine ( $31.4 \mu \mathrm{L}, 0.18 \mathrm{mmol}, 1.5$ equiv), (E)-1,2-diphenylethene (43.3 $\mathrm{mg}$, $0.24 \mathrm{mmol}, 2$ equiv) and $\mathrm{MeCN}(1.2 \mathrm{~mL})$. The reaction tube was covered with piece of aluminum foil to avoid ambient light and degassed via Ar bubbling for $10 \mathrm{~min}$. Then the piece of aluminum foil was removed and the tube was placed in a blue LED bath. After $50 \mathrm{~min}$, the reaction was monitored by 19F NMR and it showed complete conversion with $90 \%$ product. Then, the reaction was subjected to GCMS. It did not show the mass of the dibrominated stilbene product. 


\section{Experiment 3: Addition of bromine scavenger $\mathrm{Na}_{2} \mathrm{~S}_{2} \mathrm{O}_{3}$ to the reaction}

$\mathrm{Na}_{2} \mathrm{~S}_{2} \mathrm{O}_{3}$ can react with bromine and which would be expect to decolorize the brownish colored solution.

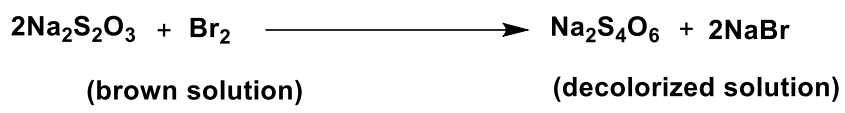

1b

same brown color and intensity

as control exp

$20 \mathrm{~min}, 67 \%$

control $\exp$ (without $\mathrm{Na}_{2} \mathrm{~S}_{2} \mathrm{O}_{3}$ ), $50 \%$

An NMR tube fitted with a rubber septum was charged with brominated sulfone $1 \mathbf{b}(50.6 \mathrm{mg}, 0.12 \mathrm{mmol}$, 1 equiv), $N, N$-diisopropylethylamine ( $31.4 \mu \mathrm{L}, 0.18 \mathrm{mmol}, 1.5$ equiv), $\mathrm{Na}_{2} \mathrm{~S}_{2} \mathrm{O}_{3}$ (47.4 mg, $0.3 \mathrm{mmol}, 2.5$ equiv) and $\mathrm{MeCN}(1.2 \mathrm{~mL})$. The reaction tube was covered with piece of aluminum foil to avoid ambient light and degassed via Ar bubbling for $10 \mathrm{~min}$. Then the piece of aluminum foil was removed and the tube was placed in a blue LED bath. After $20 \mathrm{~min}$, the reaction was monitored by $19 \mathrm{~F} \mathrm{NMR}$. $\mathrm{Na}_{2} \mathrm{~S}_{2} \mathrm{O}_{3}$ contained reaction showed $67 \%$ conversion while the control experiment showed 50\% conversion. By visual inspection, the same brown color and intensity was observed for both the reactions.

\section{Experiment 4: UV-Vis experiment}

UV/Vis spectra were recorded using $1 \mathrm{~cm}$ path quartz cuvette and Varian Cary Eclipse spectrophotometer. $\mathrm{MeCN}$ was used as the solvent. UV/Vis spectra were recorded for following mixtures.

1. Bromine $\left(0.06 \mathrm{mmol}\right.$ of $\mathrm{Br}_{2}$ in $2.1 \mathrm{ml}$ total volume of $\left.\mathrm{MeCN}\right)$

2. Bromine and DIPEA (0.06 mmol of $\mathrm{Br}_{2}$ and $0.06 \mathrm{mmol}$ of DIPEA in $2.1 \mathrm{ml}$ total volume of $\left.\mathrm{MeCN}\right)$ 
3. Reaction of $\mathbf{1 b}$ at $80 \%$ conversion

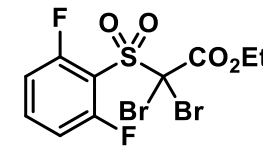

1b

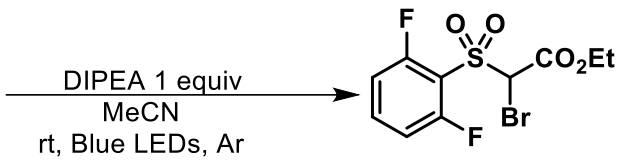

$1 \mathrm{c}$

$80 \%$ conversion

( 1b $0.12 \mathrm{mmol}$, DIPEA $0.06 \mathrm{mmol}$ in total volume of $2.1 \mathrm{ml}$ of $\mathrm{MeCN}$ )

4. Reaction of $\mathbf{1 b}$ at $80 \%$ conversion (as above) and bromine ( $0.06 \mathrm{mmol})$

While bromine does absorb in the visible region with $\lambda_{\max }=468 \mathrm{~nm}$, the reaction mixture of $\mathbf{1 b}$ (at $80 \%$ conversion) absorbs the visible region with $\lambda_{\max }=393 \mathrm{~nm}$. This suggests that bromine is neither present or involved in the reaction.

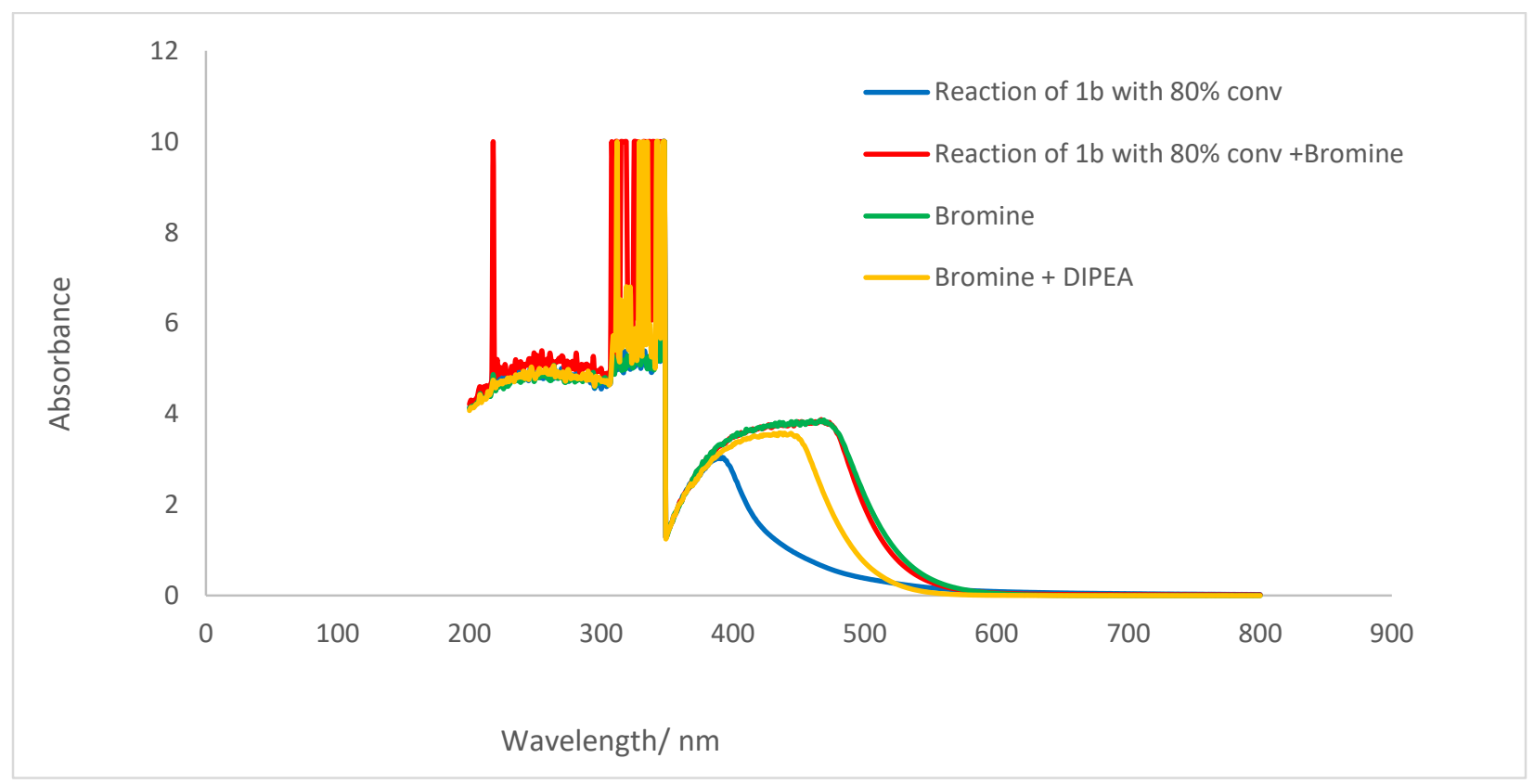


Expansion of the above spectrum:

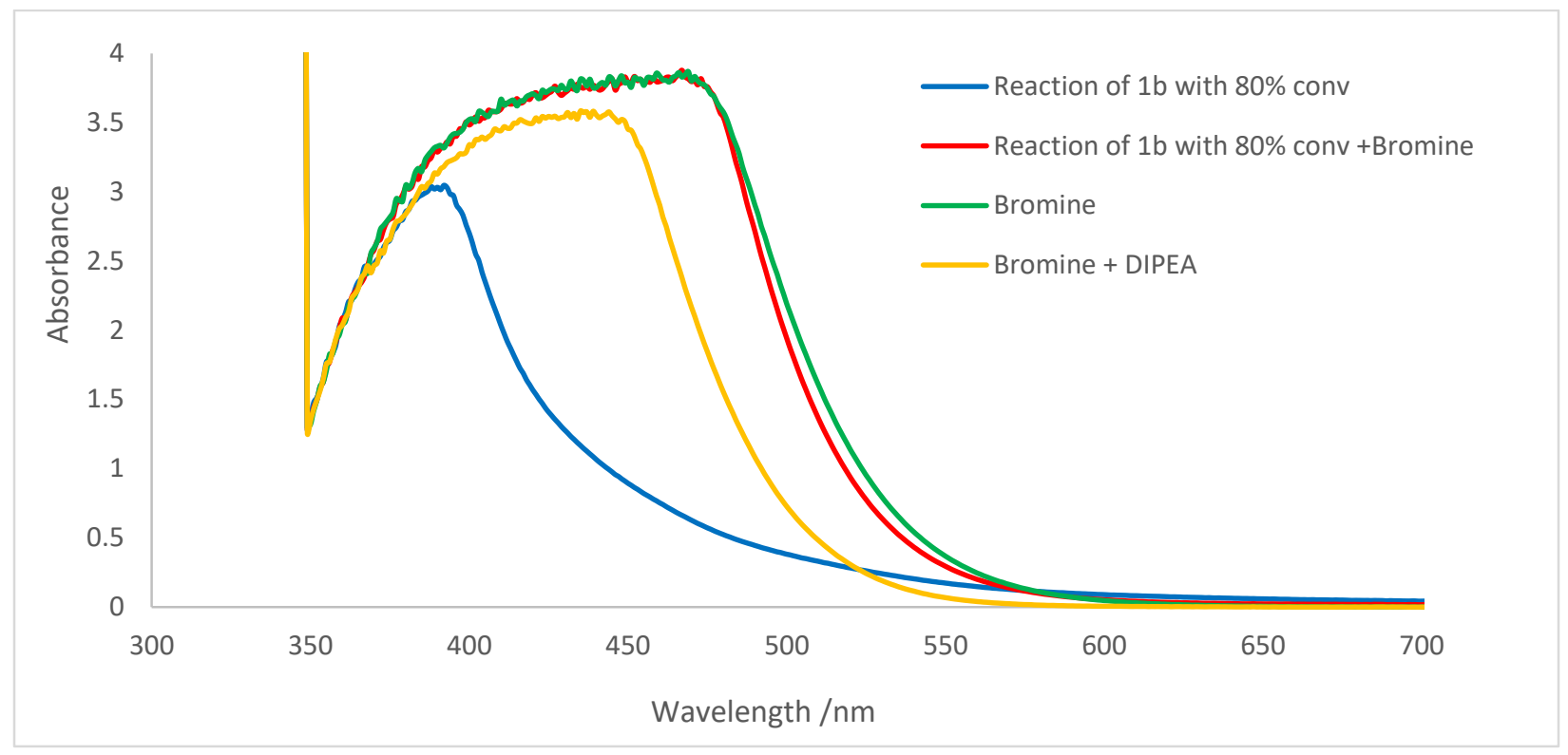

3) For the direct EDA pathway, it is proposed that a halogen-nitrogen EDA complex results in a bathochromic shift which enables excitation and subsequent loss of a bromide anion. This is based on a UV shift observed with substrate $7 \mathrm{~b}$ when mixed with DIPEA. The UV shift could be as a direct result of deprotonation forming a charged species leading to a UV shift and not due to the EDA complex.

To be clear, this is only possible for two substrates $\mathbf{7 b}$ and $\mathbf{8 b}$ which have acidic protons. Arguably, if we formed the enolate, the absorption spectrum would likely look substantially different than the EDA complex. Thus, we performed UV-Vis experiments on $\mathbf{8 b}$ and $\mathbf{9 b}$, which are nearly identical except that the last acidic proton is replaced with a bromine. We observed similar spectra, and think it is likely that these two classes of substrates still proceed through an EDA complex, though we cannot completely rule out the suggested possibility.

A UV-Vis experiment was performed on $\mathbf{9 b}$ which could not undergo such a mechanism as that suggested by the reviewer. Like $\mathbf{8 b}$, it also displays a bathochromic shift $\mathbf{7 b}$, suggesting that these two may be undergoing the same mechanism. The following spectra were recorded. 
<smiles>O=C(c1ccccc1)C(Br)Br</smiles>

$7 \mathrm{~b}$<smiles>O=C(c1ccc(C(F)(F)F)cc1)C(Br)Br</smiles>

8b<smiles>O=C(c1ccc(C(F)(F)F)cc1)C(Br)(Br)Br</smiles>

9b

$1.8 \mathbf{b}$ or $9 \mathbf{b}(0.21 \mathrm{mmol}$ of $\mathbf{8 b}$ or $\mathbf{9 b}$ in $2.1 \mathrm{~mL}$ total volume of $\mathrm{MeCN})$

2. $8 \mathbf{b}$ or $9 \mathbf{b}$ with DIPEA $(0.21 \mathrm{mmol}$ of $\mathbf{8 b}$ or $9 \mathbf{b}$ with $0.315 \mathrm{mmol}$ of DIPEA in $2.1 \mathrm{~mL}$ total volume of $\mathrm{MeCN})$

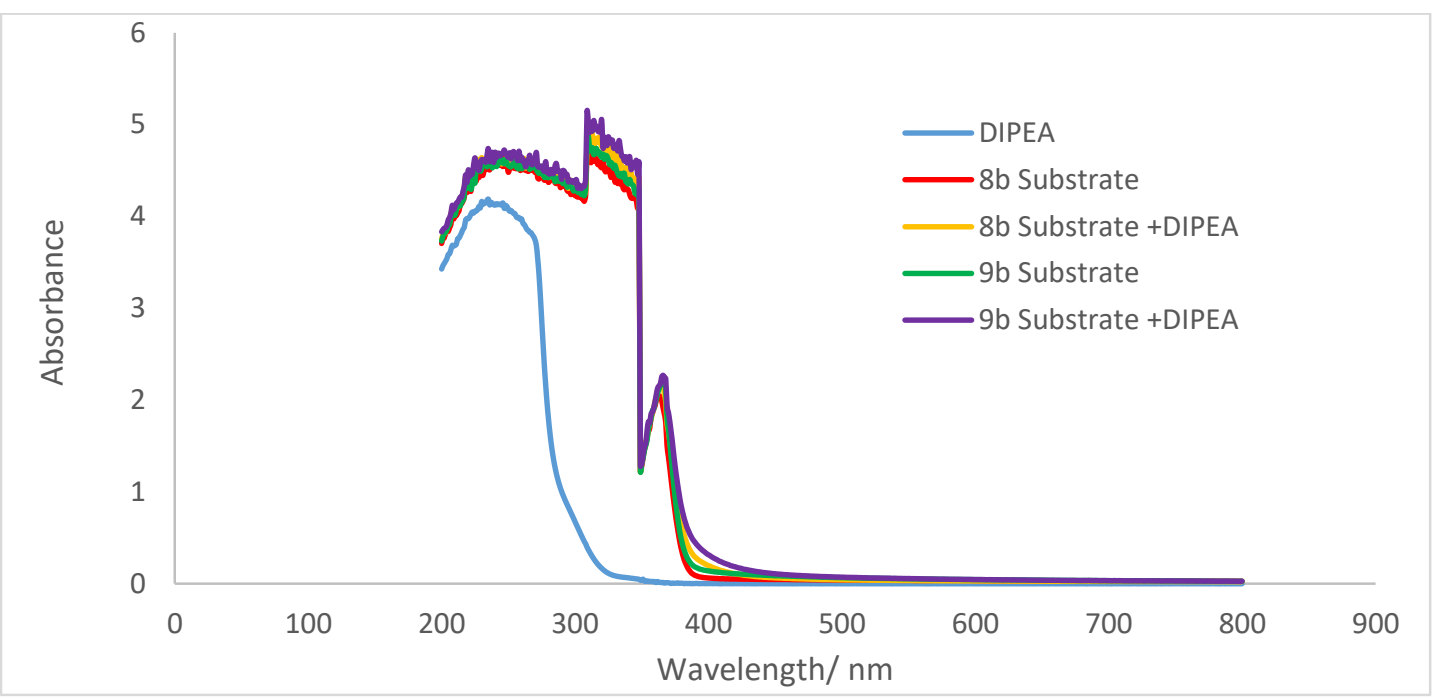

Expansion of the above spectrum:

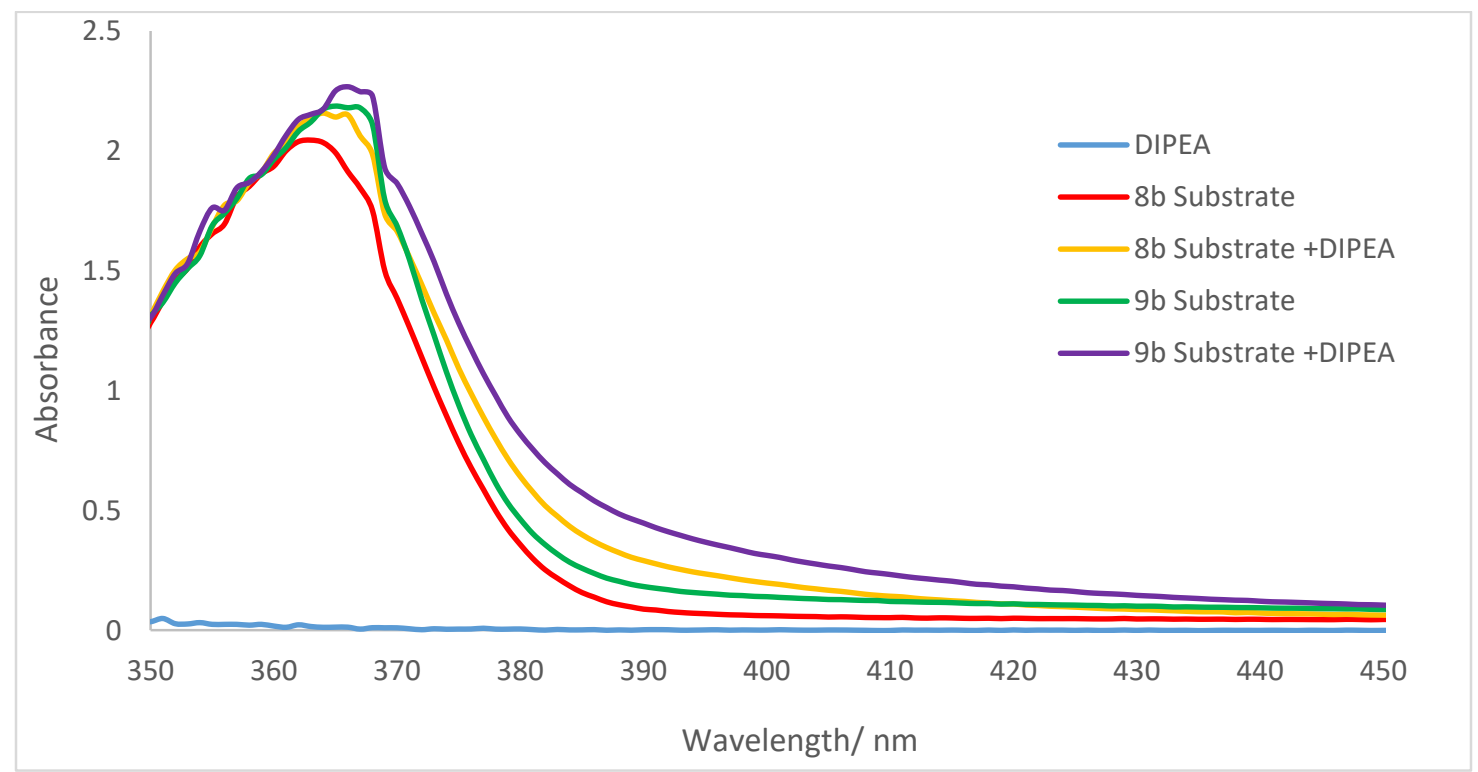


4) Purple LEDs and a vast excess of DIPEA are used in particular for dehalogenation of chlorides. This supports a hypothesis that an initial homolytic cleavage is necessary which ultimately leads to propagation in the system.

These conditions also are expected to facilitate the reaction under our proposed mechanism, unlike the proposed homolysis radical chain mechanism.

Sulfone 14b formed an EDA complex that absorbed in the UV region (given in the below), but not in the visible (hence not visually detectable). As shown below the absorption of in MeCN approaches zero near $319 \mathrm{~nm}$ but a 1:4 mixture of 14b and DIPEA showed a slight bathochromic displacement but its absorbance drops off before it reaches the visible region. This study, included in the SI, indicates that the EDA complex is likely the only species that can absorb a photon, suggesting that a radical chain mechanism that involves continual homolysis is unlikely.

UV/Vis spectra were recorded using $1 \mathrm{~cm}$ path quartz cuvette and Varian Cary Eclipse spectrophotometer. $\mathrm{MeCN}$ was used as the solvent. UV/Vis spectra were recorded for following mixtures.

1. 14b $(0.06 \mathrm{mmol}$ of $\mathbf{1 4 b}$ in $2.1 \mathrm{~mL}$ total volume of $\mathrm{MeCN})$

2. DIPEA (0.24 mmol of DIPEA in $2.1 \mathrm{~mL}$ total volume of $\mathrm{MeCN})$

3. 14b \& DIPEA (0.06 mmol of $\mathbf{1 4 b}$ and $0.24 \mathrm{mmol}$ of DIPEA in $2.1 \mathrm{~mL}$ total volume of $\mathrm{MeCN}$ )

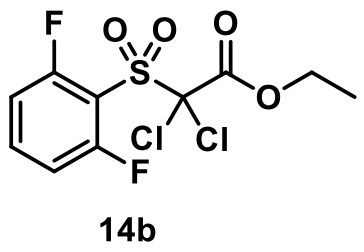

sulfone 14b did not form any visually detectable EDA complex which was supported by UV-Vis experiments. As shown below the absorption of in $\mathrm{MeCN}$ approaches zero near $319 \mathrm{~nm}$ but a 1:4 mixture of $14 \mathrm{~b}$ and DIPEA showed a slight bathochromic displacement but its absorbance too drops off before it reaches the visible region. 


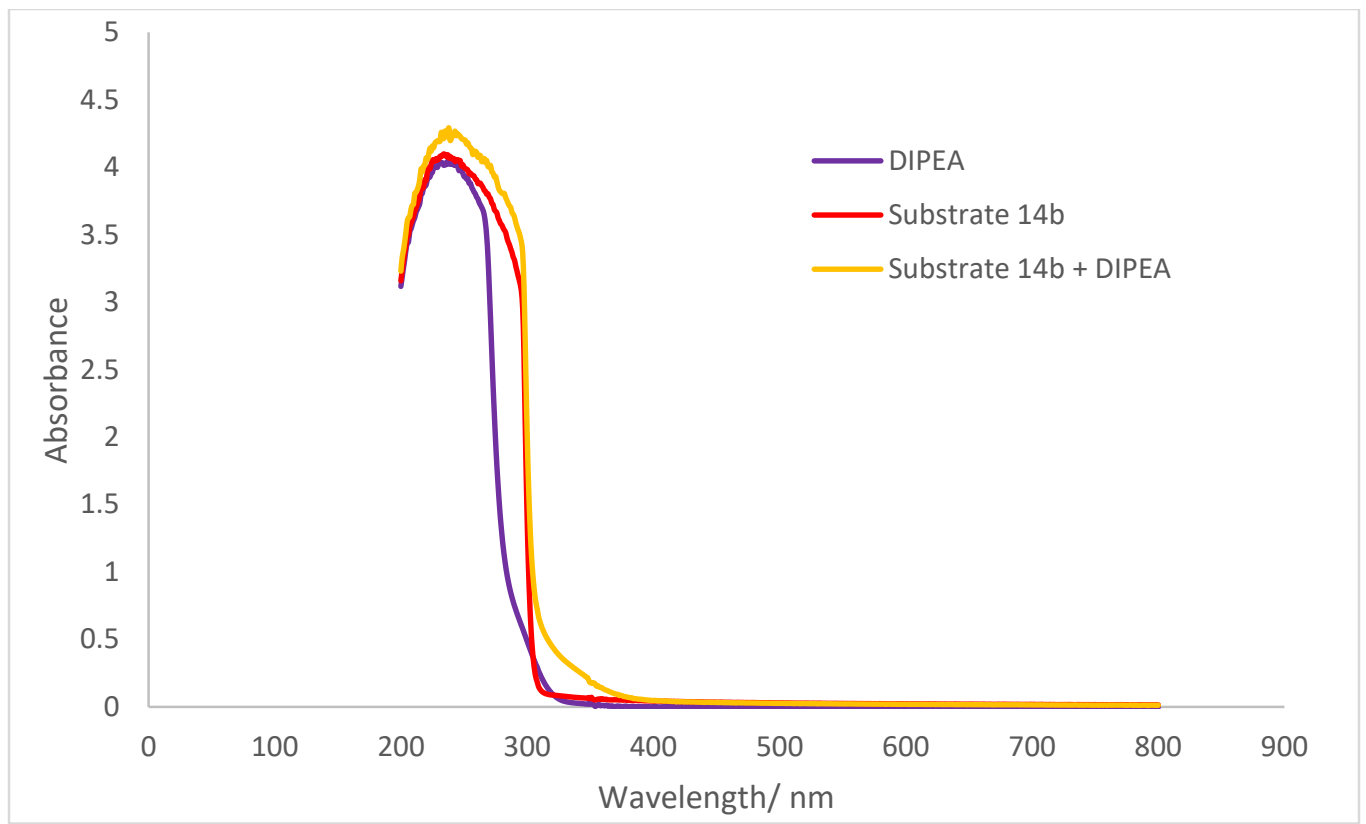

Expansion of the above spectrum:

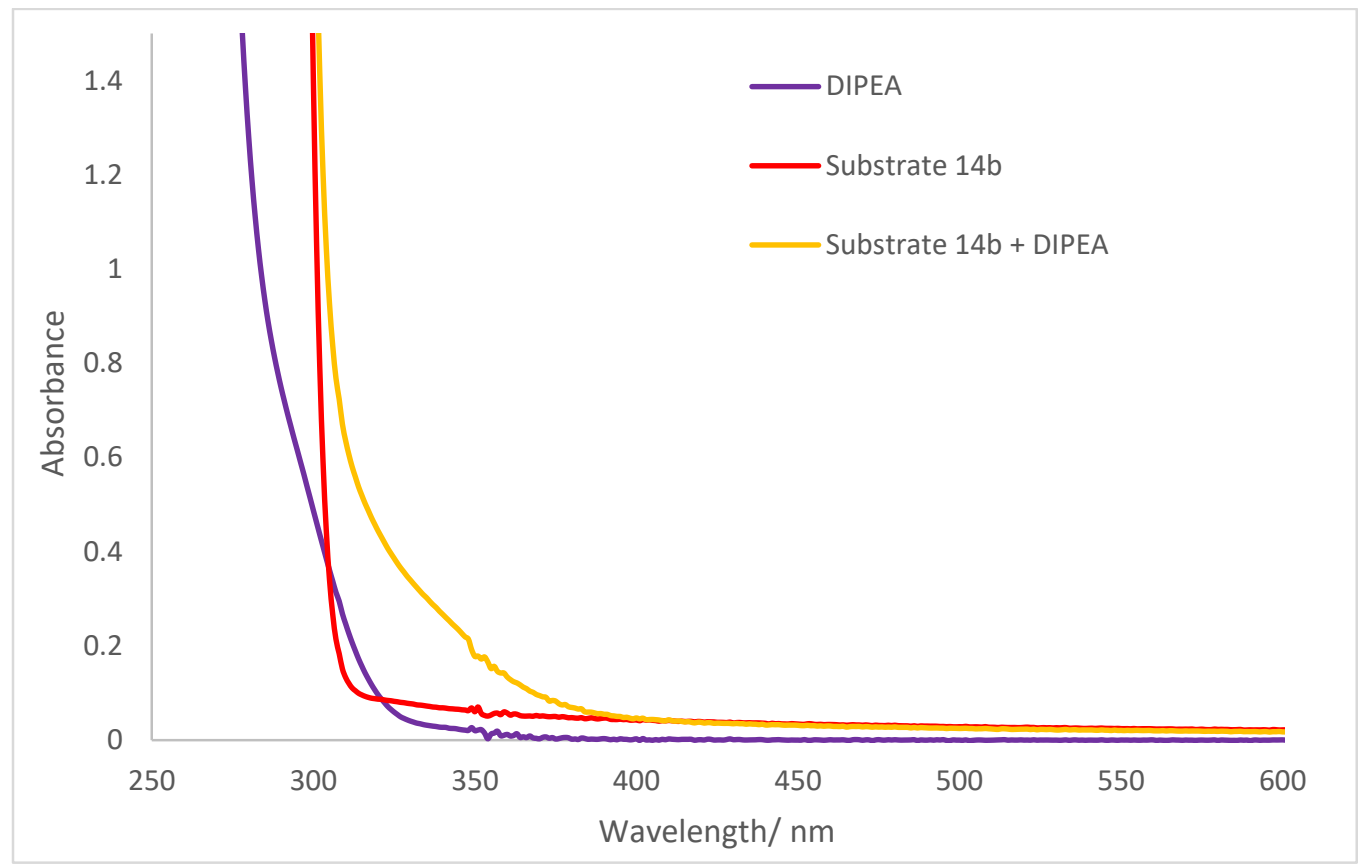




\section{Light mediated dehalogenation}

General procedure a for hydrodebromination:

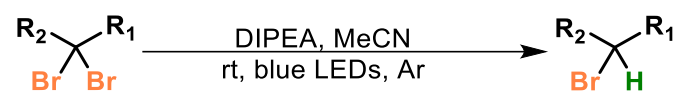

A $12 \times 75 \mathrm{~mm}$ borosilicate tube fitted with a rubber septum was charged with brominated compound $(0.12$ mmol, 1 equiv), $N, N$-diisopropylethylamine (X equivalent of amine) and $\mathrm{MeCN}$ (1.2 $\mathrm{mL}$ ). The reaction tube was covered with piece of aluminum foil to avoid ambient light and degassed via Ar bubbling for 10 min and then left under positive Ar pressure by removing the exit needle. Then, the piece of aluminum foil was removed and the tube was placed in a blue LED bath (description above) and the lower portion of the tube was submerged under the water bath which was at $28{ }^{\circ} \mathrm{C}$. The reaction was monitored by TLC, $1 \mathrm{H}$ NMR or GC-MS. After the completion of selective debromination, MeCN was removed via rotovap and the residue was treated with sat. $\mathrm{NaHCO}_{3}$ solution $(2 \mathrm{~mL})$ and extracted with DCM $(3 \times 2 \mathrm{~mL})$. The organic portions were combined and dried over anhydrous $\mathrm{MgSO}_{4}$. The crude product was concentrated in vacuo and purified via normal phase chromatography.

Ethyl 2-bromo-2-((2,6-difluorophenyl)sulfonyl)acetate

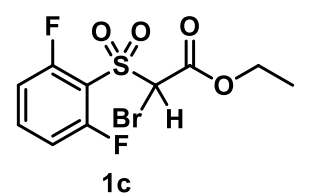

The general procedure A was followed using ethyl 2,2-dibromo-2-((2,6difluorophenyl)sulfonyl)acetate $(50.6 \mathrm{mg}, 0.12 \mathrm{mmol}, 1$ equiv) and $N, \quad N-$ diisopropylethylamine $(31.4 \mu \mathrm{L}, 0.18 \mathrm{mmol}, 1.5$ equiv) in $1.2 \mathrm{~mL} \mathrm{MeCN}$. After the completion of the reaction in $45 \mathrm{~min}$, the crude was purified via automated flash chromatography using ether in hexanes ( $0 \%$ to $100 \%$ ) with product eluting at $30 \%$ on a $4 \mathrm{~g}$ silica column to afford 1c in $93 \%$ yield $(38 \mathrm{mg}, 0.112 \mathrm{mmol})$ as an oil. ${ }^{1} \mathrm{H}$ NMR $\left(400 \mathrm{MHz}, \mathrm{CDCl}_{3}\right) \delta 7.69(\mathrm{tt}, J=8.5$, $5.9 \mathrm{~Hz}, 1 \mathrm{H}), 7.10(\mathrm{t}, J=8.4 \mathrm{~Hz}, 2 \mathrm{H}), 5.48(\mathrm{~s}, 1 \mathrm{H}), 4.36-4.24(\mathrm{~m}, 2 \mathrm{H}), 1.29(\mathrm{t}, J=7.1 \mathrm{~Hz}, 3 \mathrm{H}) .{ }^{19} \mathrm{~F} \mathrm{NMR}$ $\left(376 \mathrm{MHz}, \mathrm{CDCl}_{3}\right) \delta-103.4(\mathrm{dd}, J=8.4,5.8 \mathrm{~Hz}) .{ }^{13} \mathrm{C} \mathrm{NMR}\left(101 \mathrm{MHz}, \mathrm{CDCl}_{3}\right) \delta 161.1(\mathrm{dd}, J=263.5,3.0$ Hz), 161.3, 137.7 (t, $J=11.4$ Hz), 113.8 - $113.6(\mathrm{~m}), 113.6$ - 113.4 (m), 64.5, 60.4, 13.9. GC/MS (m/z, relative intensity) 263 (30), 224 (1), 154 (100). The compound produced thermally generated impurities under GC conditions. HRMS (ESI) calcd. for $\left[\mathrm{C}_{10} \mathrm{H}_{8} \mathrm{BrF}_{2} \mathrm{O}_{4} \mathrm{~S}\right]^{-}[\mathrm{M}-\mathrm{H}]^{-} \mathrm{m} / \mathrm{z}, 340.9295$ found 340.9301. 
Ethyl 2-bromo-2-(phenylsulfonyl)acetate

The general procedure $\mathbf{A}$ was followed using ethyl 2,2-dibromo-2-
(phenylsulfonyl)acetate $(46.3 \mathrm{mg}, 0.12 \mathrm{mmol})$ and $N, N$-diisopropylethylamine $(31.4$
$\mu \mathrm{L}, 0.18 \mathrm{mmol}, 1.5$ equiv) in $1.2 \mathrm{~mL} \mathrm{MeCN}$. After the completion of the reaction in 2 $\mathrm{h}$, the crude was purified via automated flash chromatography using EtOAc in hexanes (0\% to 100\%) with product eluting at $23 \%$ on a $4 \mathrm{~g}$ silica column to afford $2 \mathrm{c}$ in $92 \%$ yield $(33.8 \mathrm{mg}, 0.11 \mathrm{mmol})$ as an oil. ${ }^{1} \mathrm{H}$ NMR (400 MHz, $\left.\mathrm{CDCl}_{3}\right) \delta 7.98(\mathrm{~d}, J=7.3 \mathrm{~Hz}, 2 \mathrm{H}), 7.73(\mathrm{t}, J=7.5 \mathrm{~Hz}, 1 \mathrm{H}), 7.60(\mathrm{t}, J=7.8 \mathrm{~Hz}, 2 \mathrm{H}), 5.24$ $(\mathrm{s}, 1 \mathrm{H}), 4.25$ (q, $J=7.1 \mathrm{~Hz}, 2 \mathrm{H}), 1.26$ (t, $J=7.1 \mathrm{~Hz}, 3 \mathrm{H}) .{ }^{13} \mathrm{C} \mathrm{NMR}\left(101 \mathrm{MHz}, \mathrm{CDCl}_{3}\right) \delta 162.1,134.9$, 134.5, 130.4, 128.8, 63.7, 58.4, 13.6. GC/MS (m/z, relative intensity) $306\left(\mathrm{M}^{+}, 1\right), 280(1), 141(60)$. The compound produced thermally generated impurities under GC conditions. HRMS (ESI) calcd. for $\left[\mathrm{C}_{10} \mathrm{H}_{10} \mathrm{BrO}_{4} \mathrm{~S}\right]^{-}[\mathrm{M}-\mathrm{H}]^{-} \mathrm{m} / \mathrm{z}, 304.9483$ found 304.9492.

\section{Ethyl 2-bromo-2-(methylsulfonyl)acetate}

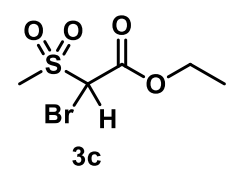

The general procedure A was followed using ethyl 2,2-dibromo-2-(methylsulfonyl)acetate (38.9 mg, $0.12 \mathrm{mmol})$ and $N, N$-diisopropylethylamine $(31.4 \mu \mathrm{L}, 0.18 \mathrm{mmol}, 1.5$ equiv) in $1.2 \mathrm{~mL} \mathrm{MeCN}$. After the completion of the reaction in $3 \mathrm{~h}$, the crude was purified via automated flash chromatography using ether in hexanes (0\% to $100 \%)$ with product eluting at $28 \%$ on a 4 g silica column to afford $\mathbf{3 c}$ in $90 \%$ yield $(26.5 \mathrm{mg}, 0.108 \mathrm{mmol})$ as an oil. ${ }^{1} \mathrm{H} \mathrm{NMR}\left(400 \mathrm{MHz}, \mathrm{CDCl}_{3}\right) \delta$ $5.04(\mathrm{~s}, 1 \mathrm{H}), 4.35$ (q, $J=7.1 \mathrm{~Hz}, 2 \mathrm{H}), 3.28(\mathrm{~s}, 3 \mathrm{H}), 1.36$ (t, $J=7.1 \mathrm{~Hz}, 3 \mathrm{H}) .{ }^{13} \mathrm{C} \mathrm{NMR}\left(101 \mathrm{MHz}, \mathrm{CDCl}_{3}\right)$ $\delta 163.2,64.3,55.8,37.2,13.9$. GC/MS (m/z, relative intensity) 216 (10), $166(10), 120$ (100). The compound produced thermally generated impurities under GC conditions. HRMS (ESI) calcd. for $\left[\mathrm{C}_{5} \mathrm{H}_{8} \mathrm{BrO}_{4} \mathrm{~S}\right]$ $\left.\mathrm{HM}^{\mathrm{H}}\right]^{-} \mathrm{m} / \mathrm{z}, 242.9327$ found 242.9335.

\section{Diethyl 2-bromomalonate}

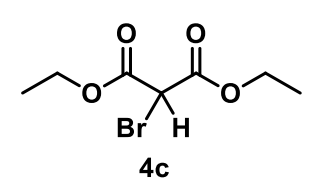

The general procedure A was followed using diethyl 2,2-dibromomalonate (38.15 mg, $0.12 \mathrm{mmol})$ and $N, N$-diisopropylethylamine $(41.8 \mu \mathrm{L}, 0.24 \mathrm{mmol}, 2$ equiv) in $1.2 \mathrm{~mL}$

$\mathrm{MeCN}$. After the completion of the reaction in $18 \mathrm{~h}$, the crude was purified via automated flash chromatography using EtOAc in hexanes (0\% to 100\%) with product eluting at $7 \%$ on a 4 $\mathrm{g}$ silica column to afford $\mathbf{4 c}$ in $91 \%$ yield $(26.2 \mathrm{mg}, 0.109 \mathrm{mmol})$ as an oil. NMR chemical shifts and mass spectrum details have reported in literature ${ }^{13}$ and NMR chemical shifts match with the literature values. ${ }^{1} \mathrm{H}$ NMR $\left(400 \mathrm{MHz}, \mathrm{CDCl}_{3}\right) \delta 4.81(\mathrm{~s}, 1 \mathrm{H}), 4.28(\mathrm{q}, J=7.1 \mathrm{~Hz}, 4 \mathrm{H}), 1.30(\mathrm{t}, J=7.1 \mathrm{~Hz}, 6 \mathrm{H}) .{ }^{13} \mathrm{C} \mathrm{NMR}(101$ $\left.\mathrm{MHz}, \mathrm{CDCl}_{3}\right) \delta 165.0,63.7,42.8,14.3$. 


\section{Ethyl 2-bromo-2-cyanoacetate}

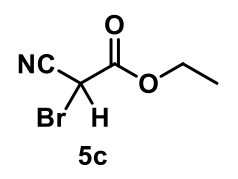

The general procedure A was followed using ethyl 2,2-dibromo-2-cyanoacetate $(32.5 \mathrm{mg}$,

$0.12 \mathrm{mmol})$ and $N, N$-diisopropylethylamine $(41.8 \mu \mathrm{L}, 0.24 \mathrm{mmol}, 2$ equiv) in $1.2 \mathrm{~mL}$

$\mathrm{MeCN}$. After the completion of the reaction in $19 \mathrm{~h}$, the crude was purified via automated flash chromatography using EtOAc in hexanes (0\% to 100\%) with product eluting at $12 \%$ on a $4 \mathrm{~g}$ silica column to afford 5c in $89 \%$ yield $(20.5 \mathrm{mg}, 0.107 \mathrm{mmol})$ as an oil. NMR chemical shifts and mass spectrum details have reported in literature ${ }^{14}$ and NMR chemical shifts match with the literature values. ${ }^{1} \mathrm{H}$ NMR $\left(400 \mathrm{MHz}, \mathrm{CDCl}_{3}\right) \delta 5.78(\mathrm{~s}, 1 \mathrm{H}), 4.38(\mathrm{q}, J=7.1 \mathrm{~Hz}, 2 \mathrm{H}), 1.36(\mathrm{t}, J=7.1 \mathrm{~Hz}, 3 \mathrm{H})$.

\section{3-Bromo-1,5-dioxaspiro[5.5]undecane-2,4-dione}

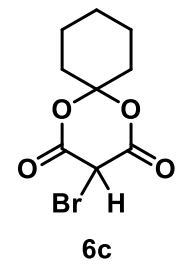

The general procedure A was followed using 3,3-dibromo-1,5-dioxaspiro[5.5]undecane-2,4dione (41 mg, $0.12 \mathrm{mmol}$ ) and $N, N$-diisopropylethylamine ( $41.8 \mu \mathrm{L}, 0.24 \mathrm{mmol}, 2$ equiv) in $1.2 \mathrm{~mL} \mathrm{MeCN}$. After the completion of the reaction in $18 \mathrm{~h}$, the crude was purified via silica plug to afford $\mathbf{6 c}$ in $85 \%$ yield as a mixture of 89:11 monodebrominated to didebrominated product based on ${ }^{1} \mathrm{H}$ NMR. ${ }^{1} \mathrm{H}$ NMR (400 MHz, $\left.\mathrm{CDCl}_{3}\right) \delta 5.13(\mathrm{~s}, 1 \mathrm{H}), 2.17-2.09(\mathrm{~m}, 2 \mathrm{H})$, $2.04-1.94(\mathrm{~m}, 4 \mathrm{H}), 1.81$ - $1.72(\mathrm{~m}, 4 \mathrm{H}), 1.57$ - 1.44 (m, 2H). ${ }^{13} \mathrm{C} \mathrm{NMR}\left(101 \mathrm{MHz}, \mathrm{CDCl}_{3}\right) \delta 161.4,108.6$, 37.2, 37.0, 35.1, 24.3, 22.7, 22.6. This compound decomposed under GC conditions. HRMS (ESI) calcd. for $\left[\mathrm{C}_{9} \mathrm{H}_{10} \mathrm{BrO}_{4}\right]^{-}[\mathrm{M}-\mathrm{H}]^{-} \mathrm{m} / \mathrm{z}, 260.9762$ found 260.9782.

\section{2-Bromo-1-phenylethan-1-one}

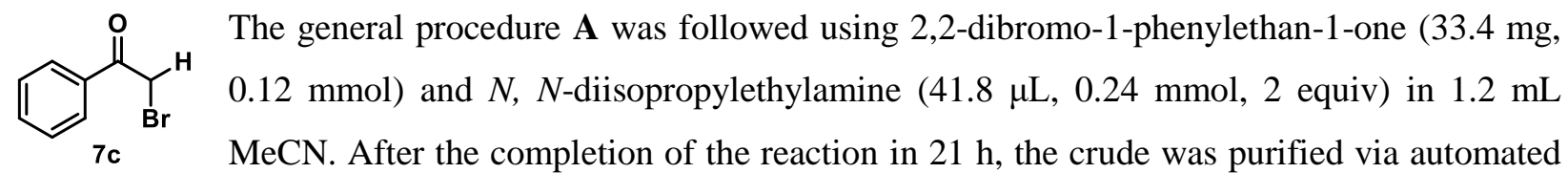
flash chromatography using EtOAc in hexanes (0\% to 100\%) with product eluting at $3 \%$ on a $4 \mathrm{~g}$ silica column to afford 7c in $93 \%$ yield $(22.2 \mathrm{mg}, 0.112 \mathrm{mmol})$ as an oil. NMR chemical shifts and mass spectrum details have reported in literature ${ }^{15}$ and NMR chemical shifts match with the literature values. ${ }^{1} \mathrm{H}$ NMR $\left(400 \mathrm{MHz}, \mathrm{CDCl}_{3}\right) \delta 7.98(\mathrm{dd}, 2 \mathrm{H}), 7.61(\mathrm{tt}, J=6.9,1.3 \mathrm{~Hz}, 1 \mathrm{H}), 7.55-7.45(\mathrm{~m}, 2 \mathrm{H}), 4.46(\mathrm{~s}, 2 \mathrm{H}) .{ }^{13} \mathrm{C}$ NMR (101 MHz, $\left.\mathrm{CDCl}_{3}\right) \delta 191.4,134.1,129.1,129.0,31.1$. 
2-Bromo-1-(4-(trifluoromethyl)phenyl)ethan-1-one

The general procedure $\mathbf{A}$ was followed using 2,2-dibromo-1-(4-
(trifluoromethyl)phenyl)ethan-1-one $(41.5 \quad \mathrm{mg}, 0.12 \mathrm{mmol})$ and $\mathrm{N}, \quad \mathrm{N}$ -
diisopropylethylamine $(41.8 \mu \mathrm{L}, 0.24 \mathrm{mmol}, 2$ equiv) in $1.2 \mathrm{~mL} \mathrm{MeCN}$. After the completion of the reaction in $20 \mathrm{~h}$, the crude was purified via automated flash chromatography using EtOAc in hexanes $(0 \%$ to $100 \%)$ with product eluting at $1 \%$ on a $4 \mathrm{~g}$ silica column to afford $8 \mathrm{c}$ in $94 \%$ yield (30.1 $\mathrm{mg}, 0.113 \mathrm{mmol})$ as an oil. ${ }^{1} \mathrm{H} \mathrm{NMR}\left(400 \mathrm{MHz}, \mathrm{CDCl}_{3}\right) \delta 8.11(\mathrm{~d}, J=8.2 \mathrm{~Hz}, 2 \mathrm{H}), 7.77(\mathrm{~d}, J=8.3 \mathrm{~Hz}$, 2H), 4.45 (s, 2H). ${ }^{19} \mathrm{~F}$ NMR (376 MHz, $\left.\mathrm{CDCl}_{3}\right) \delta-63.3 .{ }^{13} \mathrm{C} \mathrm{NMR}\left(101 \mathrm{MHz}, \mathrm{CDCl}_{3}\right) \delta 190.5,137.5-136.0$ $(\mathrm{m}), 135.3(\mathrm{q}, J=32.8 \mathrm{~Hz}), 129.5,126.1(\mathrm{q}, J=3.7 \mathrm{~Hz}), 123.5(\mathrm{q}, J=272.9 \mathrm{~Hz}), 30.4$. GC/MS (m/z, relative intensity) $266\left(\mathrm{M}^{+}, 1\right), 173(100), 145$ (50). The compound produced thermally generated impurities under GC conditions. HRMS (ESI) calcd. for $\left[\mathrm{C}_{9} \mathrm{H}_{5} \mathrm{BrF}_{3} \mathrm{O}\right]^{-}[\mathrm{M}-\mathrm{H}]^{-} \mathrm{m} / \mathrm{z}, 264.9476$ found 264.9484.

\section{2,2-Dibromo-1-(4-(trifluoromethyl)phenyl)ethan-1-one}

The general procedure $\mathbf{A}$ was followed using 2,2,2-tribromo-1-(4-
(trifluoromethyl)phenyl)ethan-1-one $(51 \quad \mathrm{mg}, 0.12 \quad \mathrm{mmol})$ and $\mathrm{N}, \quad \mathrm{N}$ -
diisopropylethylamine $(31.4 \mu \mathrm{L}, 0.18 \mathrm{mmol}, 1.5$ equiv) in $1.2 \mathrm{~mL} \mathrm{MeCN}$. After the completion of the reaction in $10 \mathrm{~h}$, the crude was purified via automated flash chromatography using EtOAc in hexanes ( $0 \%$ to $100 \%$ ) with product eluting at $0.1 \%$ on a $4 \mathrm{~g}$ silica column to afford $9 \mathrm{c}$ in $88 \%$ yield (36.7 mg, $0.106 \mathrm{mmol})$ as an oil. ${ }^{1} \mathrm{H} \mathrm{NMR}\left(400 \mathrm{MHz}, \mathrm{CDCl}_{3}\right) \delta 8.23(\mathrm{~d}, J=8.2 \mathrm{~Hz}, 2 \mathrm{H}), 7.78(\mathrm{~d}, J=8.3$ $\mathrm{Hz}, 2 \mathrm{H}), 6.62(\mathrm{~s}, 1 \mathrm{H}) .{ }^{19} \mathrm{~F}$ NMR $\left(376 \mathrm{MHz}, \mathrm{CDCl}_{3}\right) \delta-63.4 .{ }^{13} \mathrm{C} \mathrm{NMR}\left(101 \mathrm{MHz}, \mathrm{CDCl}_{3}\right) \delta 185.5,136.0$ (q, $J=33.0 \mathrm{~Hz}), 134.4-133.9(\mathrm{~m}), 130.7,127.81(\mathrm{q}, J=272.9 \mathrm{~Hz}), 126.4(\mathrm{q}, J=3.7 \mathrm{~Hz}), 39.5$. GC/MS (m/z, relative intensity) 327(1), 266 (1), 173 (100). The compound produced thermally generated impurities under GC conditions. HRMS (ESI) calcd. for $\left[\mathrm{C}_{9} \mathrm{H}_{4} \mathrm{Br}_{2} \mathrm{~F}_{3} \mathrm{O}\right]^{-}[\mathrm{M}-\mathrm{H}]^{-} \mathrm{m} / \mathrm{z}, 344.8561$ found 344.8568 .

\section{((1-Bromoethyl)sulfonyl)benzene}

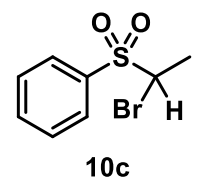

The general procedure A was followed using ((1,1-dibromoethyl)sulfonyl)benzene (39.4 mg, $0.12 \mathrm{mmol}$ ) and $N, N$-diisopropylethylamine $(41.8 \mu \mathrm{L}, 0.24 \mathrm{mmol}, 2$ equiv) in $1.2 \mathrm{~mL} \mathrm{MeCN}$.

After the completion of the reaction in $22 \mathrm{~h}$, the crude was purified via automated flash chromatography using EtOAc in hexanes ( $0 \%$ to $100 \%$ ) with product eluting at $10 \%$ on a $4 \mathrm{~g}$ silica column to afford 10c in $90 \%$ yield $(27 \mathrm{mg}, 0.108 \mathrm{mmol})$ as an oil. NMR chemical shifts and mass spectrum details 
have reported in literature ${ }^{7}$ and mass spectrum details match with the literature values. GC/MS (m/z, relative intensity) $248\left(\mathrm{M}^{+}, 2\right), 250\left(\mathrm{M}^{+}+2,2\right), 125(90), 77$ (100).

((Bromo(phenyl)methyl)sulfonyl)benzene

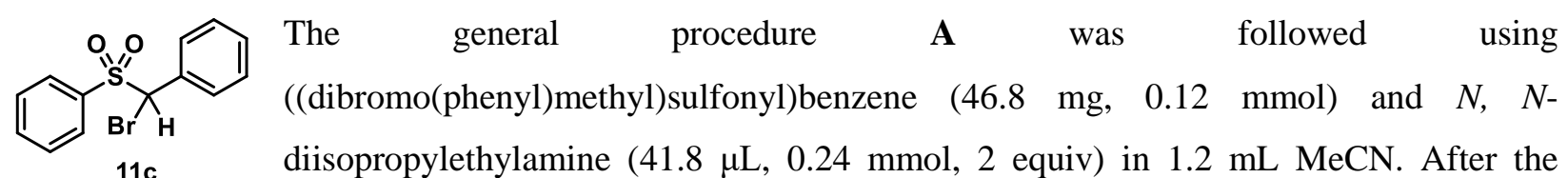
completion of the reaction in $20 \mathrm{~h}$, the crude was purified via automated flash chromatography using EtOAc in hexanes ( $0 \%$ to $100 \%$ ) with product eluting at $6 \%$ on a $4 \mathrm{~g}$ silica column to afford 11c in $91 \%$ yield (34 $\mathrm{mg}, 0.109 \mathrm{mmol}$ ) as an oil. NMR chemical shifts and mass spectrum details have reported in literature ${ }^{7}$ and NMR chemical shifts match with the literature values. ${ }^{1} \mathrm{H}$ NMR $\left(400 \mathrm{MHz}, \mathrm{CDCl}_{3}\right) \delta 7.70(\mathrm{dd}, J=8.4$, $1.2 \mathrm{~Hz}, 2 \mathrm{H}), 7.66-7.61(\mathrm{~m}, 1 \mathrm{H}), 7.50-7.43(\mathrm{~m}, 2 \mathrm{H}), 7.40-7.33(\mathrm{~m}, 3 \mathrm{H}), 7.33-7.27(\mathrm{~m}, 2 \mathrm{H}), 5.70(\mathrm{~s}$, $1 \mathrm{H}) .{ }^{13} \mathrm{C} \mathrm{NMR}\left(101 \mathrm{MHz}, \mathrm{CDCl}_{3}\right) \delta 135.0,134.6,131.2,130.5,130.4,130.2,129.0,128.7,65.8$.

\section{6-Bromo-2,2-dimethylcyclohexan-1-one}

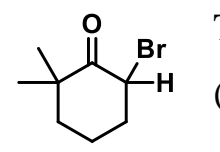

$12 c$

The general procedure A was followed using 2,2-dibromo-6,6-dimethylcyclohexan-1-one (34.1 mg, $0.12 \mathrm{mmol})$ and $N, N$-diisopropylethylamine $(41.8 \mu \mathrm{L}, 0.24 \mathrm{mmol}, 2$ equiv) in 1.2 $\mathrm{mL} \mathrm{MeCN}$. After the completion of the reaction in $25 \mathrm{~h}$, the crude was purified via automated flash chromatography using diethyl ether in hexanes (0\% to $100 \%)$ with product eluting at $1 \%$ on a $4 \mathrm{~g}$ silica column to afford $12 \mathrm{c}$ in $89 \%$ yield $(21.9 \mathrm{mg}, 0.107 \mathrm{mmol})$ as an oil. NMR chemical shifts and mass spectrum details have reported in literature ${ }^{16}$ and mass spectrum details match with the literature values. GC/MS (m/z, relative intensity) $204\left(\mathrm{M}^{+}, 10\right), 206\left(\mathrm{M}^{+}+2,10\right), 97$ (70), 69 (100).

\section{(Bromomethyl)benzene}

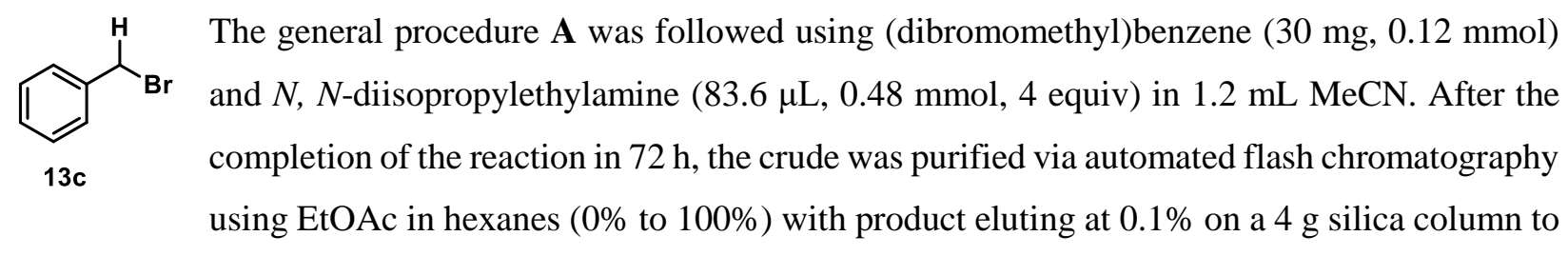
afford 13c in $80 \%$ yield (16.4 $\mathrm{mg}, 0.096 \mathrm{mmol})$ as an oil. NMR chemical shifts match with the literature 
values. ${ }^{17}{ }^{1} \mathrm{H} \mathrm{NMR}\left(400 \mathrm{MHz}, \mathrm{CDCl}_{3}\right) \delta 7.40(\mathrm{dd}, J=8.2,1.5 \mathrm{~Hz}, 2 \mathrm{H}), 7.35$ (ddd, $\left.J=7.4,5.9,1.5 \mathrm{~Hz}, 2 \mathrm{H}\right)$, $7.32-7.27(\mathrm{~m}, 1 \mathrm{H}), 4.51(\mathrm{~s}, 2 \mathrm{H}) .{ }^{13} \mathrm{C} \mathrm{NMR}\left(101 \mathrm{MHz}, \mathrm{CDCl}_{3}\right) \delta 138.2,129.5,129.3,128.9,34.0$.

\section{$\underline{\text { Hydrodebromination in large scale }}$}

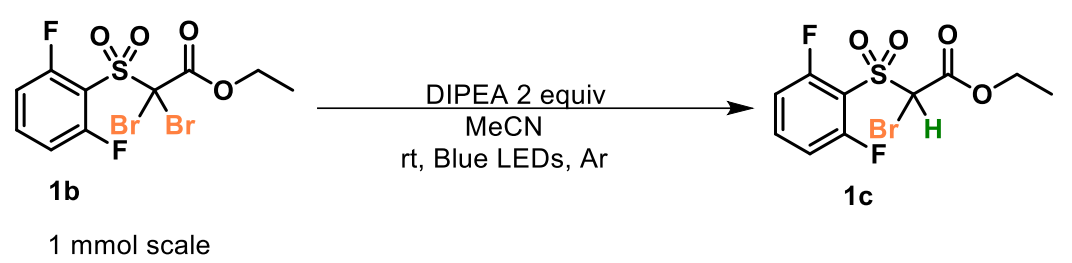

A $18 \times 150 \mathrm{~mm}$ borosilicate tube fitted with a rubber septum was charged with $\mathbf{1 b}(422 \mathrm{mg}, 1 \mathrm{mmol}, 1$ equiv), $N, N$-diisopropylethylamine ( $349 \mu \mathrm{L}, 2 \mathrm{mmol}, 2$ equiv) and $\mathrm{MeCN}(10 \mathrm{~mL})$. The reaction tube was covered with piece of aluminum foil to avoid ambient light and degassed via Ar bubbling for 30 min and then left under positive Ar pressure by removing the exit needle. Then, the piece of aluminum foil was removed and the tube was placed in a blue LED bath (description above) and the lower portion of the tube was submerged under the water bath which was at $28{ }^{\circ} \mathrm{C}$ and the reaction was stirred. The reaction was monitored by 19F NMR. After the complete consumption of $\mathbf{1 b}(6 \mathrm{~h})$, crude reaction showed $80 \%$ of $\mathbf{1 c}$ product according to $19 \mathrm{~F} \mathrm{NMR}$. MeCN was removed via rotovap and the residue was treated with sat. $\mathrm{NaHCO}_{3}$ solution $(20 \mathrm{~mL})$ and extracted with DCM $(3 \times 10 \mathrm{~mL})$. The organic portions were combined and dried over anhydrous $\mathrm{MgSO}_{4}$. The crude product was concentrated in vacuo and purified via normal phase chromatography using EtOAc in hexanes ( $0 \%$ to $100 \%$ ) with product eluting at $26 \%$ on a $40 \mathrm{~g}$ silica column to afford $1 \mathrm{c}$ in $76 \%$ as a solid. 


\section{General procedure B for hydrodechlorination}

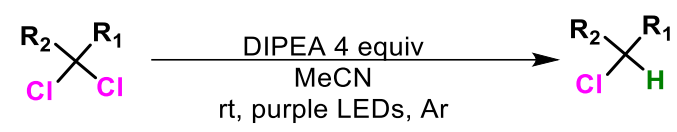

This procedure is identical to general procedure A except that the blue LEDs were exchanged with violet LEDs and increased loading of amine was used. This procedure was used for all the hydrodechlorination reactions. Substrate $(0.12 \mathrm{mmol}, 1$ equiv) and $N, N$-diisopropylethylamine ( $83.6 \mu \mathrm{L}, 0.48 \mathrm{mmol}, 4$ equiv) in $1.2 \mathrm{~mL}$ MeCN. The tube was placed in a purple LEDs bath. The reaction was monitored by TLC, $1 \mathrm{H}$ NMR or GC-MS. After the completion of selective dechlorination, MeCN was removed via rotovap and the residue was treated with sat. $\mathrm{NaHCO}_{3}$ solution $(2 \mathrm{~mL})$ and extracted with DCM $(3 \times 2 \mathrm{~mL})$. The organic portions were combined and dried over anhydrous $\mathrm{MgSO}_{4}$. The crude product was concentrated in vacuo and purified via normal phase chromatography.

Ethyl 2-chloro-2-((2,6-difluorophenyl)sulfonyl)acetate

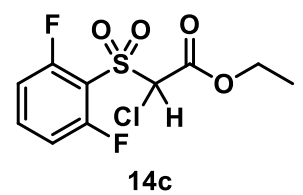

The general procedure $\mathbf{B}$ was followed using ethyl 2,2-dichloro-2-((2,6difluorophenyl)sulfonyl)acetate (40 mg, $0.12 \mathrm{mmol}$ ) and $N, N$-diisopropylethylamine (83.6 $\mu \mathrm{L}, 0.48 \mathrm{mmol}, 4$ equiv) in $1.2 \mathrm{~mL} \mathrm{MeCN}$. After the completion of the reaction in $50 \mathrm{~h}$, the crude was purified via automated flash chromatography using EtOAc in hexanes ( $0 \%$ to $100 \%$ ) with product eluting at $20 \%$ on a $4 \mathrm{~g}$ silica column to afford $\mathbf{1 4 c}$ in $85 \%$ yield $(30.5$ $\mathrm{mg}, 0.102 \mathrm{mmol})$ as an oil. ${ }^{1} \mathrm{H} \mathrm{NMR}\left(400 \mathrm{MHz}, \mathrm{CDCl}_{3}\right) \delta 7.70(\mathrm{tt}, J=8.5,5.9 \mathrm{~Hz}, 1 \mathrm{H}), 7.10(\mathrm{t}, J=8.5 \mathrm{~Hz}$, $2 \mathrm{H}), 5.44(\mathrm{~s}, 1 \mathrm{H}), 4.35(\mathrm{qq}, J=6.8,3.6 \mathrm{~Hz}, 2 \mathrm{H}), 1.32(\mathrm{t}, J=7.1 \mathrm{~Hz}, 3 \mathrm{H}) .{ }^{19} \mathrm{~F} \mathrm{NMR}\left(376 \mathrm{MHz}, \mathrm{CDCl}_{3}\right) \delta-$ $103.5(\mathrm{dd}, J=8.5,5.8 \mathrm{~Hz}) .{ }^{13} \mathrm{C}$ NMR $\left(101 \mathrm{MHz}, \mathrm{CDCl}_{3}\right) \delta 161.2(\mathrm{dd}, J=263.8,3.1 \mathrm{~Hz}), 161.1,137.8(\mathrm{t}, J$ $=11.3 \mathrm{~Hz}), 113.8-113.7(\mathrm{~m}), 113.6-113.4(\mathrm{~m}), 72.6,64.5,13.9 . \mathrm{GC} / \mathrm{MS}$ (m/z, relative intensity) $270(5)$, 177 (100), 161 (60). The compound produced thermally generated impurities under GC conditions. HRMS (ESI) calcd. for $\left[\mathrm{C}_{10} \mathrm{H}_{8} \mathrm{ClF}_{2} \mathrm{O}_{4} \mathrm{~S}\right]^{-}[\mathrm{M}-\mathrm{H}]^{-} \mathrm{m} / \mathrm{z}, 296.9800$ found 296.9808.

ethyl 2,2-dichloroacetate

The general procedure B was followed using ethyl 2,2,2-trichloroacetate (23 mg, 0.12
${ }_{15 \mathbf{c}}^{\mathbf{H}} \mathbf{C l}$ mmol) and $N, N$-diisopropylethylamine $(83.6 \mu \mathrm{L}, 0.48 \mathrm{mmol}, 4$ equiv) in $1.2 \mathrm{~mL} \mathrm{MeCN}$.
After the completion of the reaction in $72 \mathrm{~h}$, the crude was purified via automated flash 
chromatography using EtOAc in hexanes (0\% to $100 \%$ ) with product eluting at $10 \%$ on a $4 \mathrm{~g}$ silica column to afford $15 \mathrm{c}$ in $70 \%$ yield $(13.2 \mathrm{mg}, 0.084 \mathrm{mmol})$ as an oil. NMR chemical shifts and mass spectrum details have reported in literature ${ }^{18}$ and NMR chemical shifts match with the literature values. ${ }^{1} \mathrm{H}$ NMR $(400 \mathrm{MHz}$, $\left.\mathrm{CDCl}_{3}\right) \delta 5.93(\mathrm{~s}, 1 \mathrm{H}), 4.33(\mathrm{qd}, J=7.1,1.5 \mathrm{~Hz}, 2 \mathrm{H}), 1.35(\mathrm{td}, J=8.7,6.7,1.6 \mathrm{~Hz}, 3 \mathrm{H}) .{ }^{13} \mathrm{C} \mathrm{NMR}(101$ $\left.\mathrm{MHz}, \mathrm{CDCl}_{3}\right) \delta 165.0,64.8,64.2,14.3$.

\section{Benzyl 2,2-dichloroacetate}

The general procedure $\mathbf{B}$ was followed using benzyl 2,2,2-trichloroacetate $(30.4 \mathrm{mg}$,
$0.12 \mathrm{mmol})$ and $N, N$-diisopropylethylamine $(83.6 \mu \mathrm{L}, 0.48 \mathrm{mmol}, 4$ equiv) in $1.2 \mathrm{~mL}$
$\mathrm{MeCN}$. After the completion of the reaction in $60 \mathrm{~h}$, the crude was purified via automated flash chromatography using EtOAc in hexanes (0\% to $100 \%)$ with product eluting at $20 \%$ on a $4 \mathrm{~g}$ silica column to afford $\mathbf{1 6 c}$ in $78 \%$ yield $(20.5 \mathrm{mg}, 0.094 \mathrm{mmol})$ as an oil. ${ }^{1} \mathrm{H} \mathrm{NMR}\left(400 \mathrm{MHz}, \mathrm{CDCl}_{3}\right)$ $\delta 7.39$ (s, 5H), 5.98 (s, 1H), 5.29 (s, 2H). ${ }^{13} \mathrm{C} \mathrm{NMR}\left(101 \mathrm{MHz}, \mathrm{CDCl}_{3}\right) \delta 164.8,134.6,129.4,129.2,128.9$, 69.5, 64.7. GC/MS (m/z, relative intensity) $218\left(\mathrm{M}^{+}, 10\right), 107$ (18), 91 (100). The compound produced thermally generated impurities under GC conditions. HRMS (ESI) calcd. for $\left[\mathrm{C}_{9} \mathrm{H}_{7} \mathrm{Cl}_{2} \mathrm{O}_{2}\right]^{-}[\mathrm{M}-\mathrm{H}]^{-} \mathrm{m} / \mathrm{z}$, 216.9823 found 216.9785 . 


\section{Reference}

1.(a) Suryakiran, N.; Prabhakar, P.; Srikanth Reddy, T.; Chinni Mahesh, K.; Rajesh, K.; Venkateswarlu, Y., Chemoselective mono halogenation of $\beta$-keto-sulfones using potassium halide and hydrogen peroxide; synthesis of halomethyl sulfones and dihalomethyl sulfones. Tetrahedron Lett. 2007, 48, 877; (b) 5,5Dibromo-2,2-dimethyl-1,3-dioxane-4,6-dione. In Encyclopedia of Reagents for Organic Synthesis; (c) Raghunadh, A.; Meruva, S. B.; Kumar, N. A.; Kumar, G. S.; Rao, L. V.; Syam Kumar, U. K., An Efficient and Practical Synthesis of Aryl and Hetaryl $\alpha$-Keto Esters. Synthesis 2012, 44, 283; (d) Lenihan, B. D.; Shechter, $\mathrm{H}$., Chemistry of Conversions of [o-[1-Halo-1-(p-tolylsulfonyl)alkyl]benzyl]trimethylsilanes to oQuinodimethanes and Benzocyclobutenes. J. Org. Chem. 1998, 63, 2086; (e) Zhang, G.-B.; Wang, F.-X.; Du, J.-Y.; Qu, H.; Ma, X.-Y.; Wei, M.-X.; Wang, C.-T.; Li, Q.; Fan, C.-A., Toward the Total Synthesis of Palhinine A: Expedient Assembly of Multifunctionalized Isotwistane Ring System with Contiguous Quaternary Stereocenters. Org. Lett. 2012, 14, 3696; (f) Ivanov, I. V.; Dolotov, S. M.; Kobeleva, O. I.; Valova, T. M.; Barachevsky, V. A.; Traven, V. F., Photoactivation of fluorescence of rhodamine dyes in the presence of haloalkanes. Russ. Chem. Bull. 2013, 62, 1195; (g) Diethyl Dibromomalonate. In Encyclopedia of Reagents for Organic Synthesis.

2.Zou, L.-H.; Li, Y.-C.; Li, P.-G.; Zhou, J.; Wu, Z., Solvent-Controlled $\alpha$-Monobromination, $\alpha, \alpha$-Dibromination or Imidation of 1,3-Diketones with N-Bromosuccinimide. Eur. J. Org. Chem. 2018, 2018, 5639.

3.Tajbakhsh, M.; Khazaei, A.; Mahalli, M. S.; Vaghi, R. G., N,N-DIBROMOBENZENESULFONAMIDE: A USEFUL REGENRABLE REAGENT FOR BROMINATION OF VARIOUS CARBANIONIC SUBSTRATES. Phosphorus, Sulfur, and Silicon and the Related Elements 2004, 179, 1159.

4.Wu, P.; Xu, S.; Xu, H.; Hu, H.; Zhang, W., One-pot syntheses of $\alpha, \alpha$-dibromoacetophenones from aromatic alkenes with 1,3-dibromo-5,5-dimethylhydantoin. Tetrahedron Lett. 2017, 58, 618.

5.Wu, C.; Xin, X.; Fu, Z.-M.; Xie, L.-Y.; Liu, K.-J.; Wang, Z.; Li, W.; Yuan, Z.-H.; He, W.-M., Water-controlled selective preparation of $\alpha$-mono or $\alpha, \alpha^{\prime}$-dihalo ketones via catalytic cascade reaction of unactivated alkynes with 1,3-dihalo-5,5-dimethylhydantoin. Green Chem. 2017, 19, 1983.

6.Jayaraman, A.; Cho, E.; Kim, J.; Lee, S., Decarboxylative Tribromination for the Selective Synthesis of Tribromomethyl Ketone and Tribromovinyl Derivatives. Adv. Synth. Catal. 2018, 360, 3978.

7.Poteat, C. M.; Lindsay, V. N. G., Controlled $\alpha$-mono- and $\alpha, \alpha$-di-halogenation of alkyl sulfones using reagent-solvent halogen bonding. Chem. Commun. 2019, 55, 2912.

8.Corey, E. J.; Topie, T. H.; Wozniak, W. A., Stereochemistry of $\alpha$-halo ketones. VI. The stereochemistry of $\alpha$-brominated $\alpha$-methyl-, $\alpha, \alpha$-dimethyl-, and $\alpha, \alpha^{\prime}$-dibenzylcyclohexanones. J. Am. Chem. Soc. 1955, 77, 5415.

9.Smela, M. P.; Hoye, T. R., A Traceless Tether Strategy for Achieving Formal Intermolecular HexadehydroDiels-Alder Reactions. Org. Lett. 2018, 20, 5502.

10.Tang, H.; Radosz, M.; Shen, Y., Synthesis and self-assembly of thymine- and adenine-containing homopolymers and diblock copolymers. J. Polym. Sci., Part A: Polym. Chem. 2006, 44, 5995. 
11.Taichi, S.; Wataru, K.; Teruaki, M., Efficient Method for the Preparation of Carboxylic Acid Alkyl Esters or Alkyl Phenyl Ethers by a New-Type of Oxidation-Reduction Condensation Using 2,6-Dimethyl-1,4benzoquinone and Alkoxydiphenylphosphines. Bulletin of the Chemical Society of Japan 2003, 76, 1645.

12.(a) Maji, T.; Karmakar, A.; Reiser, O., Visible-Light Photoredox Catalysis: Dehalogenation of Vicinal Dibromo-, $\alpha$-Halo-, and $\alpha, \alpha$-Dibromocarbonyl Compounds. J. Org. Chem. 2011, 76, 736; (b) Nunes, C. M.; Steffens, D.; Monteiro, A. L., Synthesis of Tri- and Tetrasubstituted Olefins by Palladium Cross-Coupling Reaction. Synlett 2007, 2007, 0103; (c) Hirose, T.; Miyazaki, Y.; Watabe, M.; Akimoto, S.; Tachikawa, T.; Kodama, K.; Yasutake, M., Trialkylsilylethynyl-substituted triphenylenes and hexabenzocoronenes: highly soluble liquid crystalline materials and their hole transport abilities. Tetrahedron 2015, 71, 4714.

13.(a) Delon, L.; Laurent, P.; Blancou, H., New synthesis of polyfluoroalkyl racemic $\alpha$-amino acids. J. Fluor. Chem. 2005, 126, 1487; (b) Terent'ev, A. B.; Vasil'eva, T. T.; Mysova, N. E.; Chakhovskaya, O. V., Reactions of Diethyl Dibromomalonate and Ethyl 2,2-Dichloroacetoacetate with Water and Carbonyl Compounds (Aldehydes and Ketones) in the Presence of Pentacarbonyliron. Russ. J. Org. Chem. 2004, 40, 924.

14.(a) Alinezhad, H.; Tajbakhsh, M.; Tehrani, S. S., 2011, 32; (b) Yamada, Y.; Yasuda, H., A Convenient Synthesis of Dialkyl (E)-2,3-Dicyanobutendioates. Synthesis 1990, 1990, 768.

15.Xing, Y.; Zhang, M.; Ciccarelli, S.; Lee, J.; Catano, B., Aulll-Catalyzed Formation of $\alpha$-Halomethyl Ketones from Terminal Alkynes. Eur. J. Org. Chem. 2017, 2017, 781.

16.Frimer, A. A.; Gilinsky-Sharon, P.; Aljadeff, G.; Gottlieb, H. E.; Hameiri-Buch, J.; Marks, V.; Philosof, R.; Rosental, Z., Superoxide anion radical (O2.bul.-)-mediated base-catalyzed autoxidation of enones. J. Org. Chem. 1989, 54, 4853.

17.Lee, C.-H.; Lee, S.-M.; Min, B.-H.; Kim, D.-S.; Jun, C.-H., Ferric(III) Chloride Catalyzed Halogenation Reaction of Alcohols and Carboxylic Acids Using $\alpha, \alpha$-Dichlorodiphenylmethane. Org. Lett. 2018, 20, 2468.

18.(a) Tsurugi, H.; Hayakawa, A.; Kando, S.; Sugino, Y.; Mashima, K., Mixed-ligand complexes of paddlewheel dinuclear molybdenum as hydrodehalogenation catalysts for polyhaloalkanes. Chem Sci 2015, 6, 3434; (b) Gallucci, R. R.; Going, R., Chlorination of aliphatic ketones in methanol. J. Org. Chem. 1981, 46, 2532. 
${ }^{1} \mathrm{H}$ NMR (400 MHz, $\left.\mathrm{CDCl}_{3}\right)$ spectrum of 1b Ethyl 2,2-dibromo-2-((2,6-difluorophenyl)sulfonyl)acetate

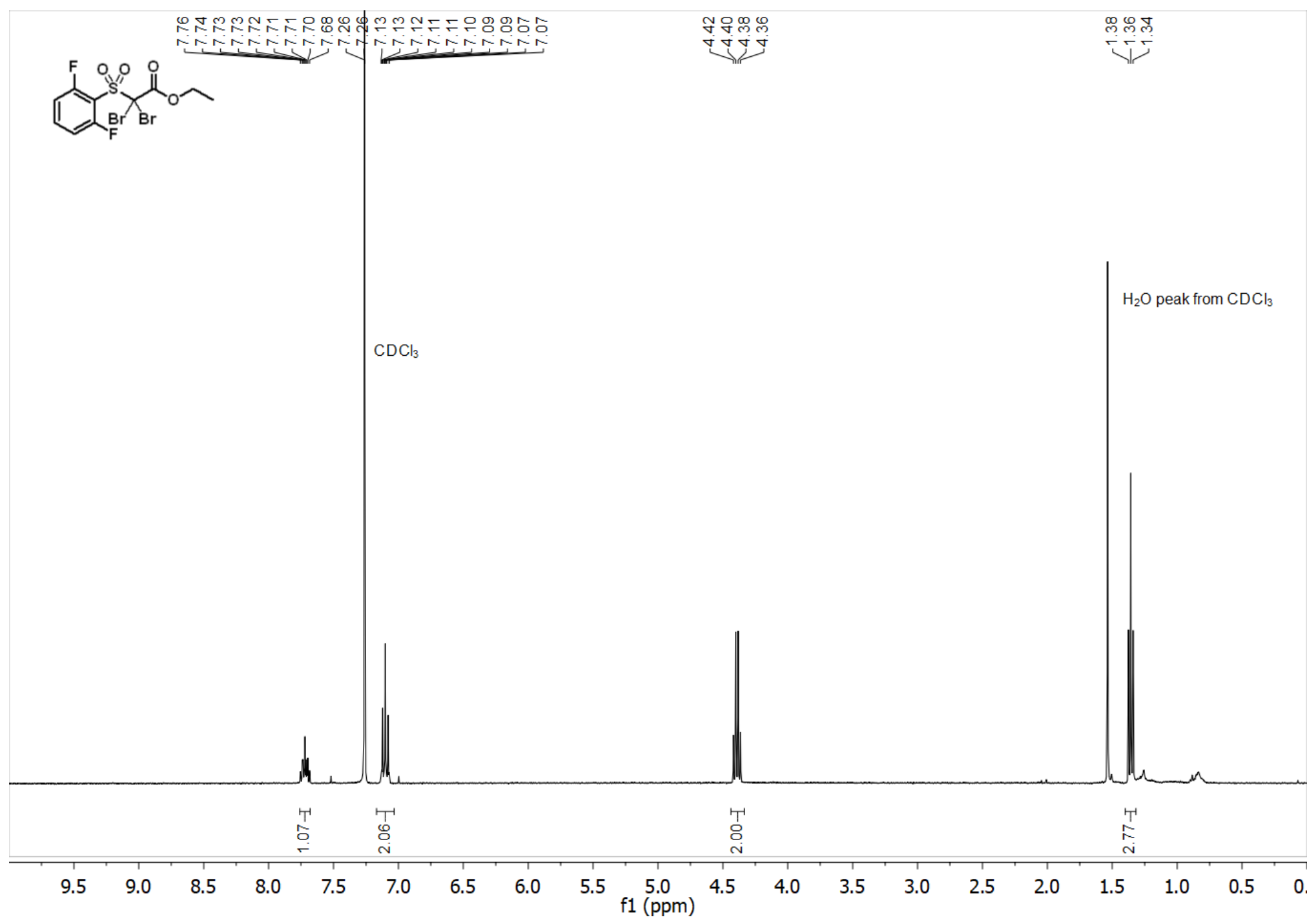


${ }^{19}$ F NMR (376 MHz, CDCl $)$ spectrum of 1b Ethyl 2,2-dibromo-2-((2,6-difluorophenyl)sulfonyl)acetate

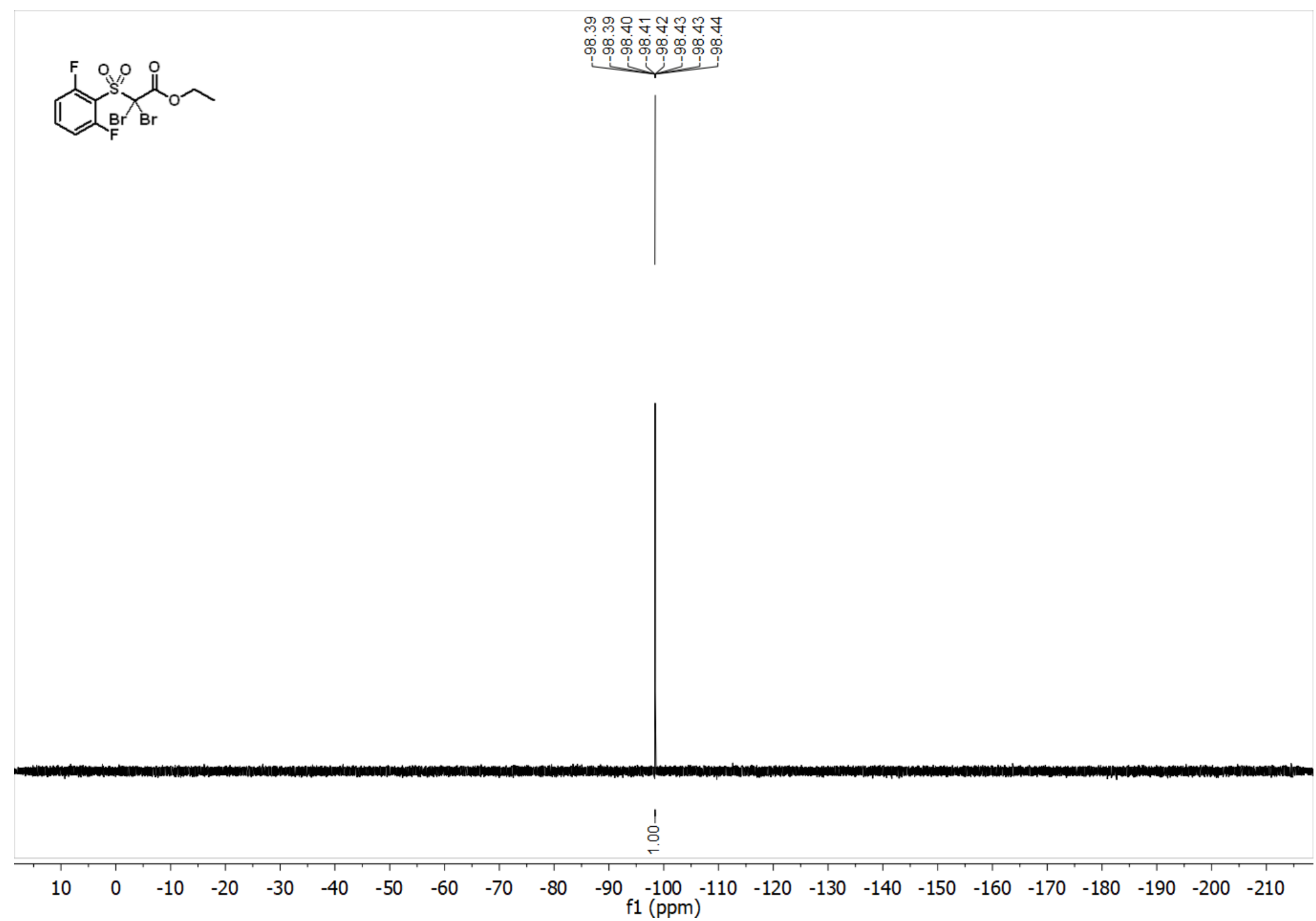


${ }^{13} \mathrm{C}$ NMR (101 MHz, $\left.\mathrm{CDCl}_{3}\right)$ spectrum of 1b Ethyl 2,2-dibromo-2-((2,6-difluorophenyl)sulfonyl)acetate

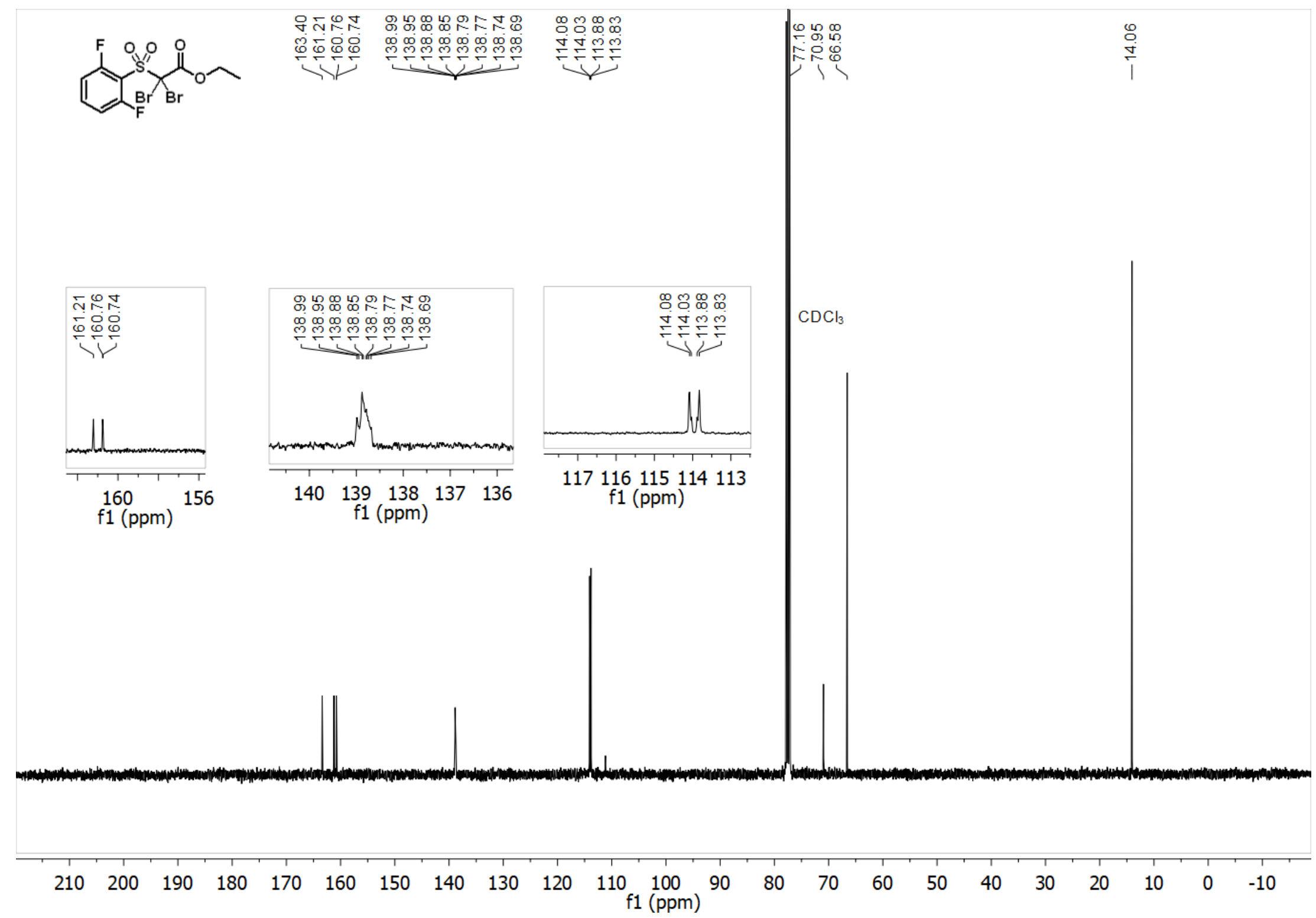


${ }^{1} \mathrm{H}$ NMR (400 MHz, $\mathrm{CDCl}_{3}$ ) spectrum of 2b Ethyl 2,2-dibromo-2-(phenylsulfonyl)acetate

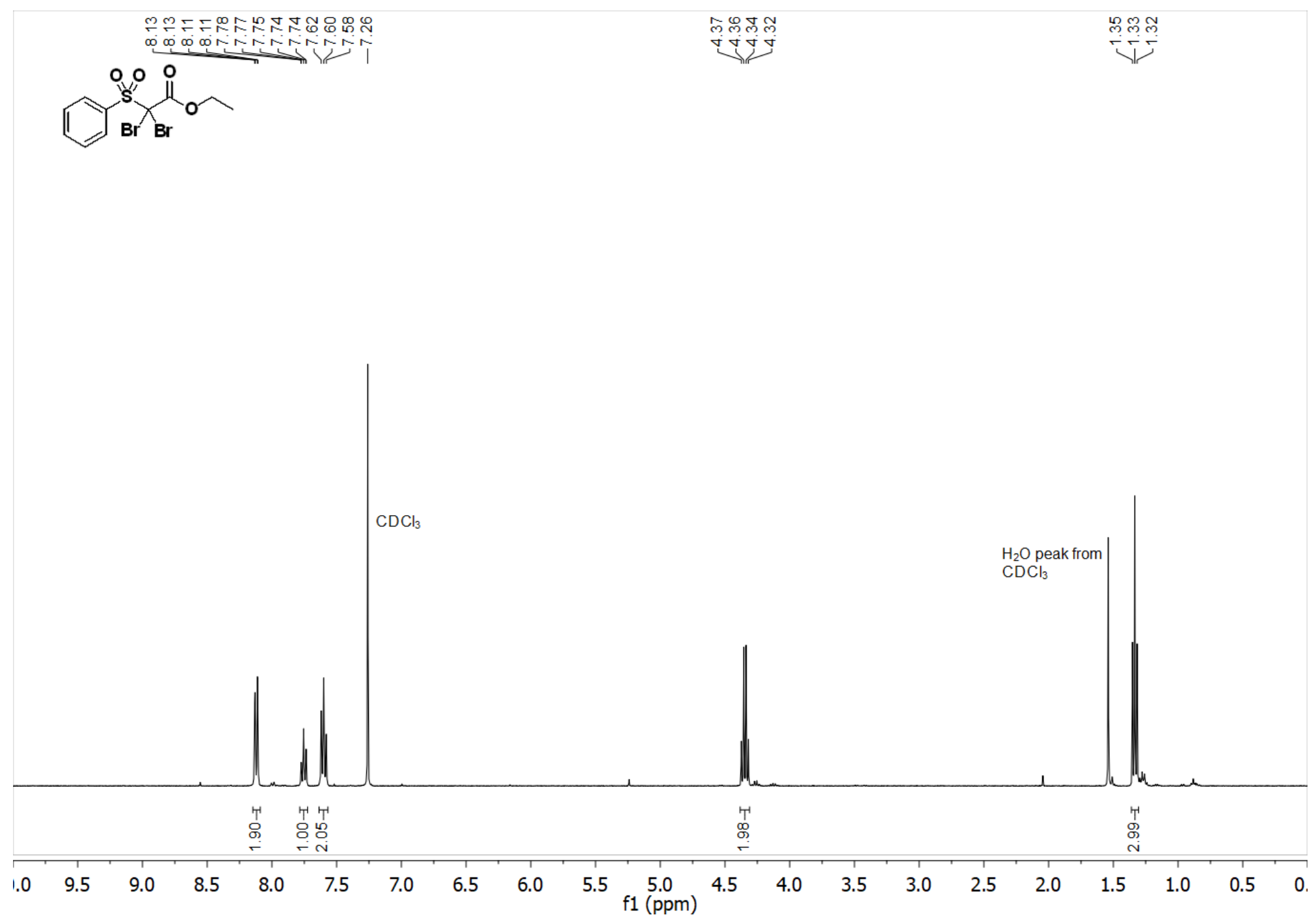


${ }^{13} \mathrm{C}$ NMR (101 MHz, $\mathrm{CDCl}_{3}$ ) spectrum of 2b Ethyl 2,2-dibromo-2-(phenylsulfonyl)acetate

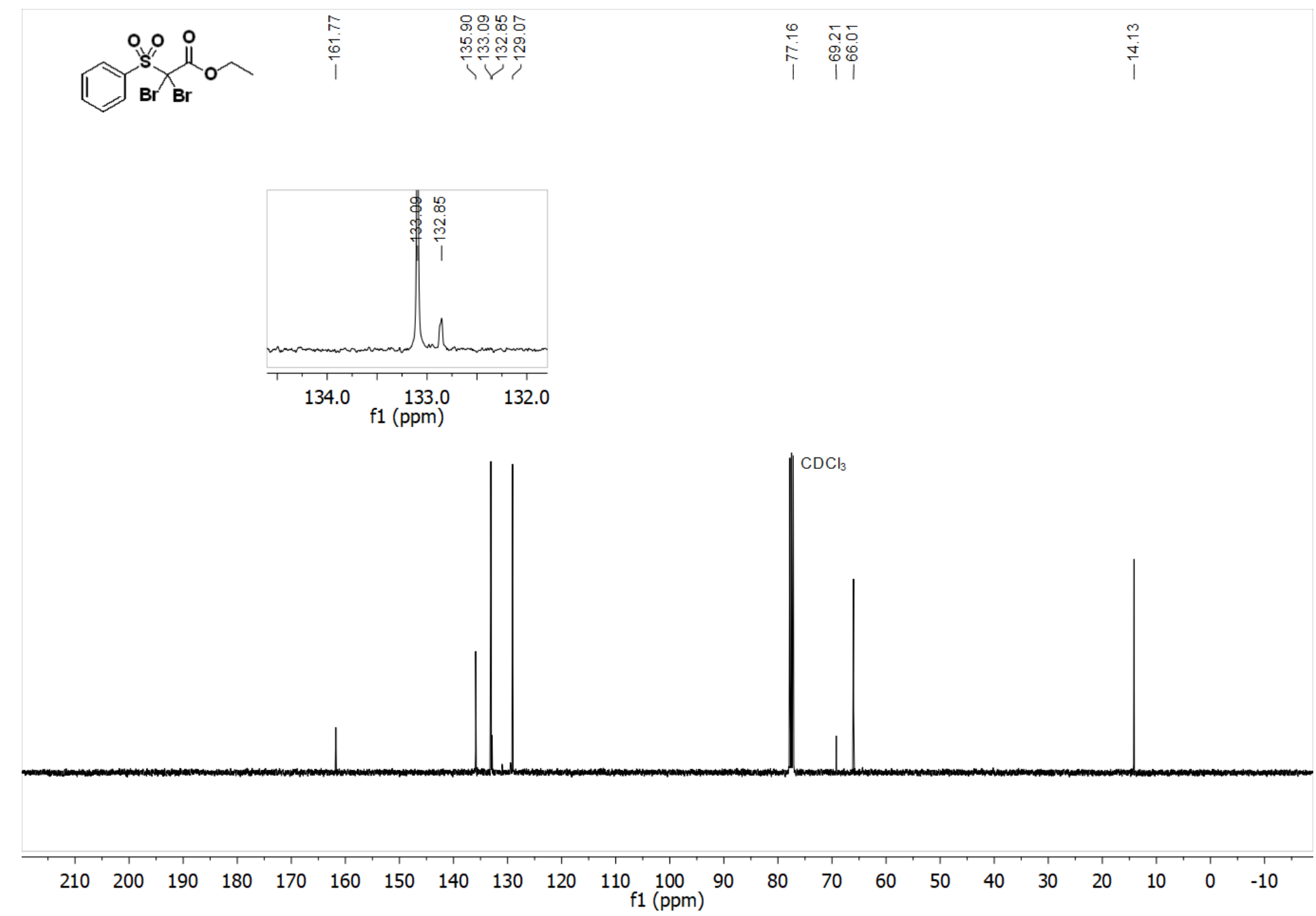


${ }^{1} \mathrm{H}$ NMR (400 MHz, $\mathrm{CDCl}_{3}$ ) spectrum of 3b Ethyl 2,2-dibromo-2-(methylsulfonyl)acetate

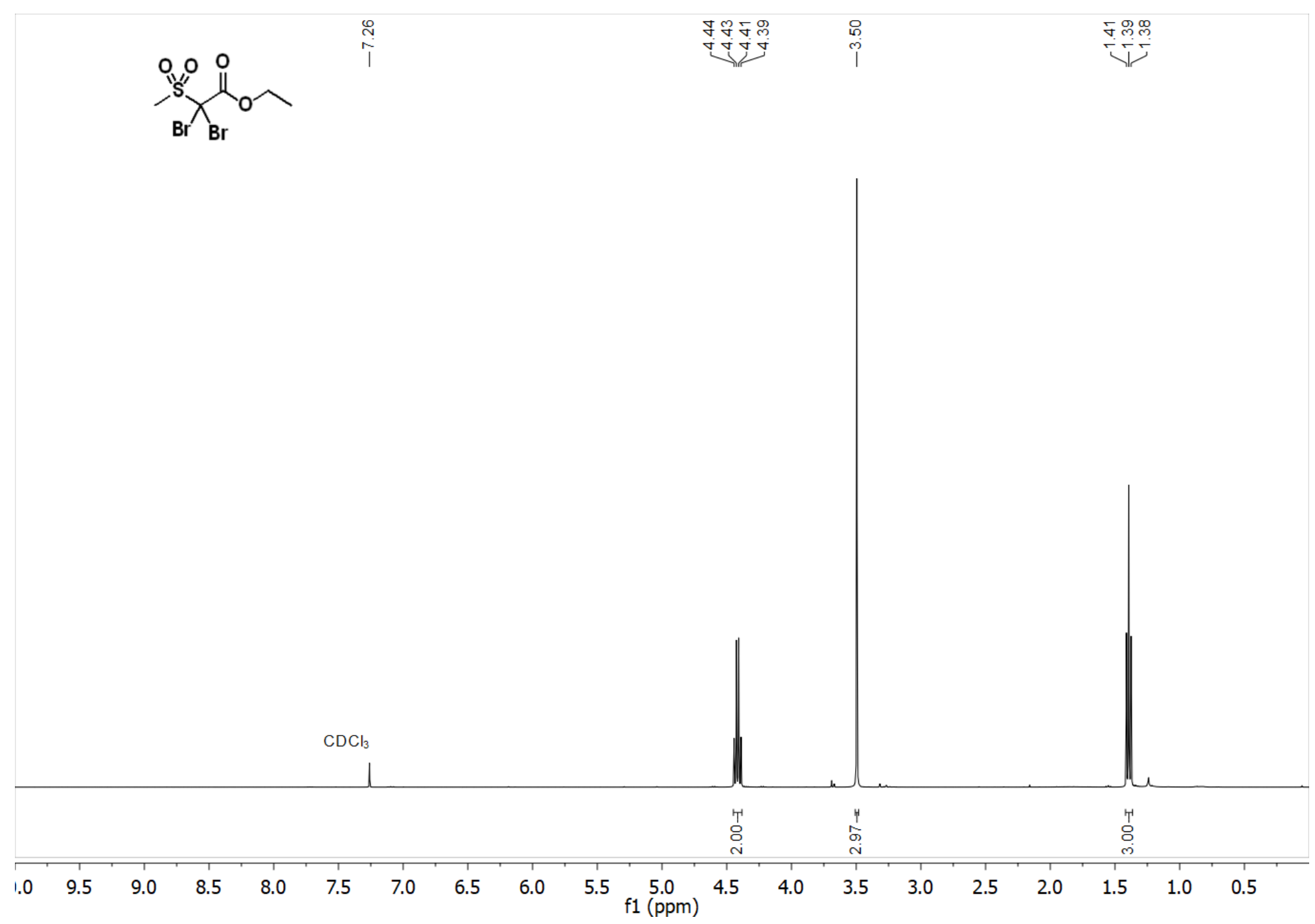


${ }^{13} \mathrm{C}$ NMR (101 MHz, $\mathrm{CDCl}_{3}$ ) spectrum of 3b Ethyl 2,2-dibromo-2-(methylsulfonyl)acetate

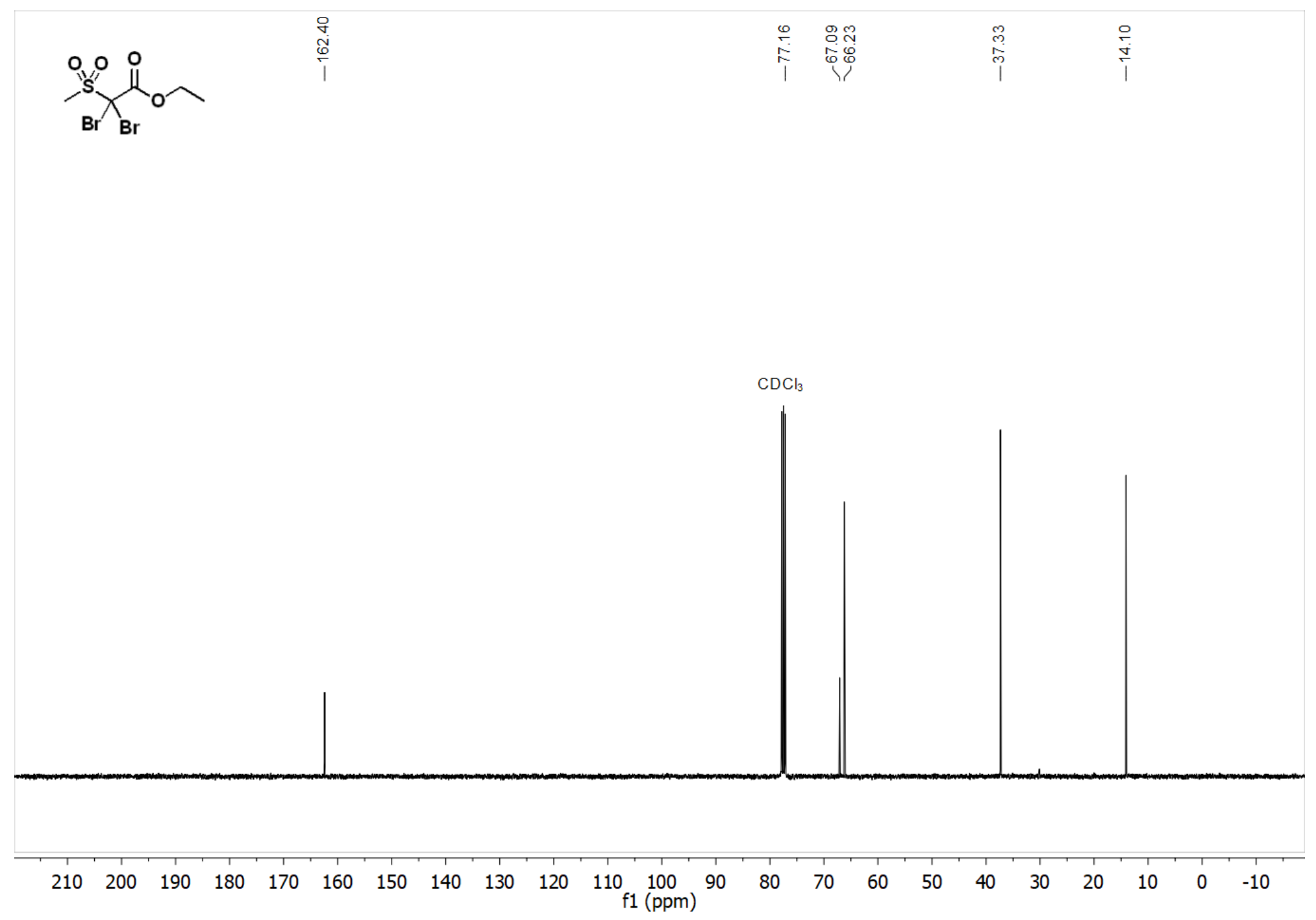


${ }^{1} \mathrm{H}$ NMR (400 MHz, $\mathrm{CDCl}_{3}$ ) spectrum of 6b 3,3-Dibromo-1,5-dioxaspiro[5.5]undecane-2,4-dione

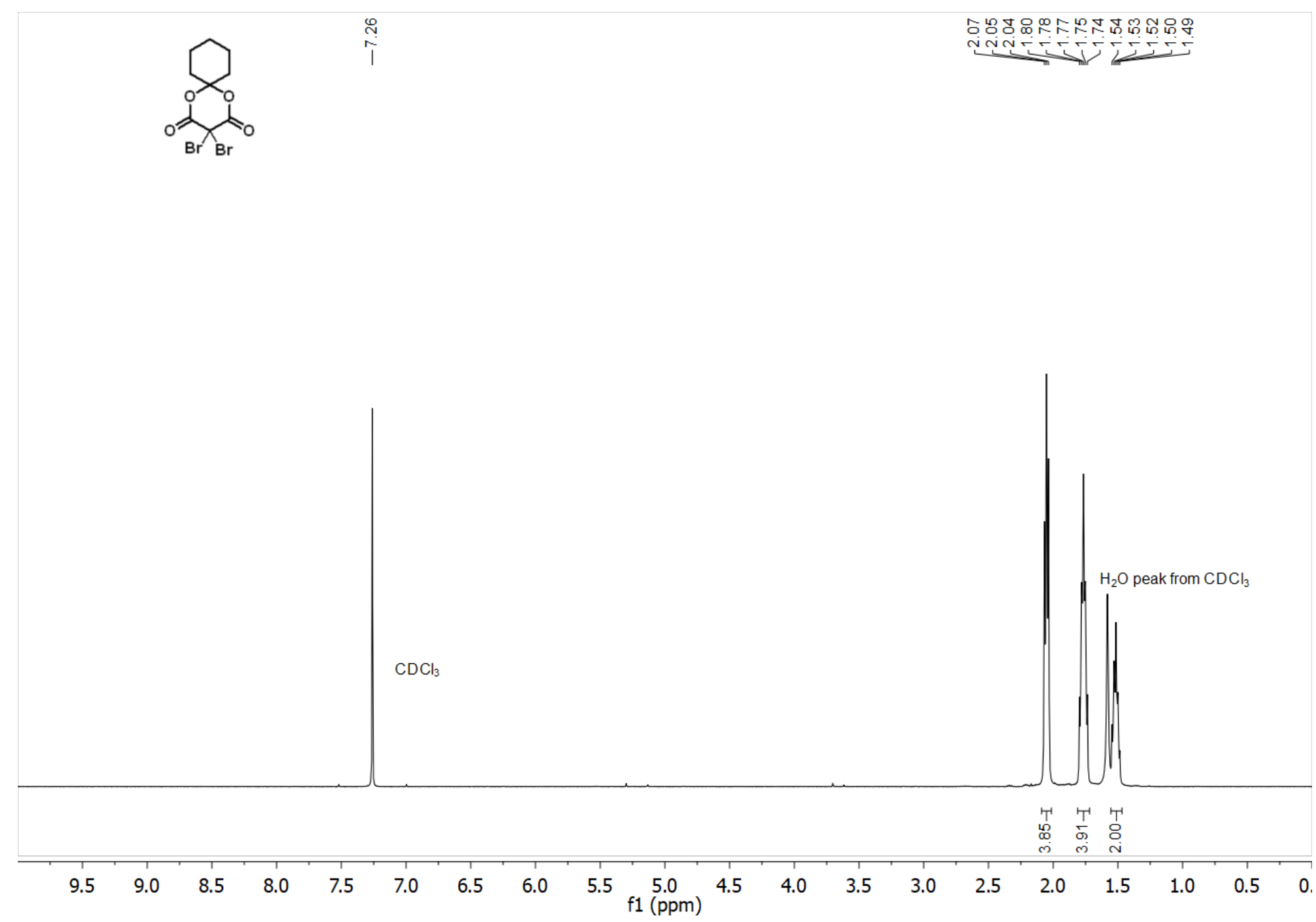


${ }^{13} \mathrm{C}$ NMR (101 MHz, $\mathrm{CDCl}_{3}$ ) spectrum of 6b 3,3-Dibromo-1,5-dioxaspiro[5.5]undecane-2,4-dione

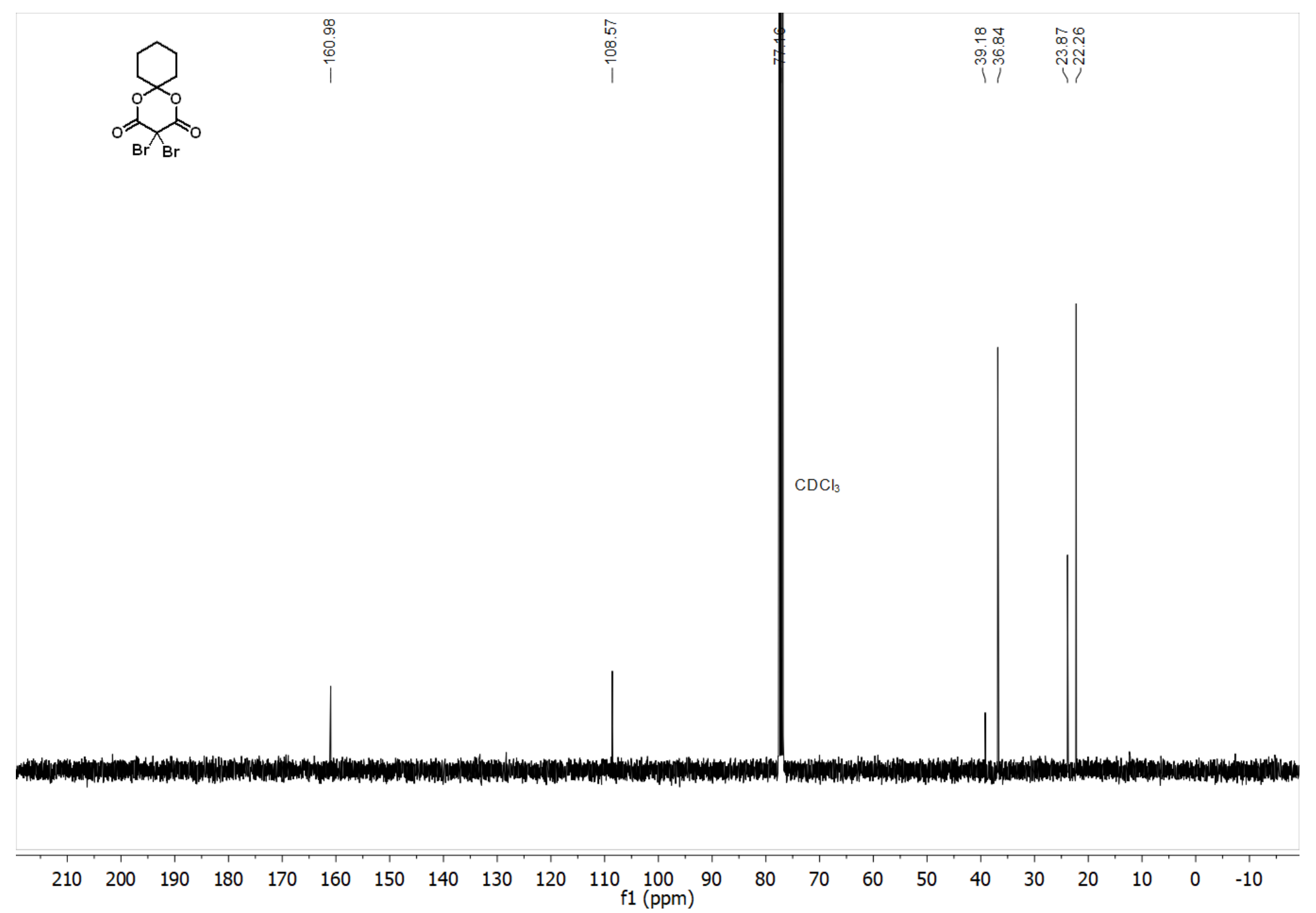


${ }^{1} \mathrm{H}$ NMR (400 MHz, $\mathrm{CDCl}_{3}$ ) spectrum of 14b Ethyl 2,2-dichloro-2-((2,6-difluorophenyl)sulfonyl)acetate

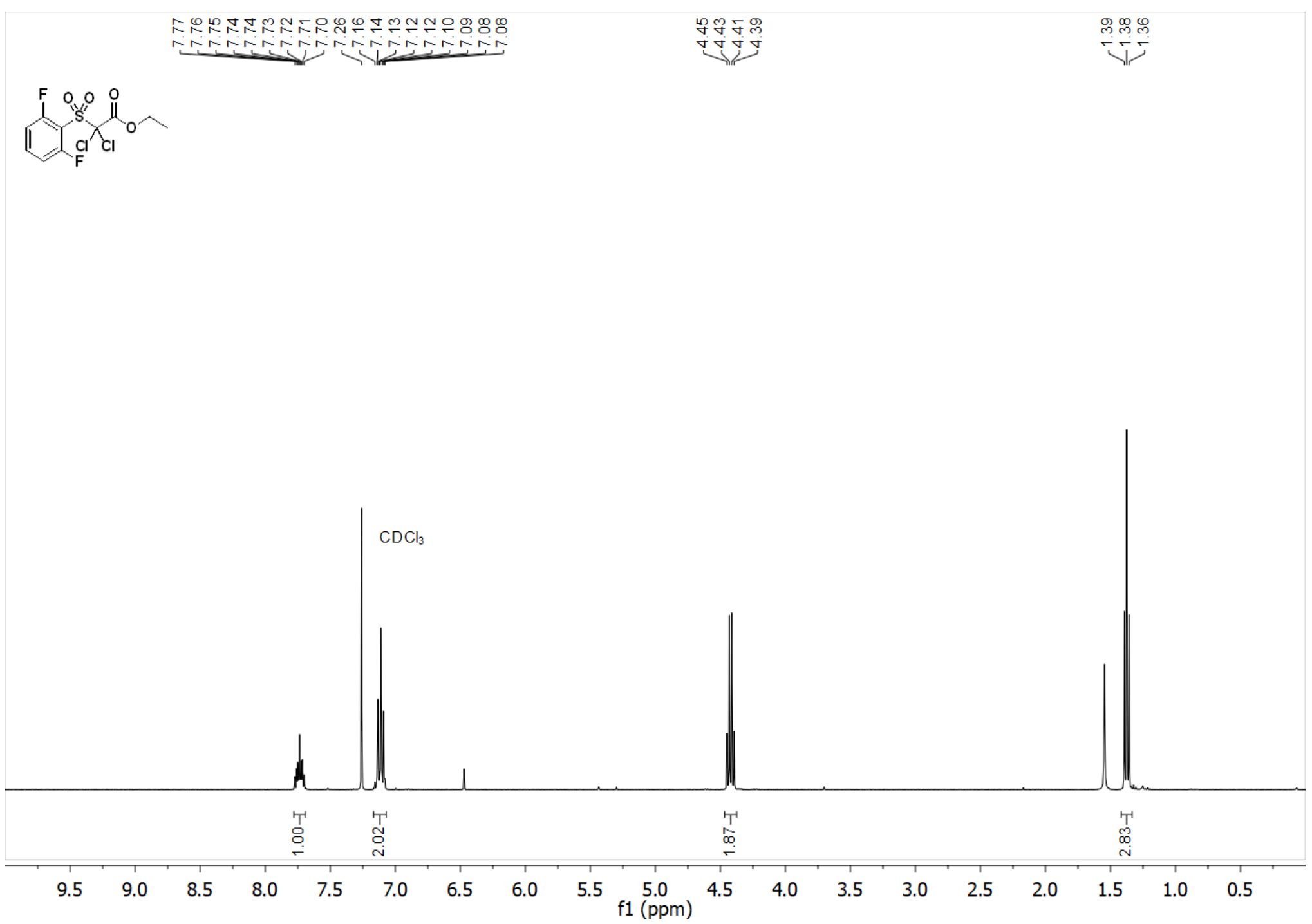


${ }^{19} \mathrm{~F}$ NMR (376 MHz, $\left.\mathrm{CDCl}_{3}\right)$ spectrum of 14b Ethyl 2,2-dichloro-2-((2,6-difluorophenyl)sulfonyl)acetate

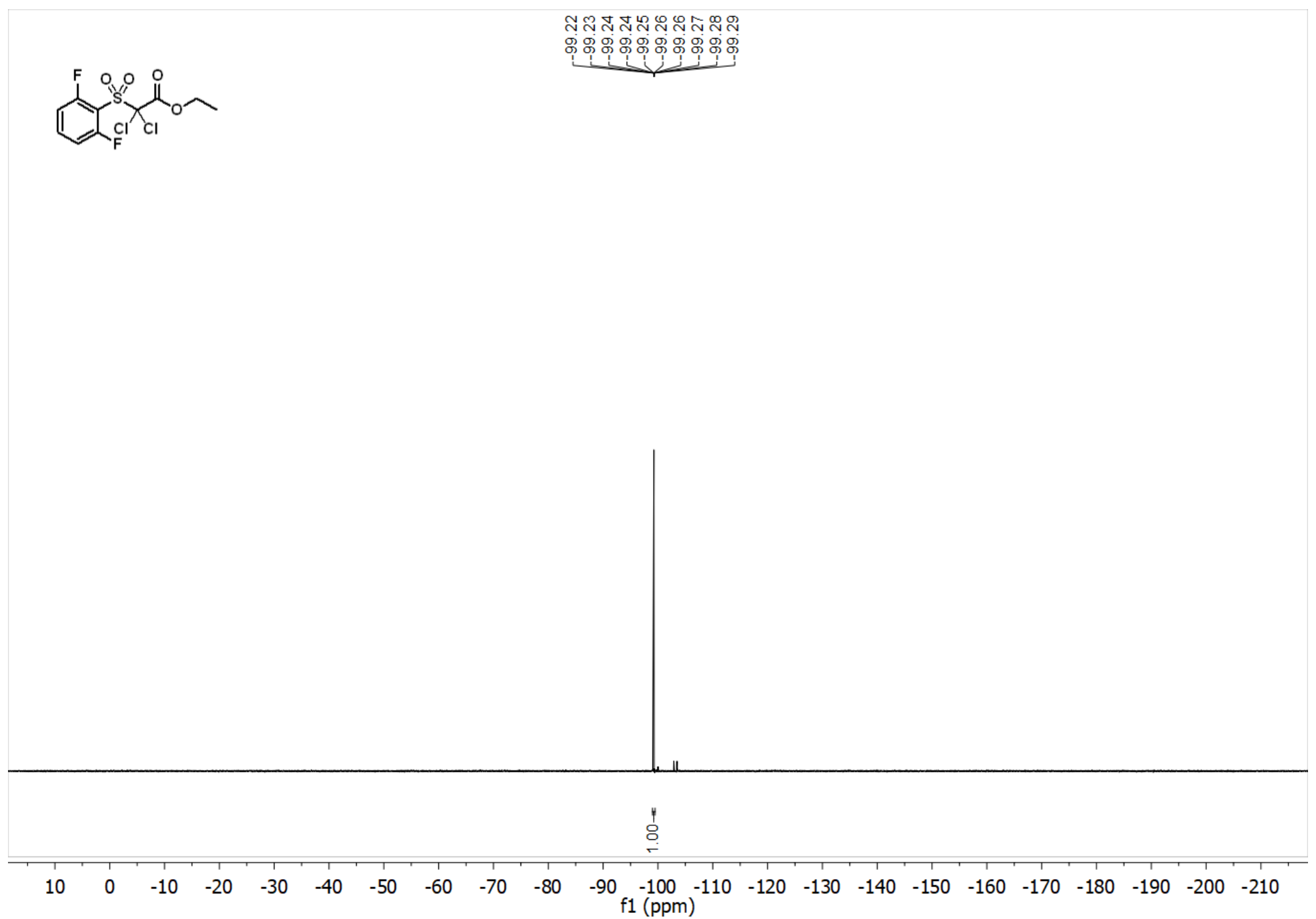


${ }^{13} \mathrm{C}$ NMR (151 MHz, $\left.\mathrm{CDCl}_{3}\right)$ spectrum of 14b Ethyl 2,2-dichloro-2-((2,6-difluorophenyl)sulfonyl)acetate

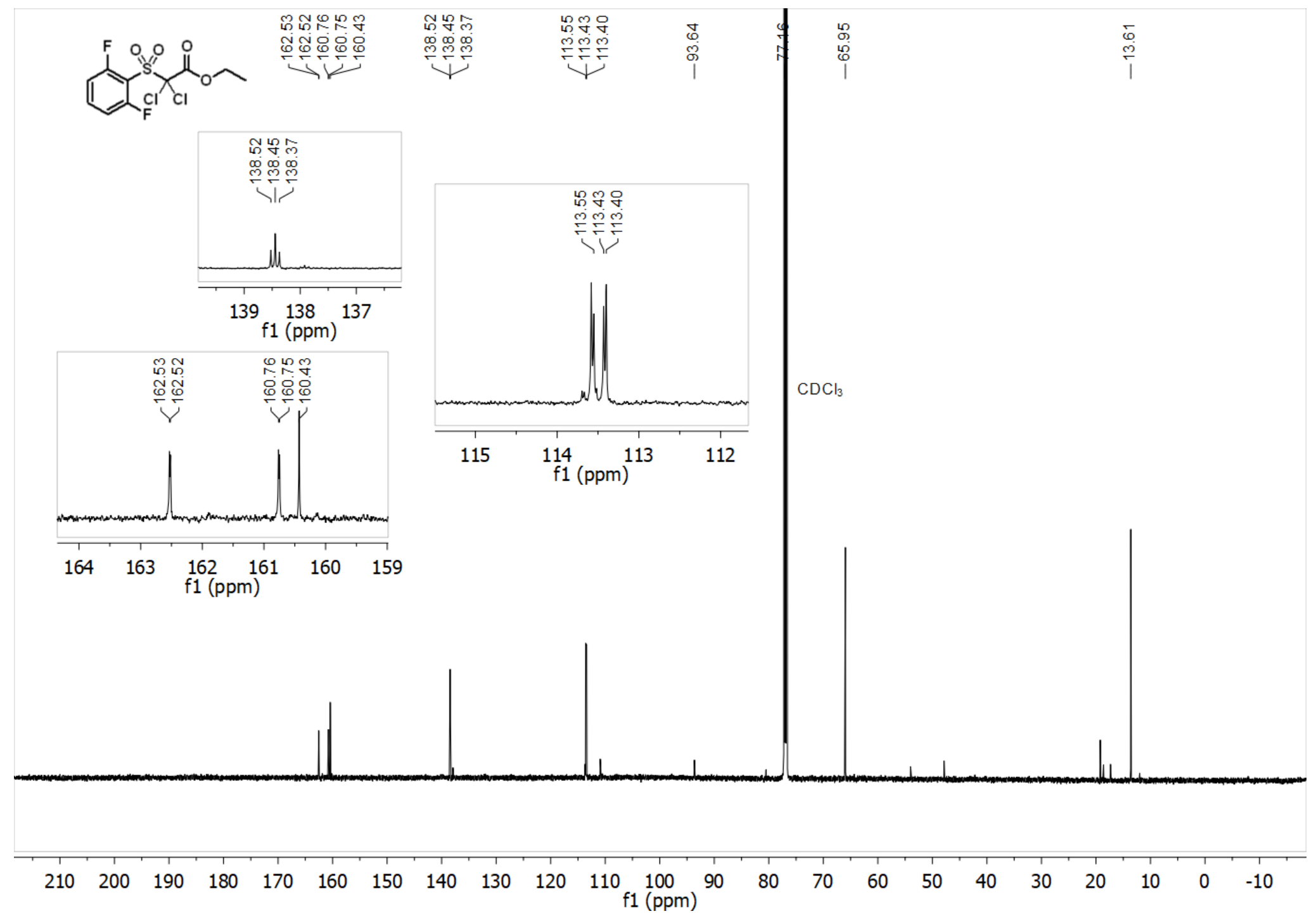


${ }^{1} \mathrm{H}$ NMR (400 MHz, $\left.\mathrm{CDCl}_{3}\right)$ spectrum of 1c ethyl 2-bromo-2-((2,6-difluorophenyl)sulfonyl)acetate

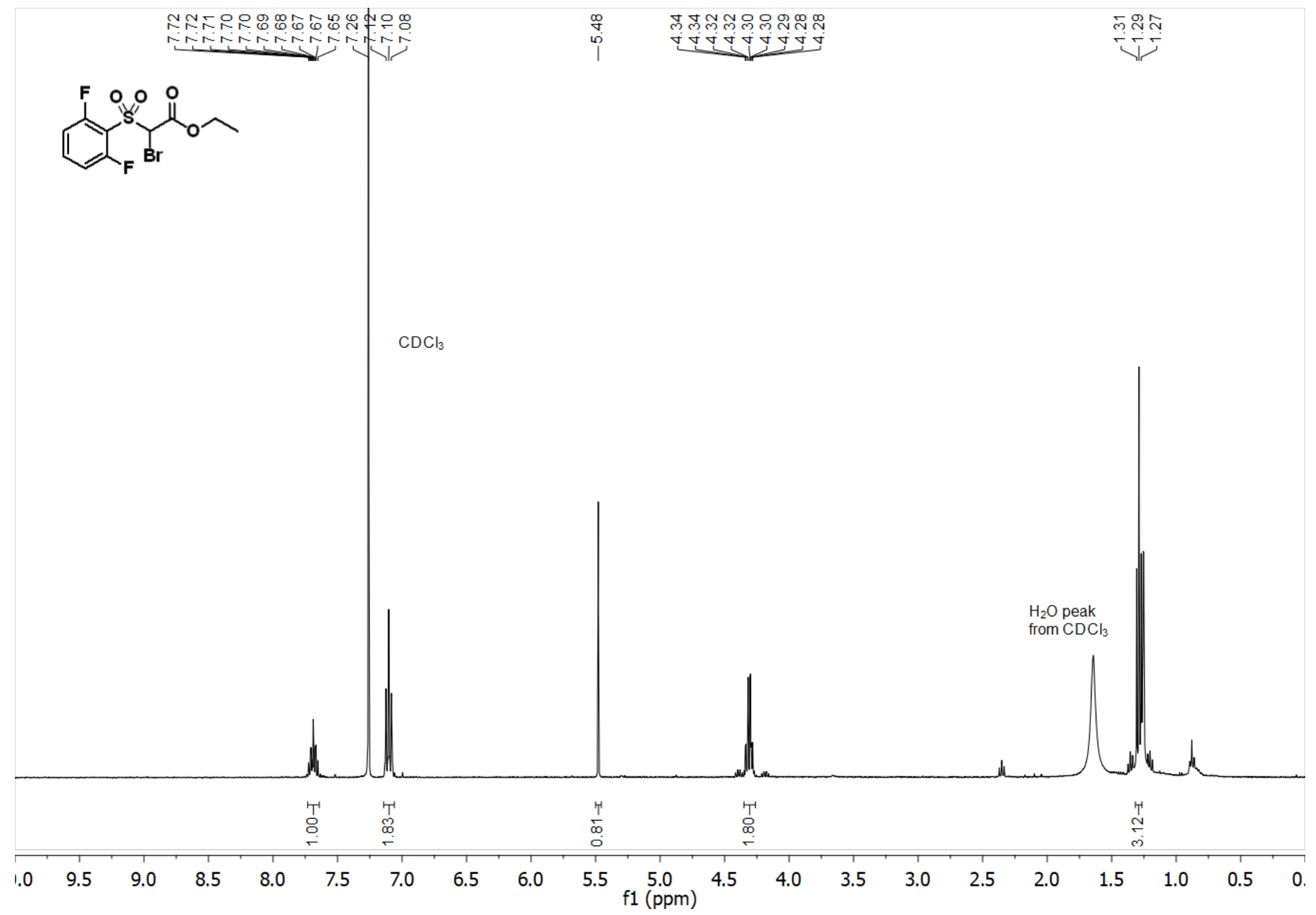


${ }^{19}$ F NMR (376 MHz, $\left.\mathrm{CDCl}_{3}\right)$ spectrum of 1c ethyl 2-bromo-2-((2,6-difluorophenyl)sulfonyl)acetate

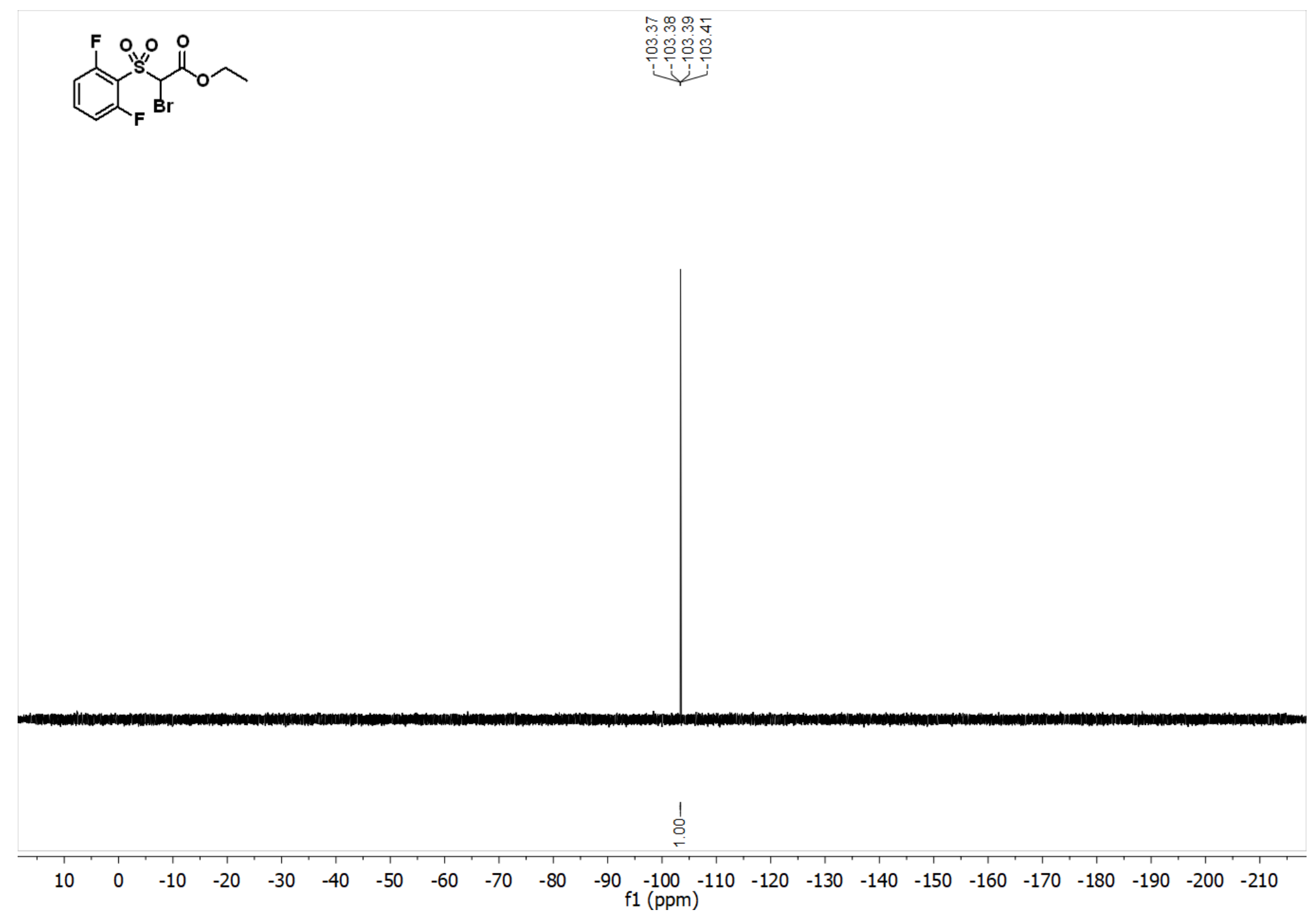


${ }^{13} \mathrm{C}$ NMR (101 MHz, $\left.\mathrm{CDCl}_{3}\right)$ spectrum of 1c ethyl 2-bromo-2-((2,6-difluorophenyl)sulfonyl)acetate

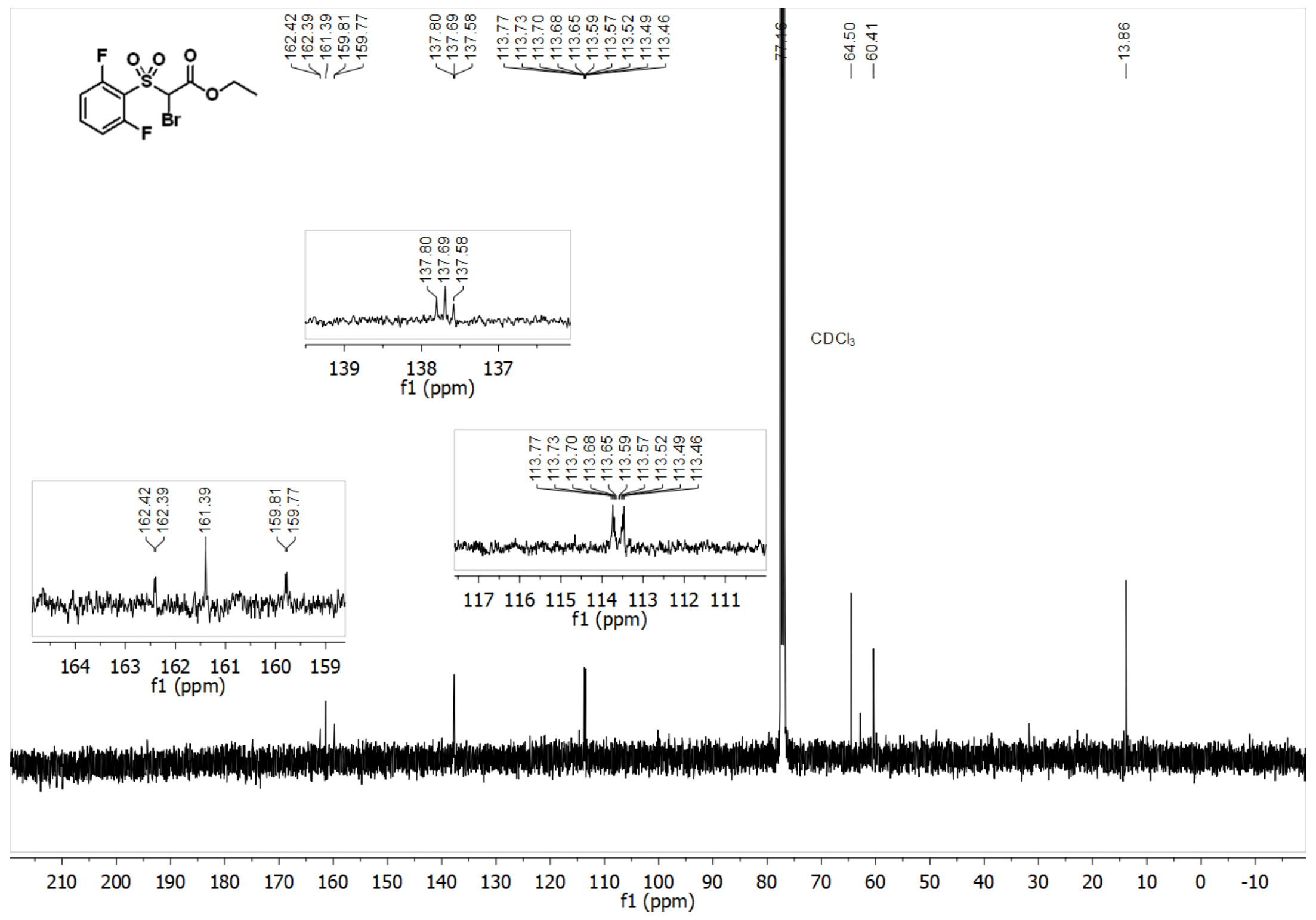


GC and MS of 1c ethyl 2-bromo-2-((2,6-difluorophenyl)sulfonyl)acetate

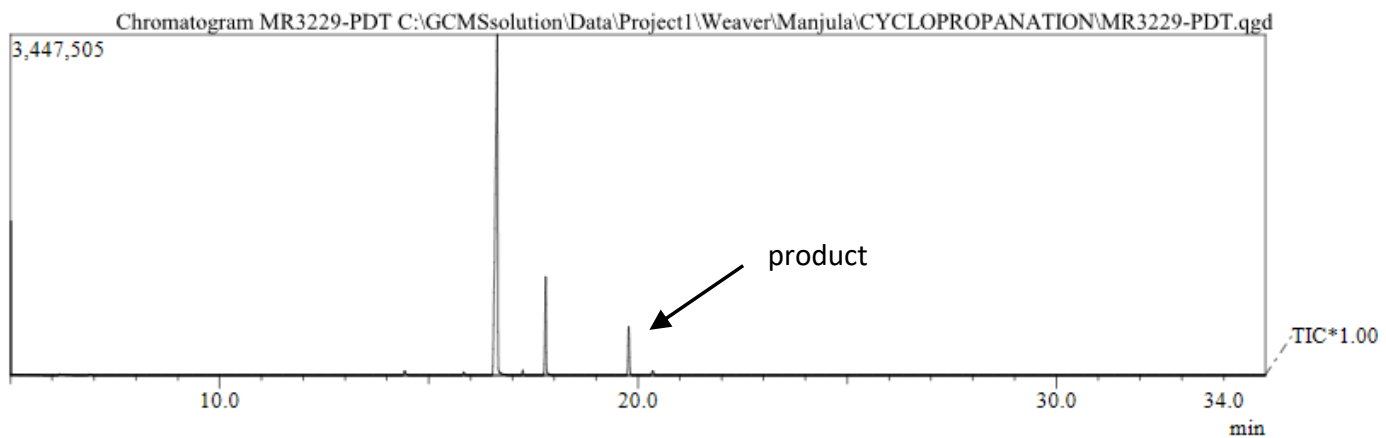

Spectrum

Line\#:1 R.Time: 19.8 (Scan\#̈:1775)

MassPeaks:53

RawMod.Single 19.8(1775) BasePeak:154(138135)

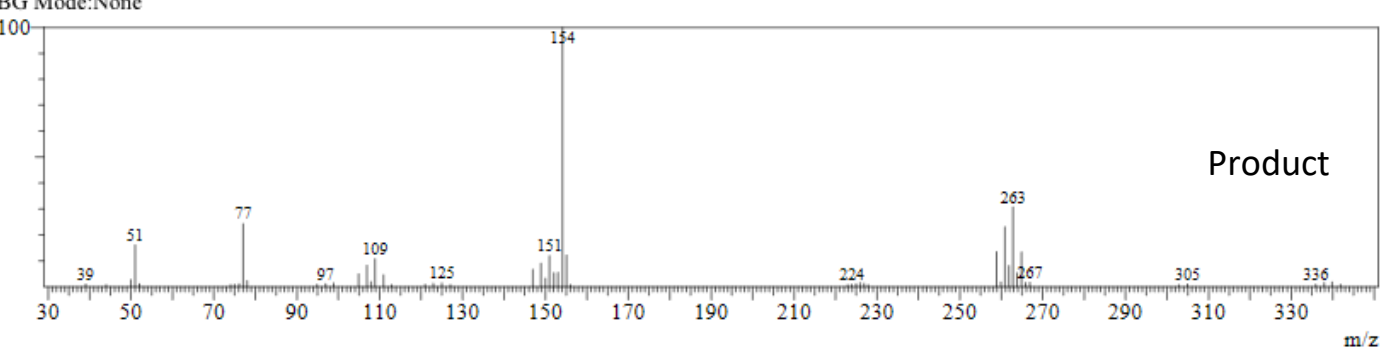

Line\#:2 R. Time: 17.8 (Scan\#:1536)

MassPeaks:94 17 (17.8(1536) BasePeak:177(102340)

RawMode:Single

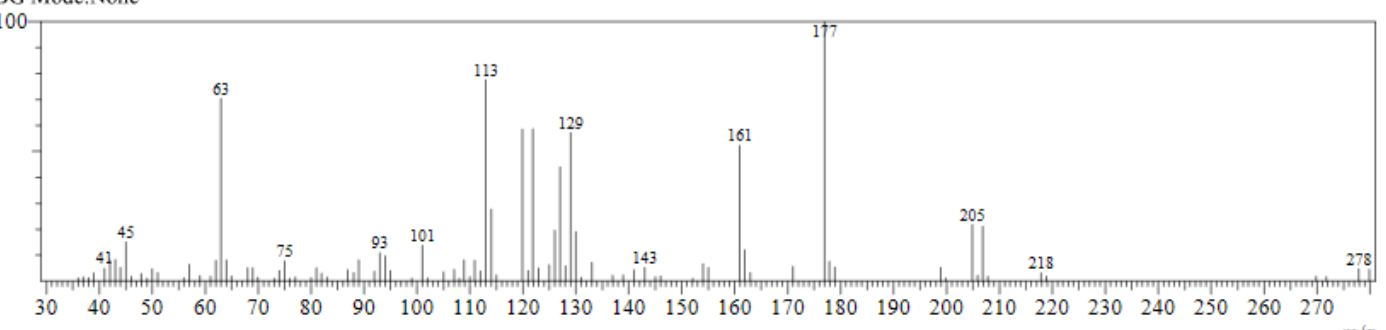


${ }^{1} \mathrm{H}$ NMR (400 MHz, $\mathrm{CDCl}_{3}$ ) spectrum of 2c ethyl 2-bromo-2-(phenylsulfonyl)acetate

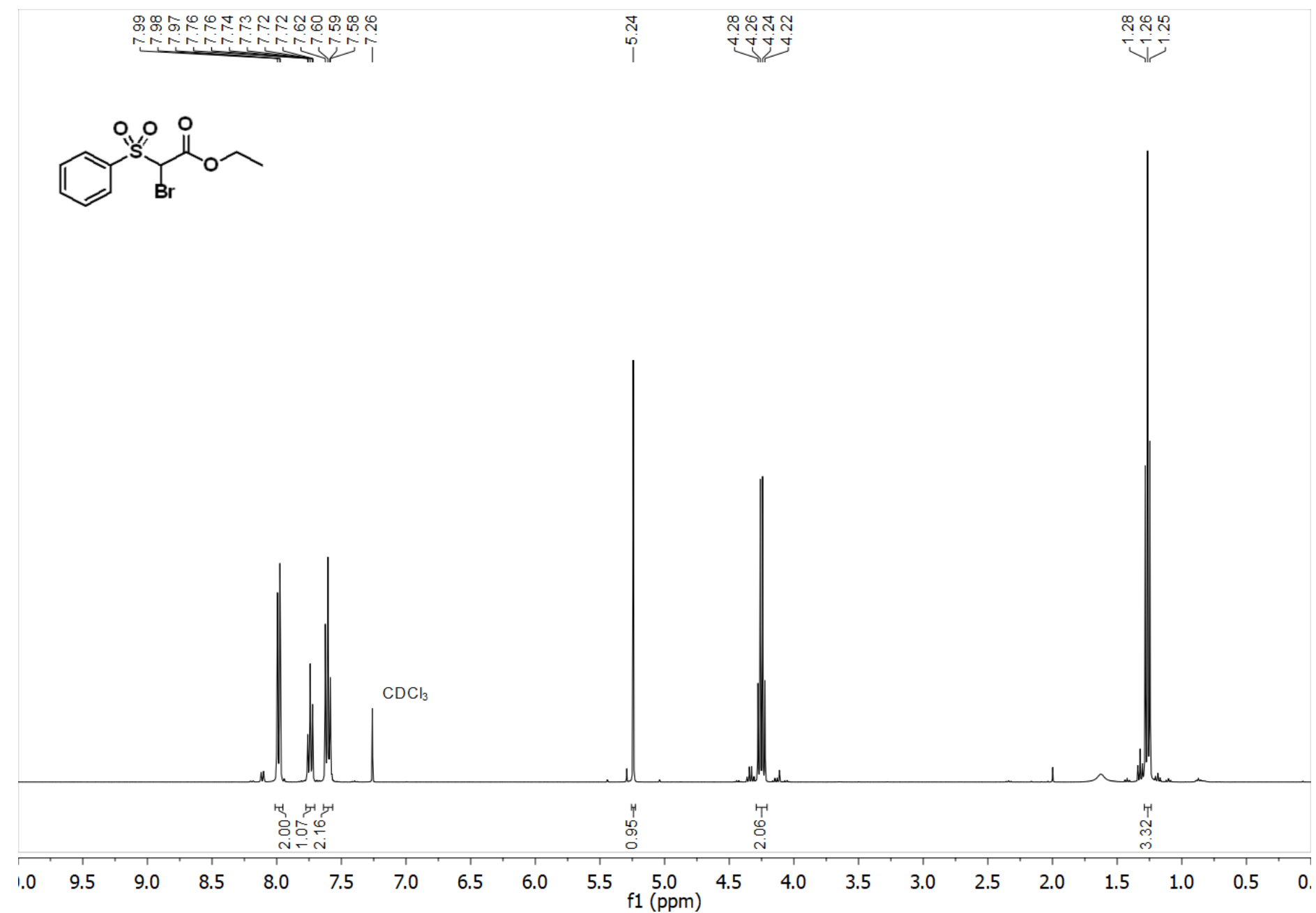


${ }^{13} \mathrm{C}$ NMR (101 MHz, $\mathrm{CDCl}_{3}$ ) spectrum of 2c ethyl 2-bromo-2-(phenylsulfonyl)acetate

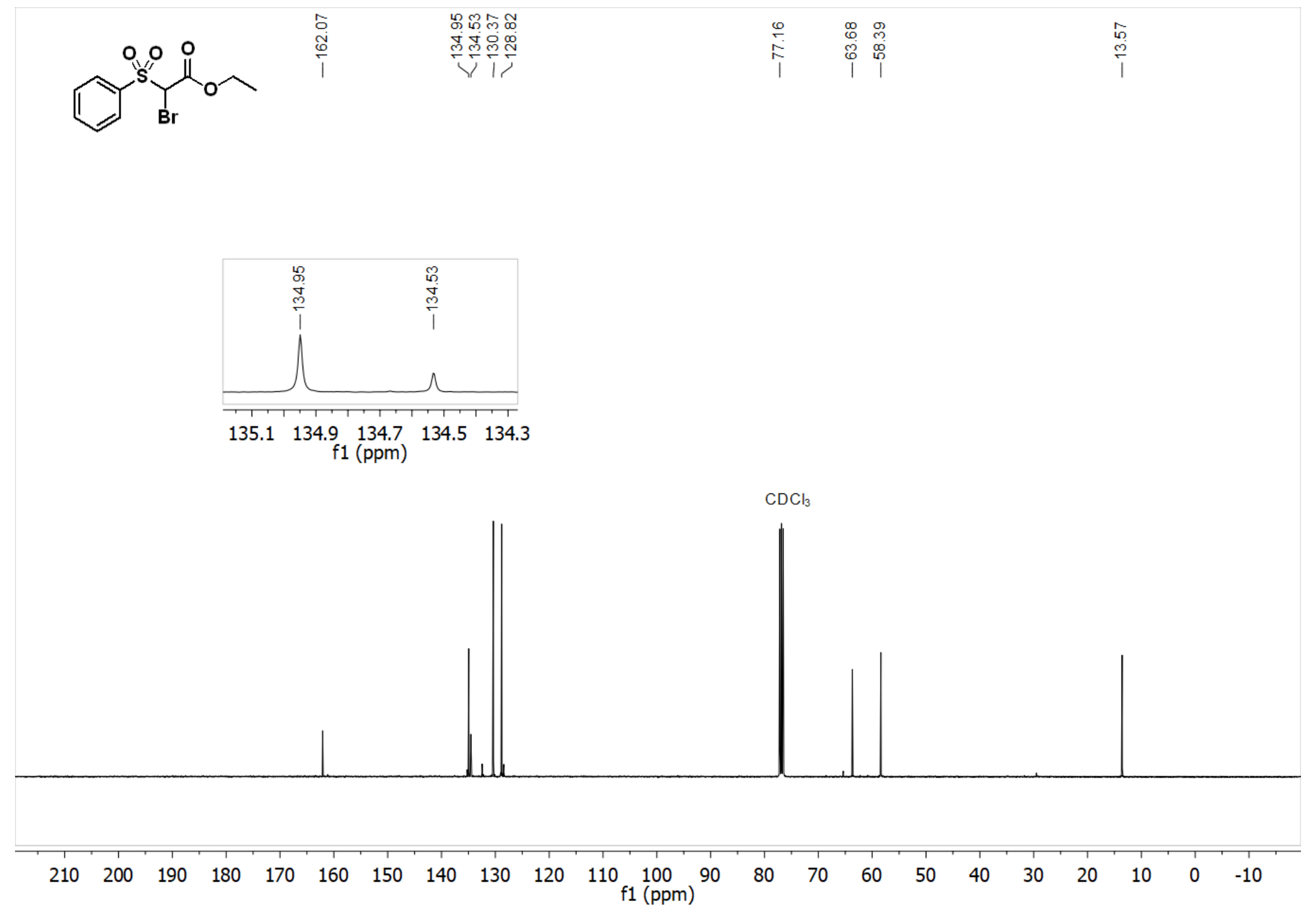




\section{GC and MS of 2c ethyl 2-bromo-2-(phenylsulfonyl)acetate}

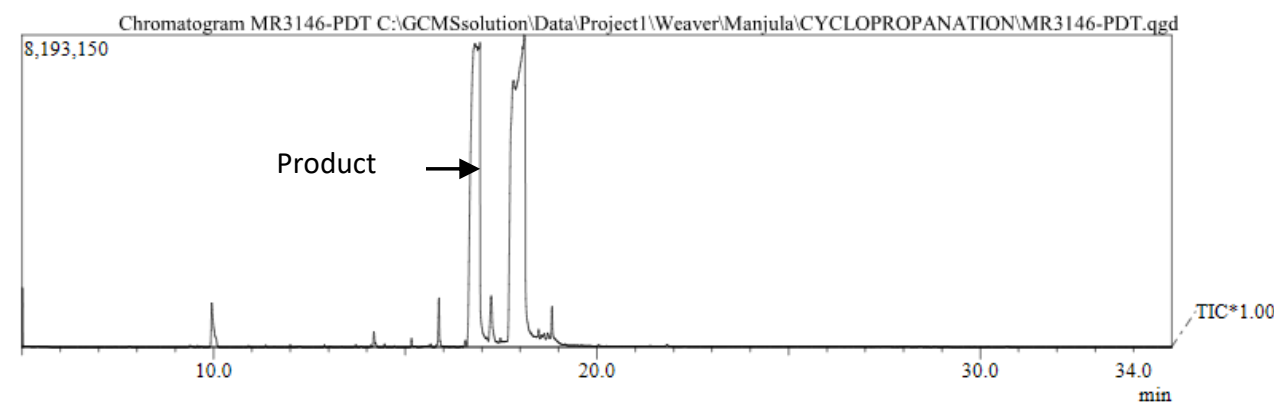

Spectrum

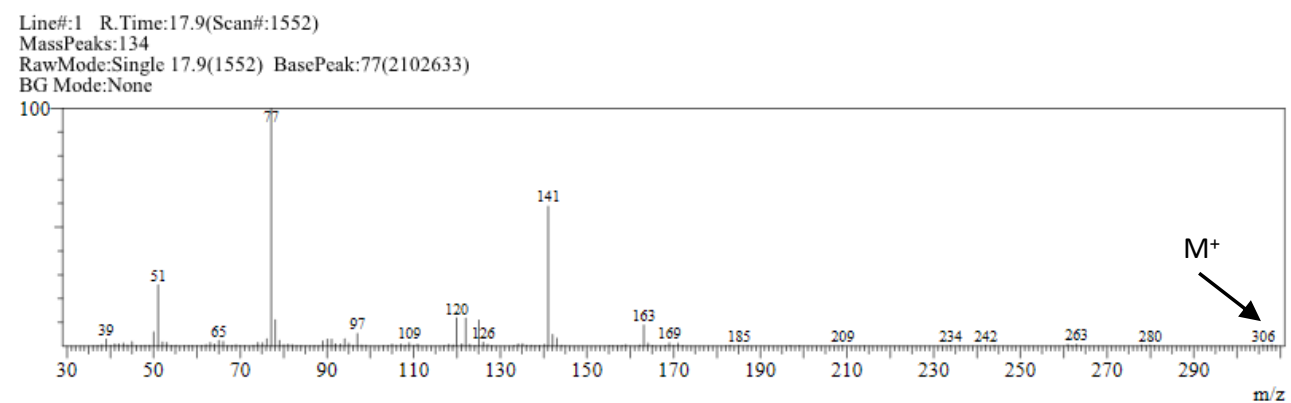

Line\#:2 R.Time:16.8(Scan\#:1419)

RawMode:Single 16.8(1419) BasePeak:77(2358321)

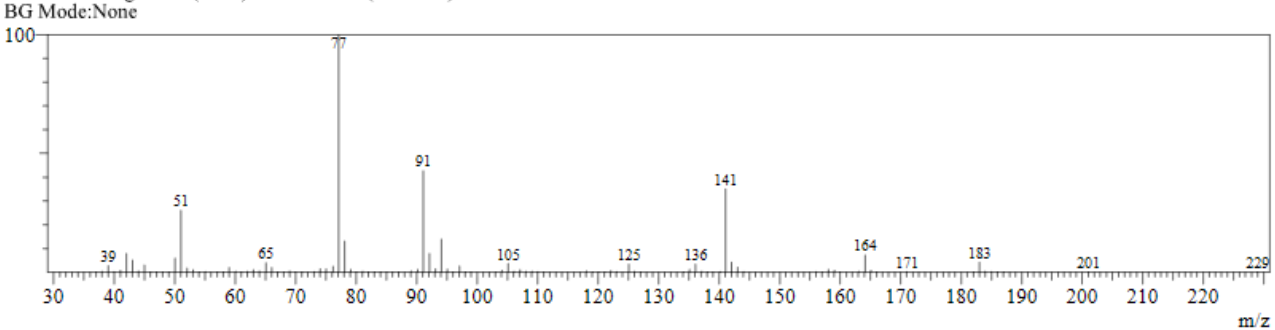


${ }^{1} \mathrm{H}$ NMR (400 MHz, $\mathrm{CDCl}_{3}$ ) spectrum of 3c ethyl 2-bromo-2-(methylsulfonyl)acetate

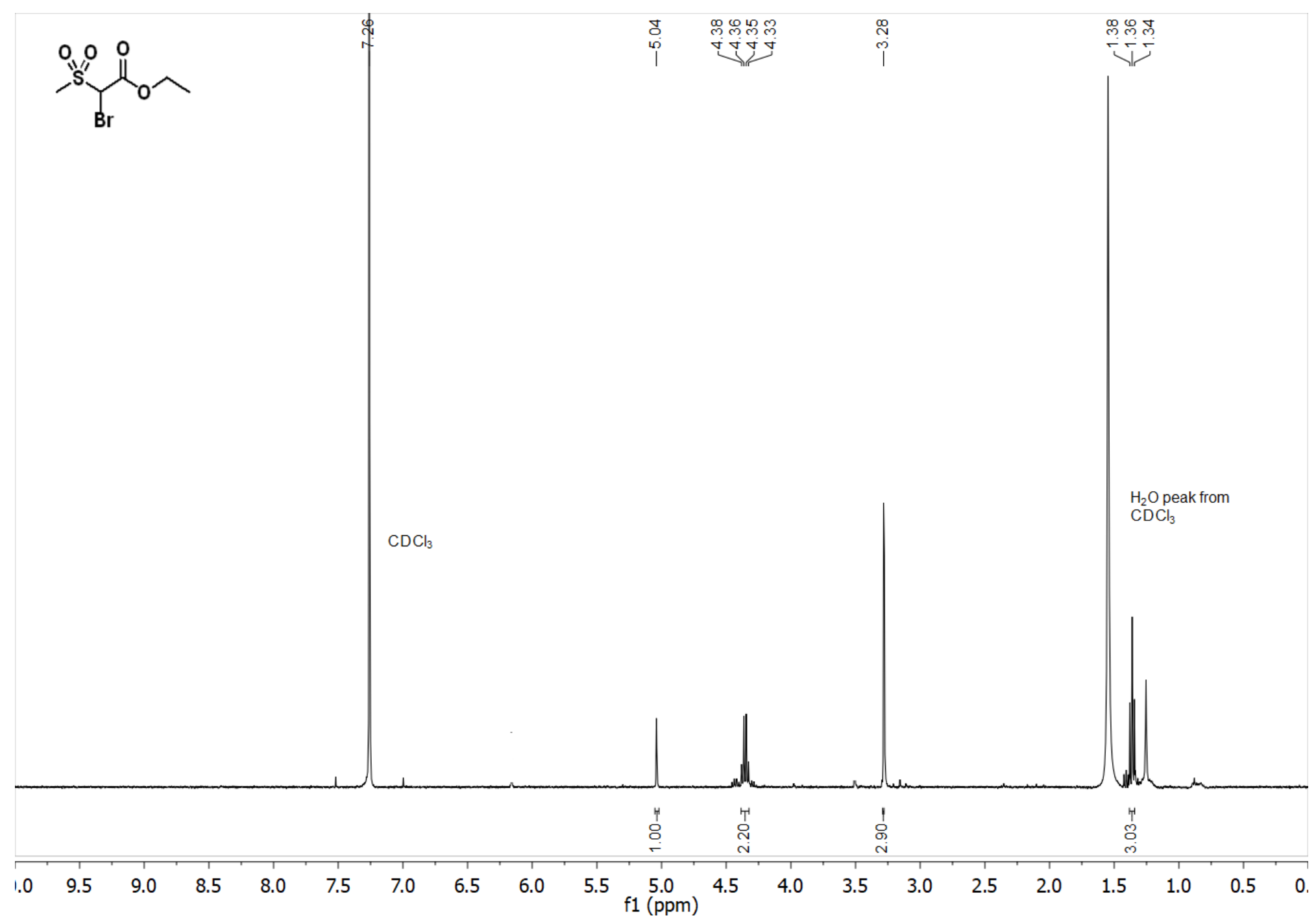


${ }^{13} \mathrm{C}$ NMR (101 MHz, $\mathrm{CDCl}_{3}$ ) spectrum of 3c ethyl 2-bromo-2-(methylsulfonyl)acetate

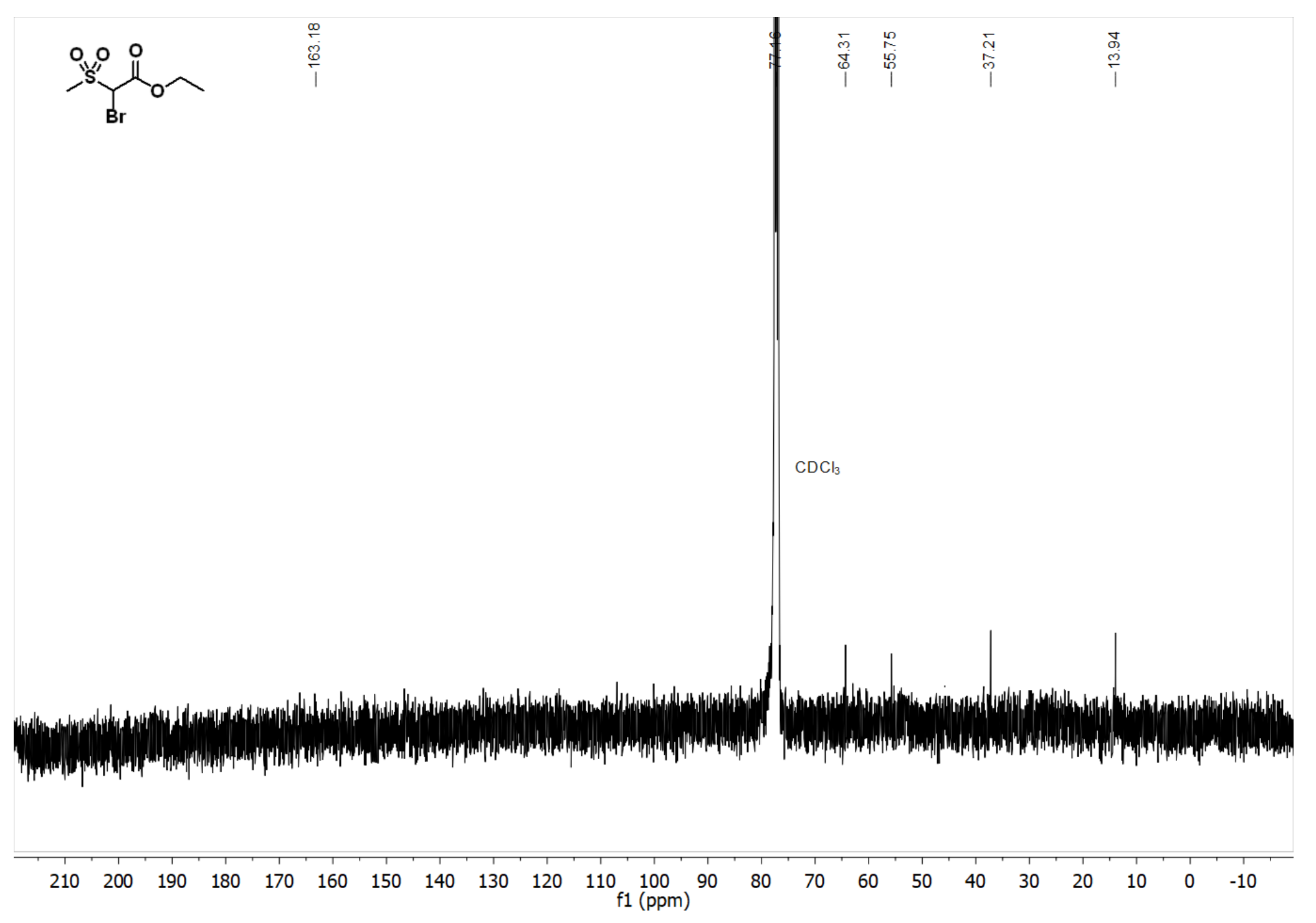




\section{GC and MS of 3c ethyl 2-bromo-2-(methylsulfonyl)acetate}

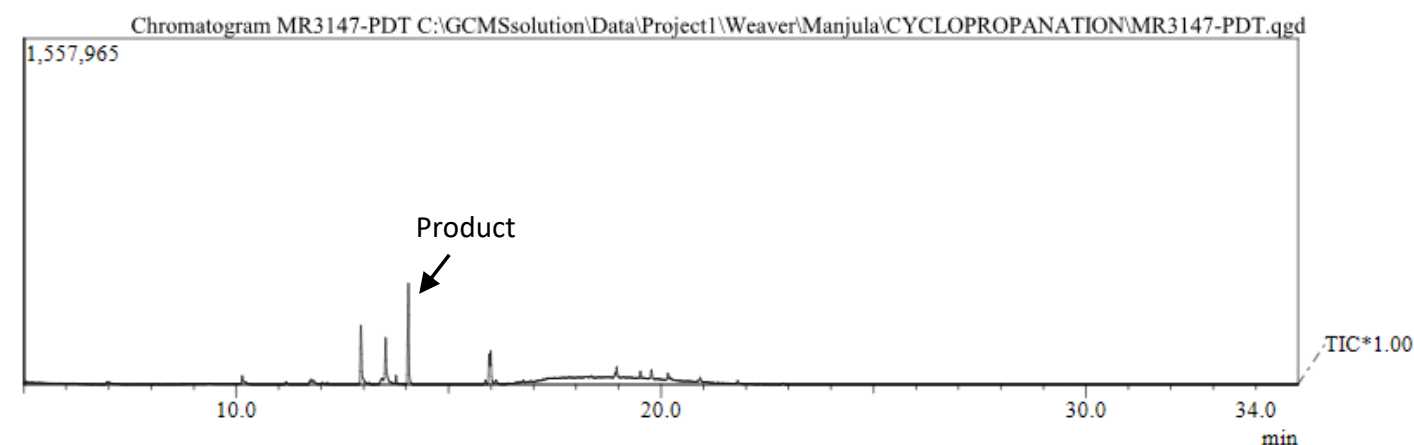

Spectrum

Line\#:1 R.Time: 16.0 (Scan\#:1318)

$$
\text { MassPeaks:27 }
$$

RawMode:Single 16.0(1318) BasePeak:180(14954

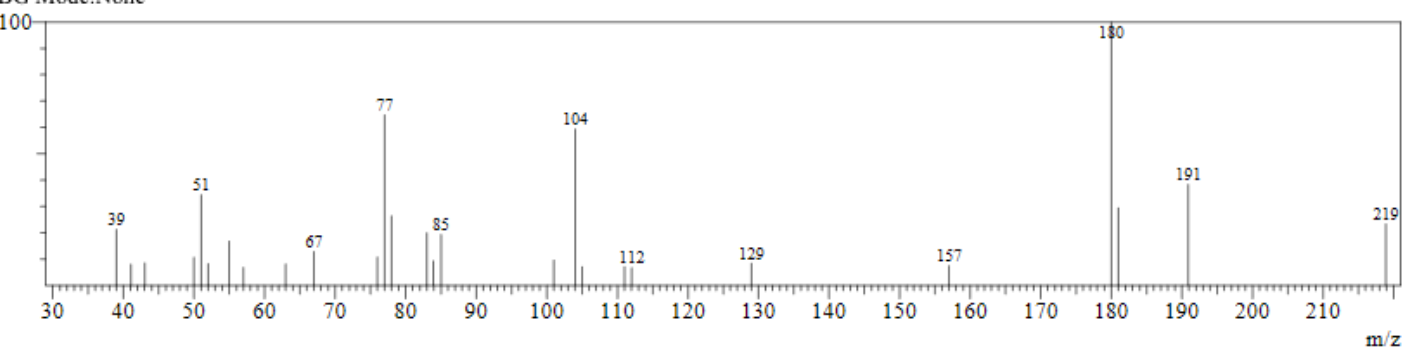

Line\#:2 R.Time:14.1(Scan\#:1088)

RawMode:Single 14.1(1088) BasePeak:120(46498)

BG Mode:None

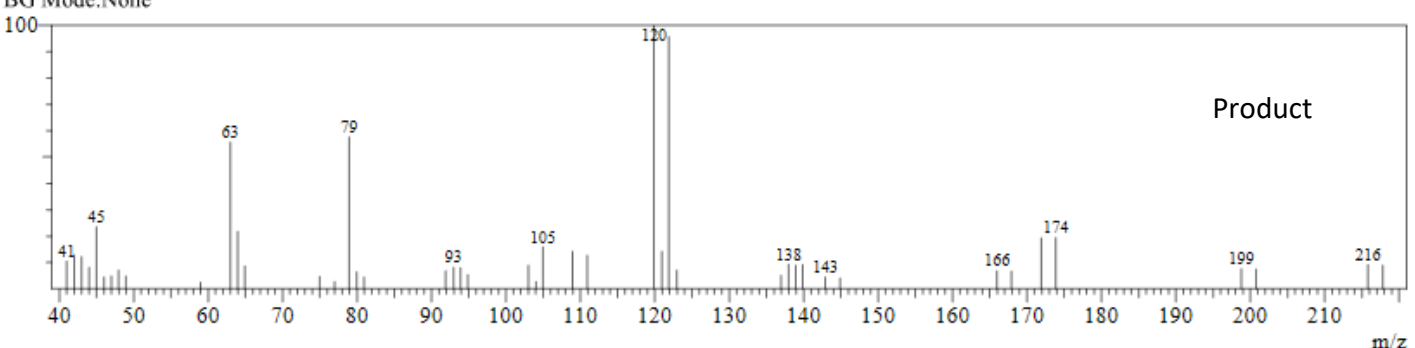


${ }^{1} \mathrm{H}$ NMR (400 MHz, $\mathrm{CDCl}_{3}$ ) spectrum of $4 \mathrm{c}$ diethyl 2-bromomalonate

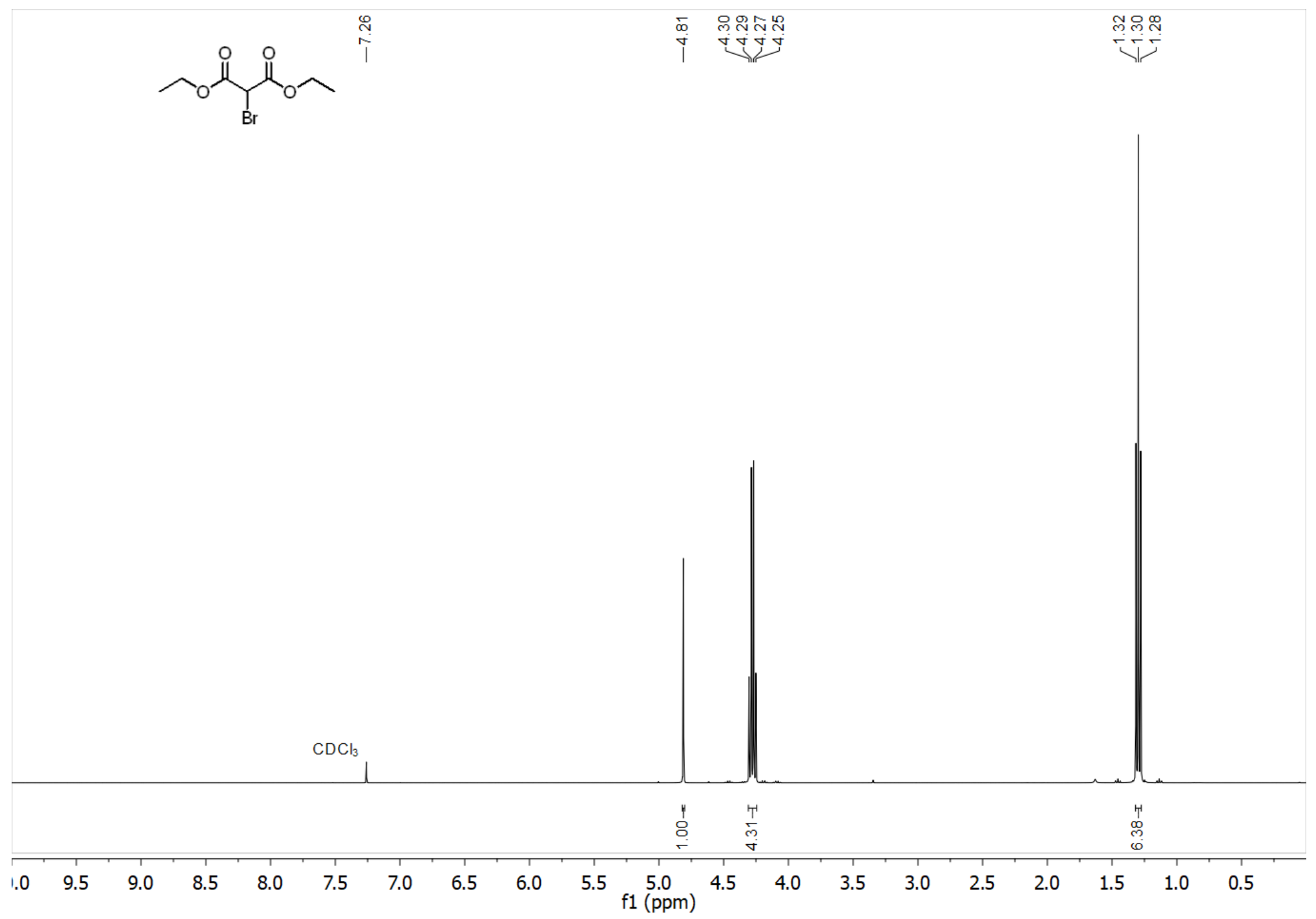

63 
${ }^{13} \mathrm{C}$ NMR (101 MHz, $\left.\mathrm{CDCl}_{3}\right)$ spectrum of 4c diethyl 2-bromomalonate

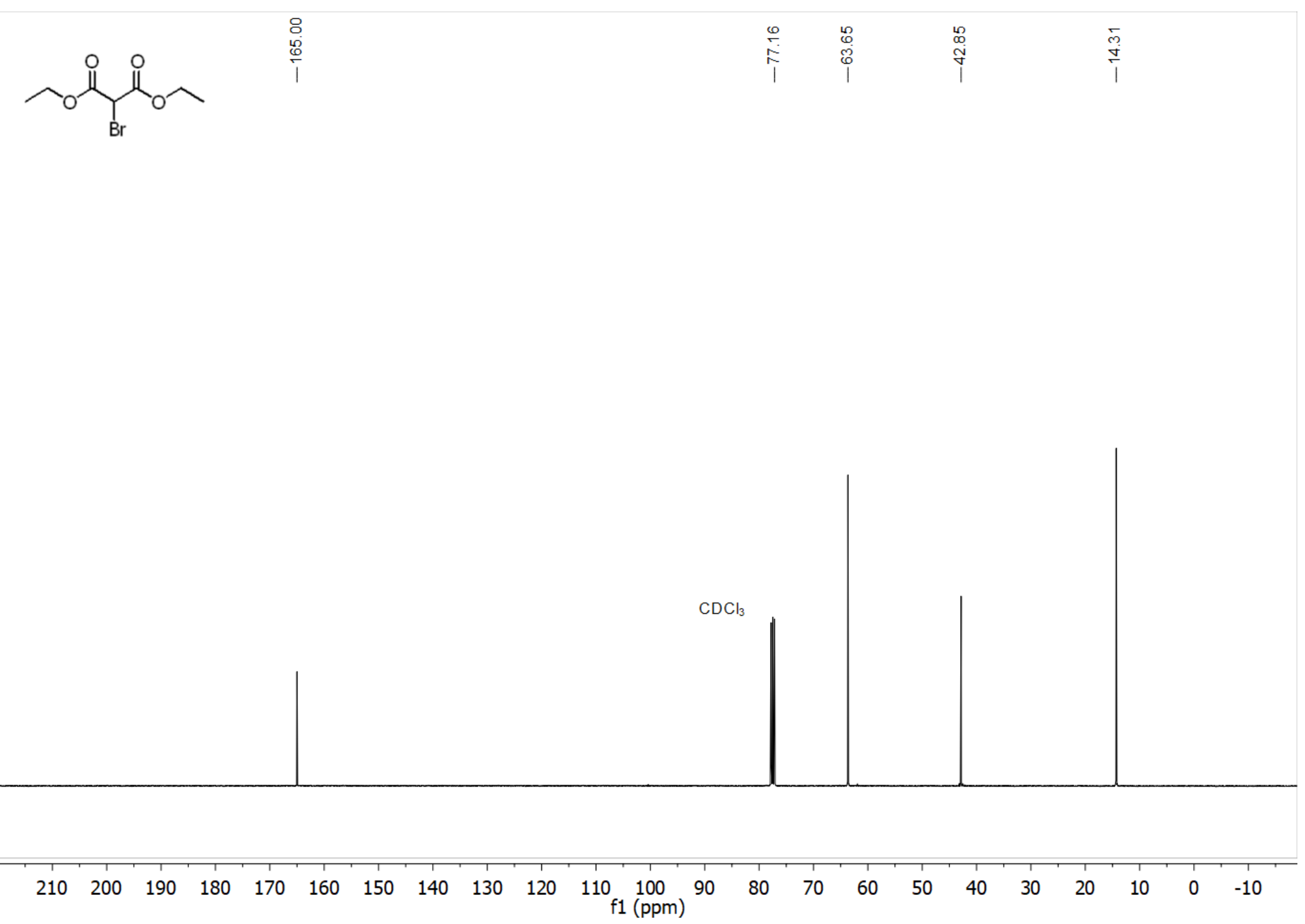


${ }^{1} \mathrm{H}$ NMR (400 MHz, $\mathrm{CDCl}_{3}$ ) spectrum of 5c ethyl 2-bromo-2-cyanoacetate

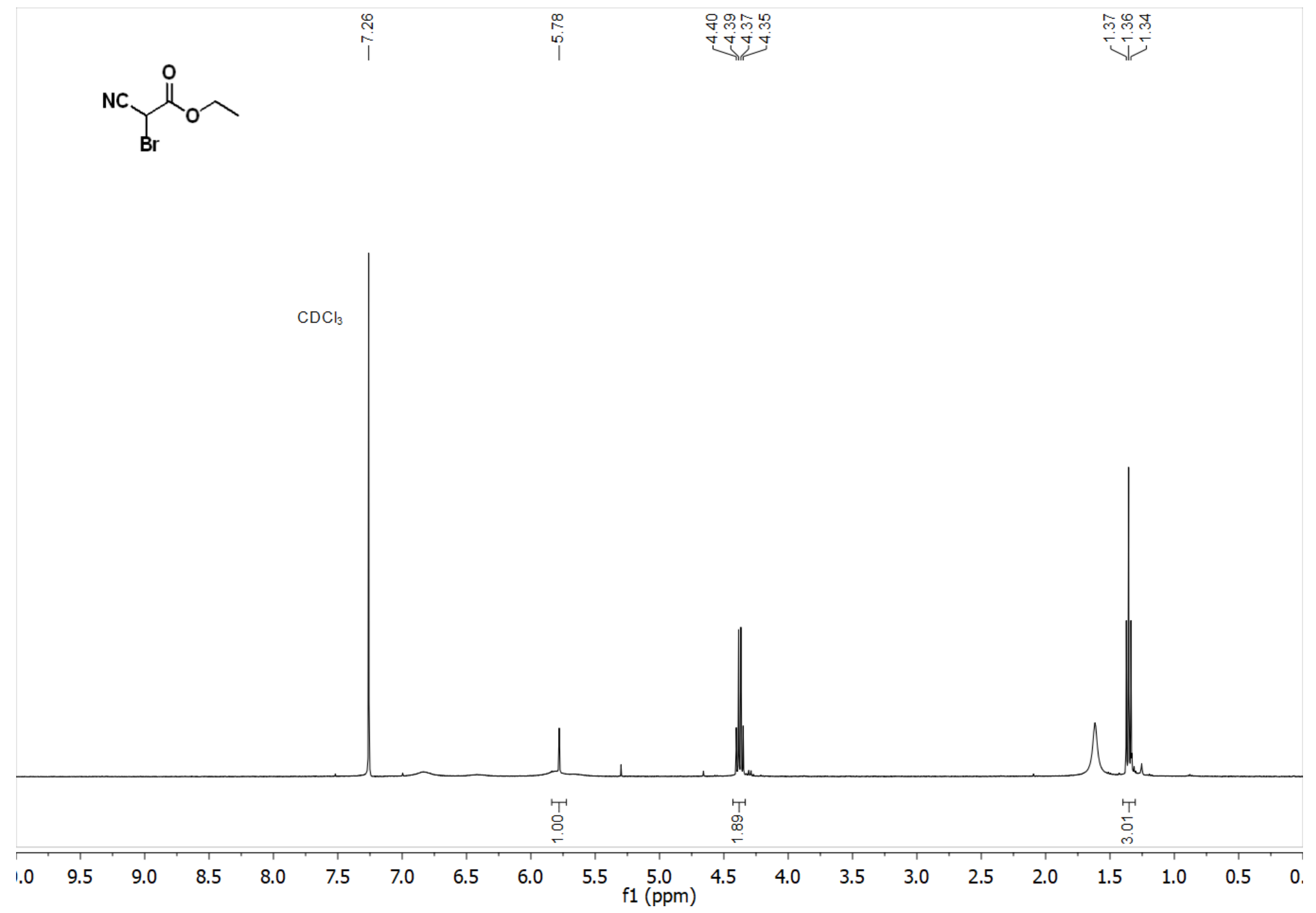


${ }^{1} \mathrm{H}$ NMR (400 MHz, $\mathrm{CDCl}_{3}$ ) spectrum of 6c 3-bromo-1,5-dioxaspiro[5.5]undecane-2,4-dione

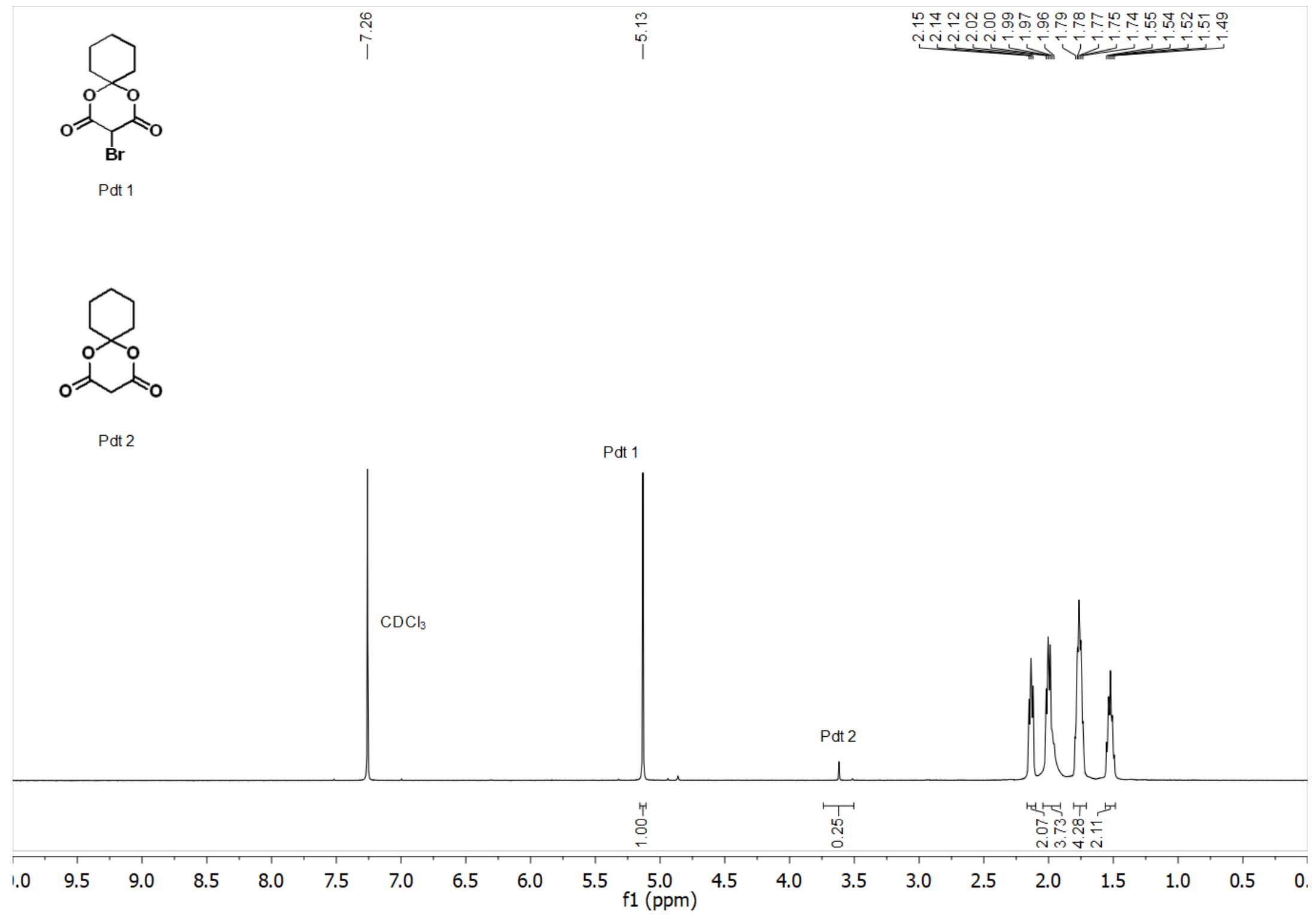


${ }^{13} \mathrm{C}$ NMR (101 MHz, $\mathrm{CDCl}_{3}$ ) spectrum of 6c 3-bromo-1,5-dioxaspiro[5.5]undecane-2,4-dione
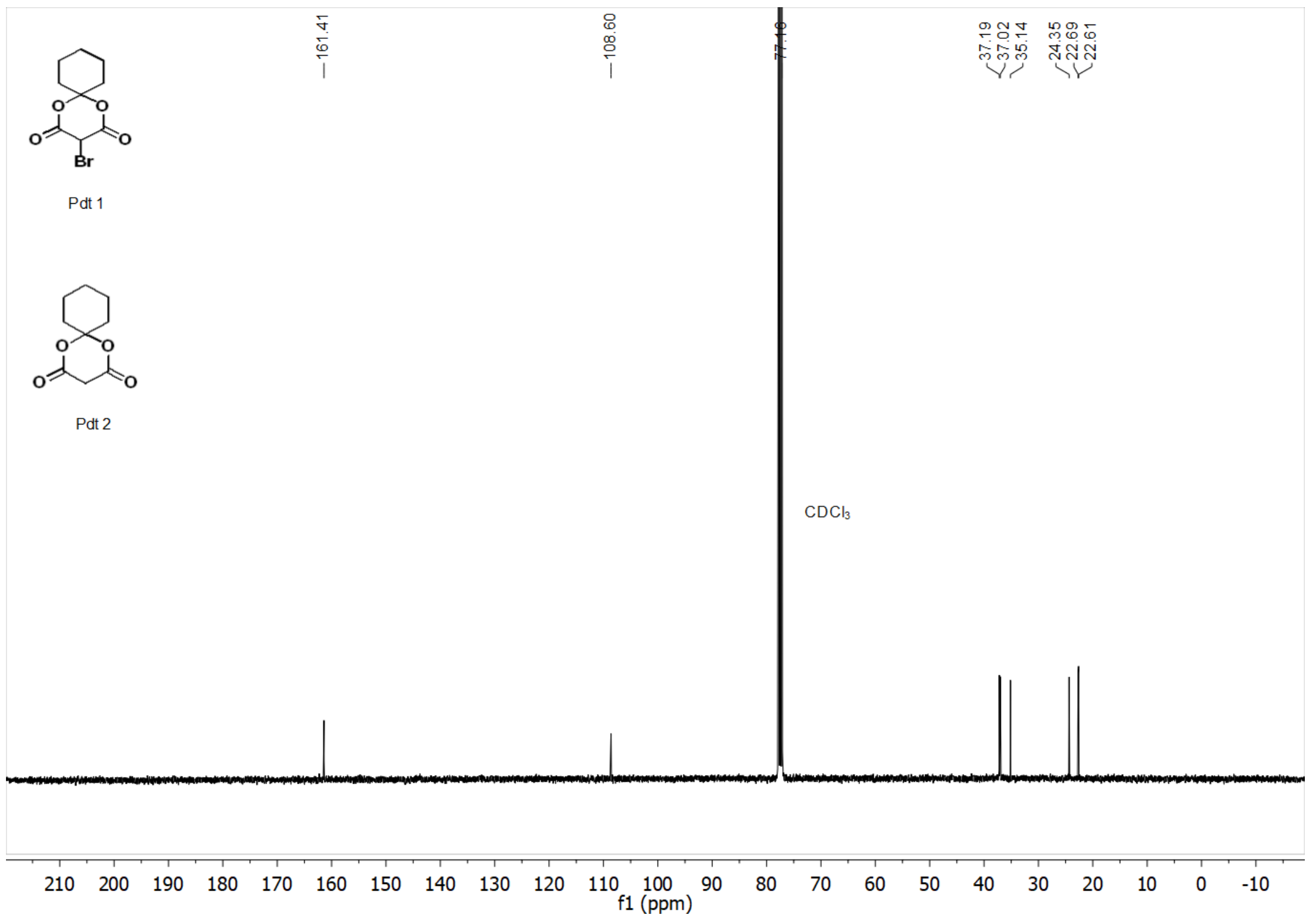
${ }^{1} \mathrm{H}$ NMR (400 MHz, $\mathrm{CDCl}_{3}$ ) spectrum of 7c 2-Bromo-1-phenylethan-1-one

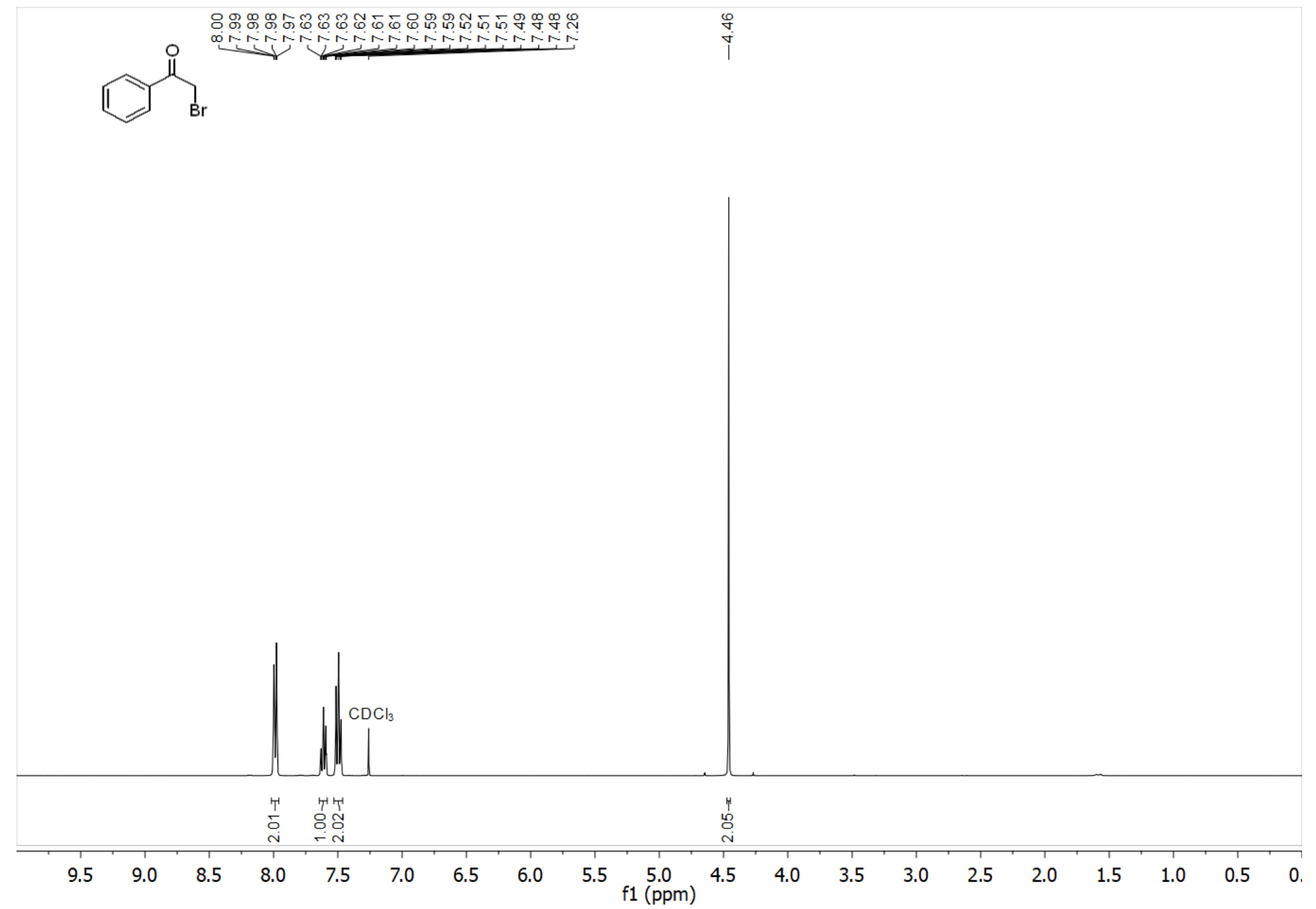


${ }^{13} \mathrm{C}$ NMR (101 MHz, $\mathrm{CDCl}_{3}$ ) spectrum of 7c 2-Bromo-1-phenylethan-1-one

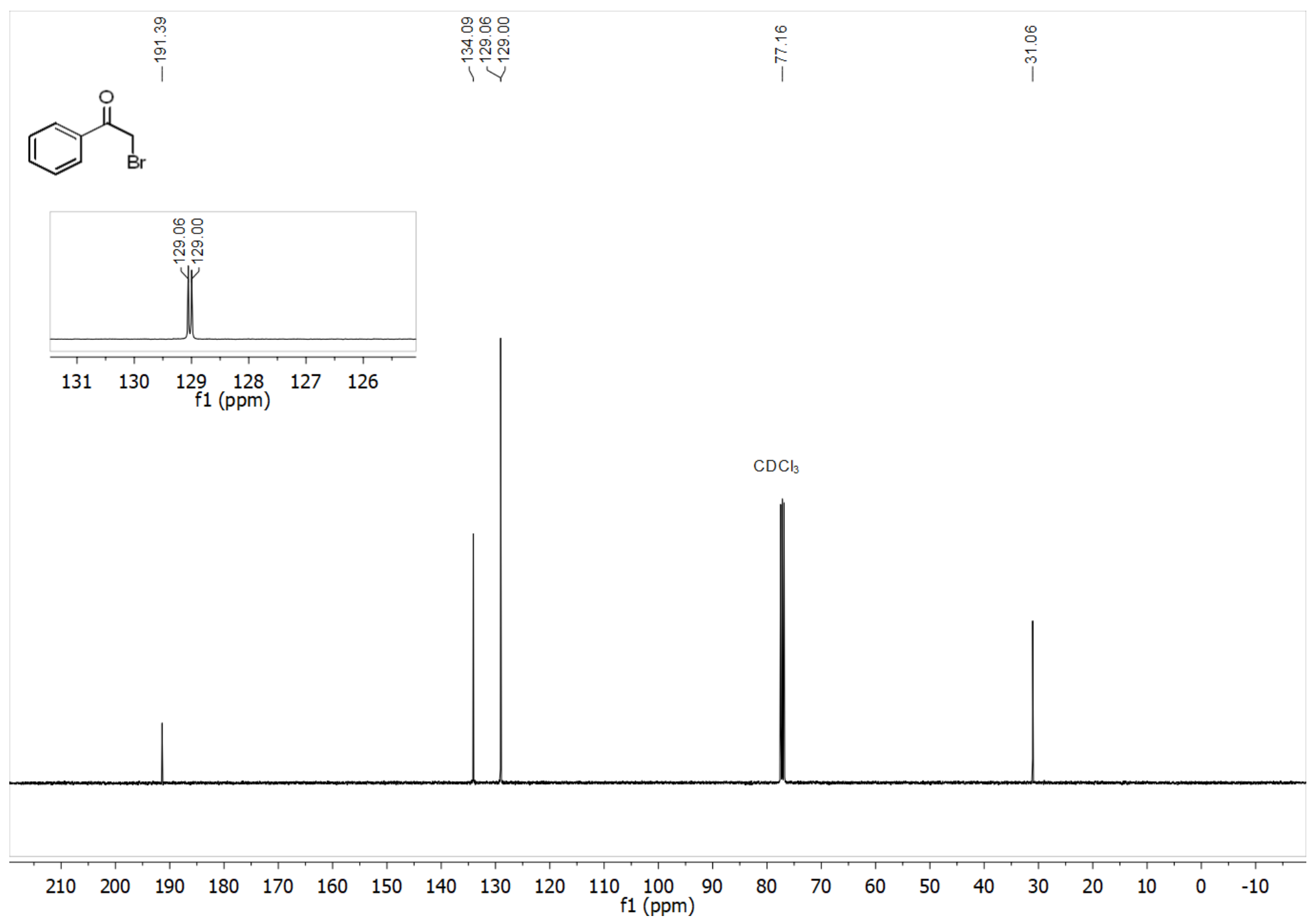


${ }^{1} \mathrm{H}$ NMR (400 MHz, $\mathrm{CDCl}_{3}$ ) spectrum of 8c 2-bromo-1-(4-(trifluoromethyl)phenyl)ethan-1-one

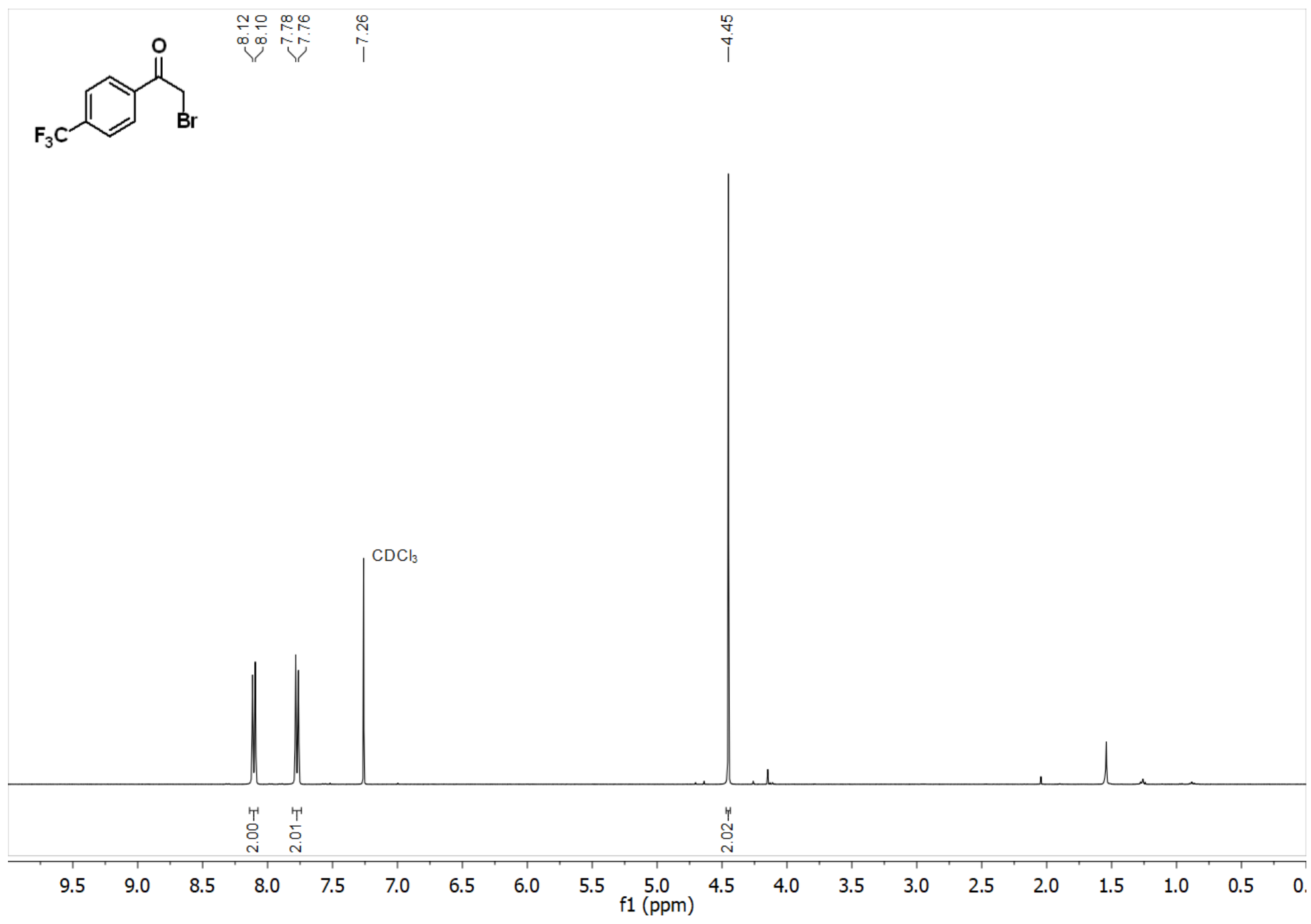


${ }^{19}$ F NMR (376 MHz, $\mathrm{CDCl}_{3}$ ) spectrum of 8c 2-bromo-1-(4-(trifluoromethyl)phenyl)ethan-1-one

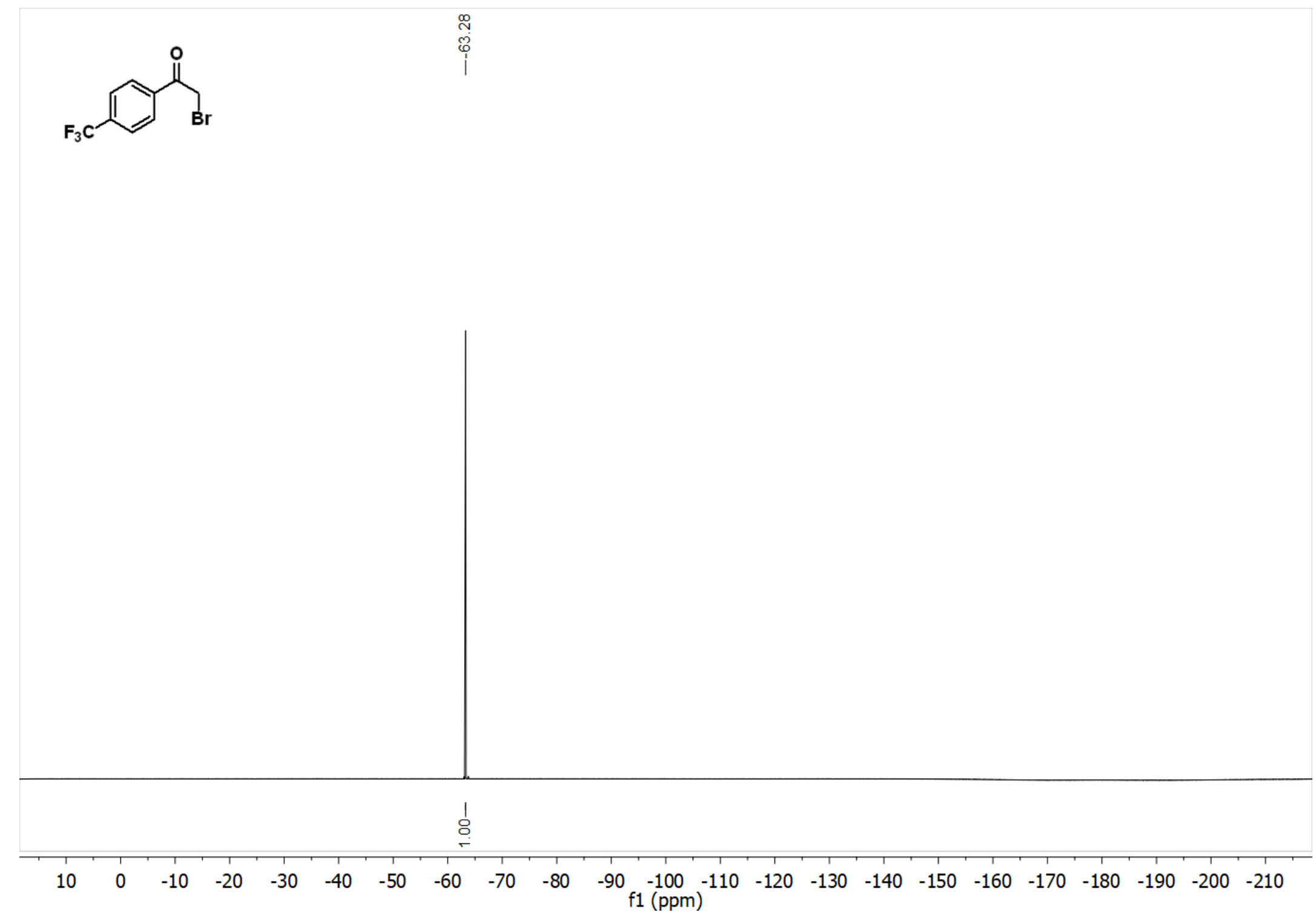


${ }^{13} \mathrm{C}$ NMR (101 MHz, $\mathrm{CDCl}_{3}$ ) spectrum of 8c 2-bromo-1-(4-(trifluoromethyl)phenyl)ethan-1-one

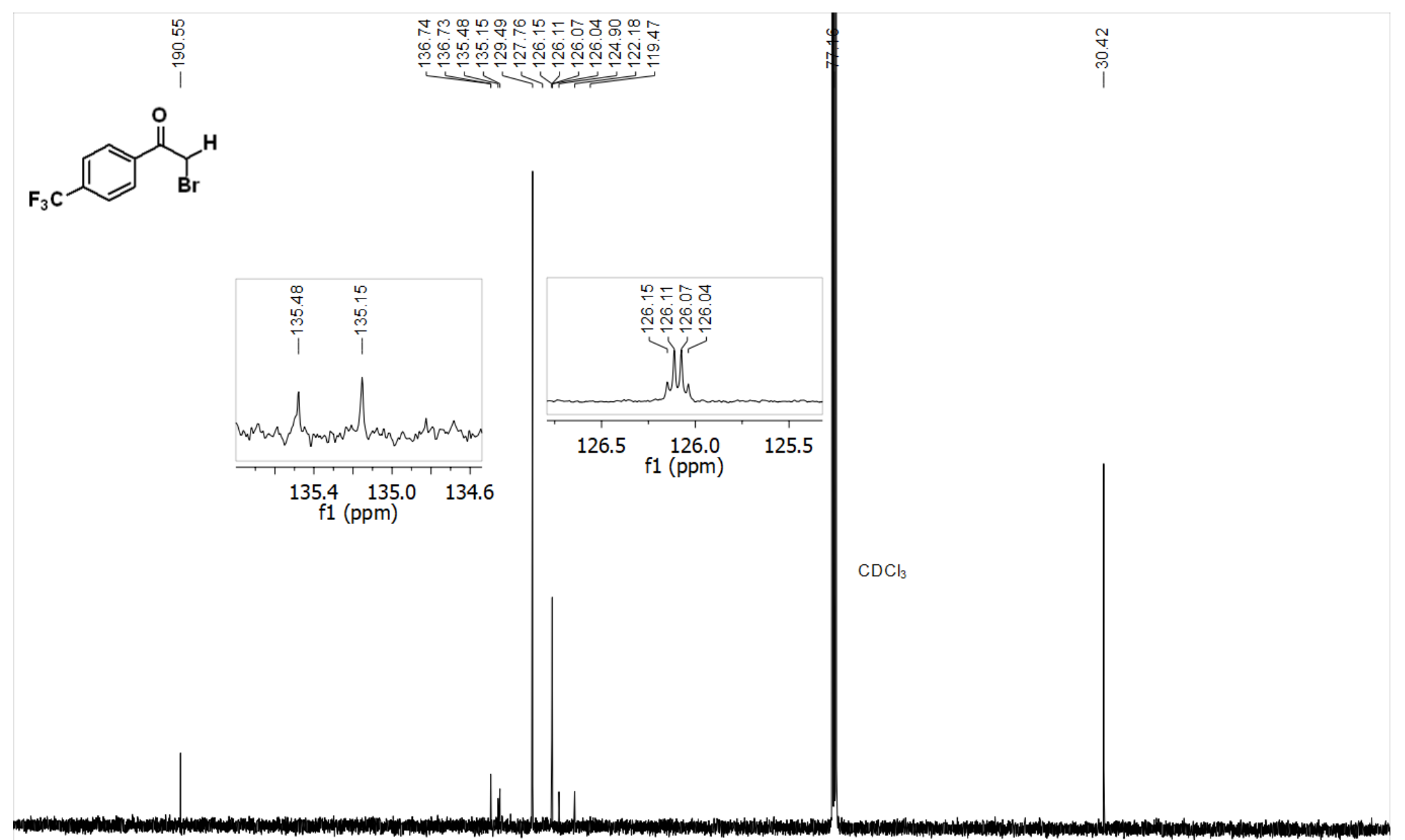

$\begin{array}{lllllllllllllllllllllll}210 & 200 & 190 & 180 & 170 & 160 & 150 & 140 & 130 & 120 & 110 & 100 & 90 & 80 & 70 & 60 & 50 & 40 & 30 & 20 & 10 & 0 & -10\end{array}$ 


\section{GC and MS of 8c 2-bromo-1-(4-(trifluoromethyl)phenyl)ethan-1-one}

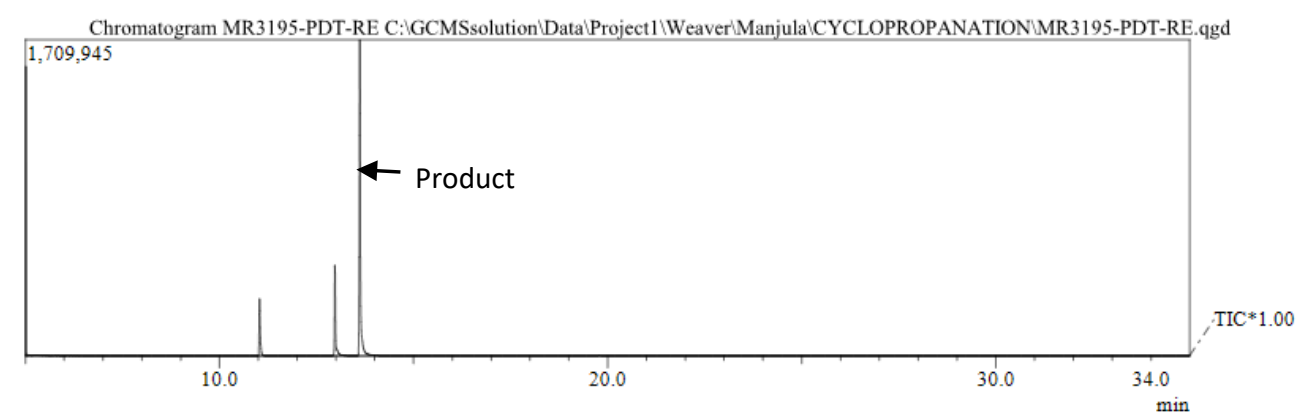

Spectrum

Line\#:1 R.Time:13.6(Scan\#:1035)

RawMode:Single 13.6(1035) BasePeak:173(601558)

BG Mode: None

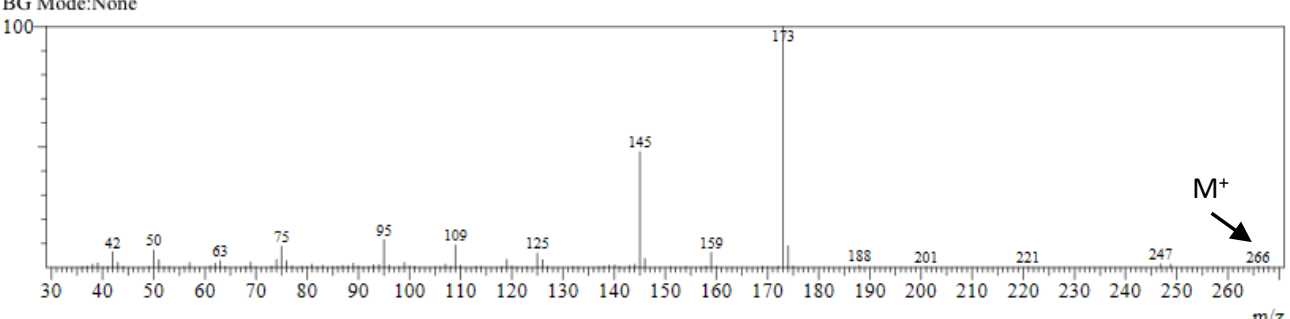

Line\#:2 R.Time:13.0(Scan\#:958)

RawMode:Single 13.0(958) BasePeak:173(151463)

BG Mode: None

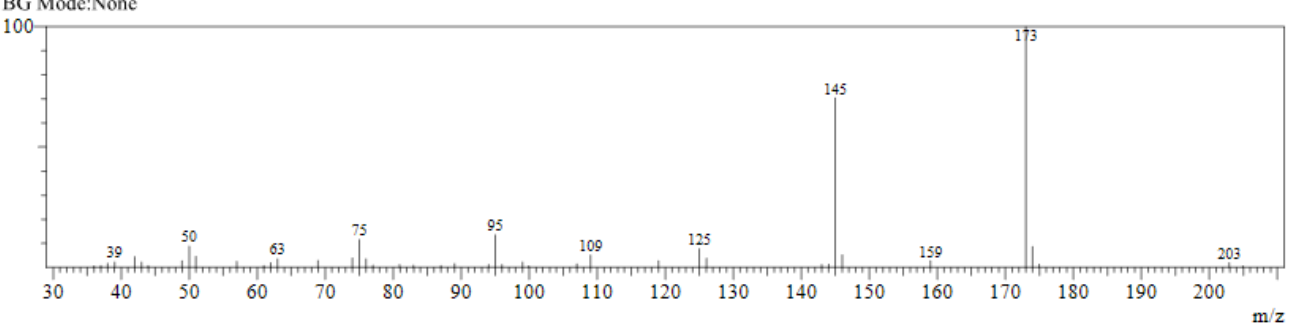


${ }^{1} \mathrm{H}$ NMR (400 MHz, $\mathrm{CDCl}_{3}$ ) spectrum of 9c 2,2-dibromo-1-(4-(trifluoromethyl)phenyl)ethan-1-one

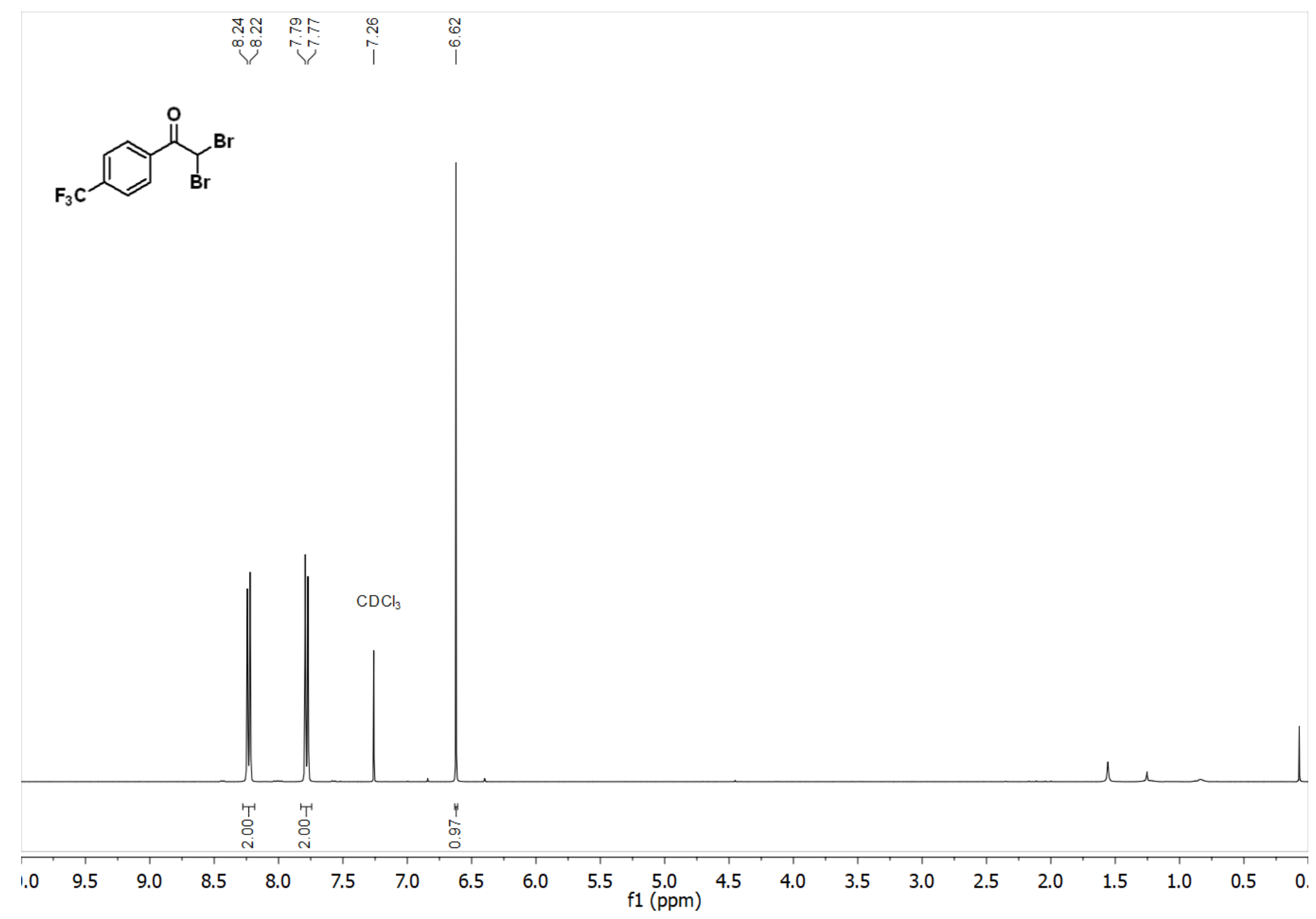


${ }^{19}$ F NMR (376 MHz, $\mathrm{CDCl}_{3}$ ) spectrum of 9c 2,2-dibromo-1-(4-(trifluoromethyl)phenyl)ethan-1-one

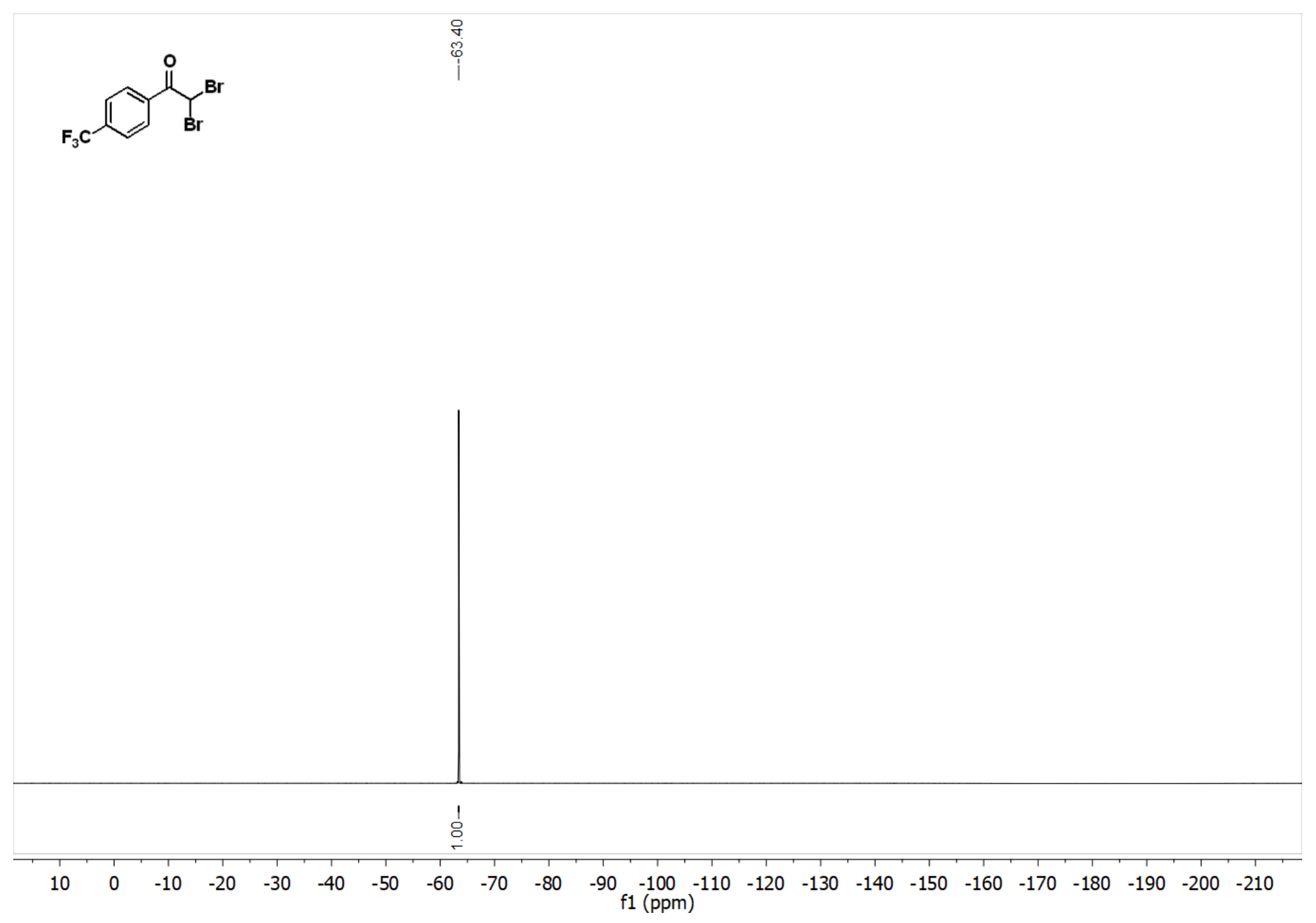


${ }^{13} \mathrm{C}$ NMR (101 MHz, $\mathrm{CDCl}_{3}$ ) spectrum of 9c 2,2-dibromo-1-(4-(trifluoromethyl)phenyl)ethan-1-one

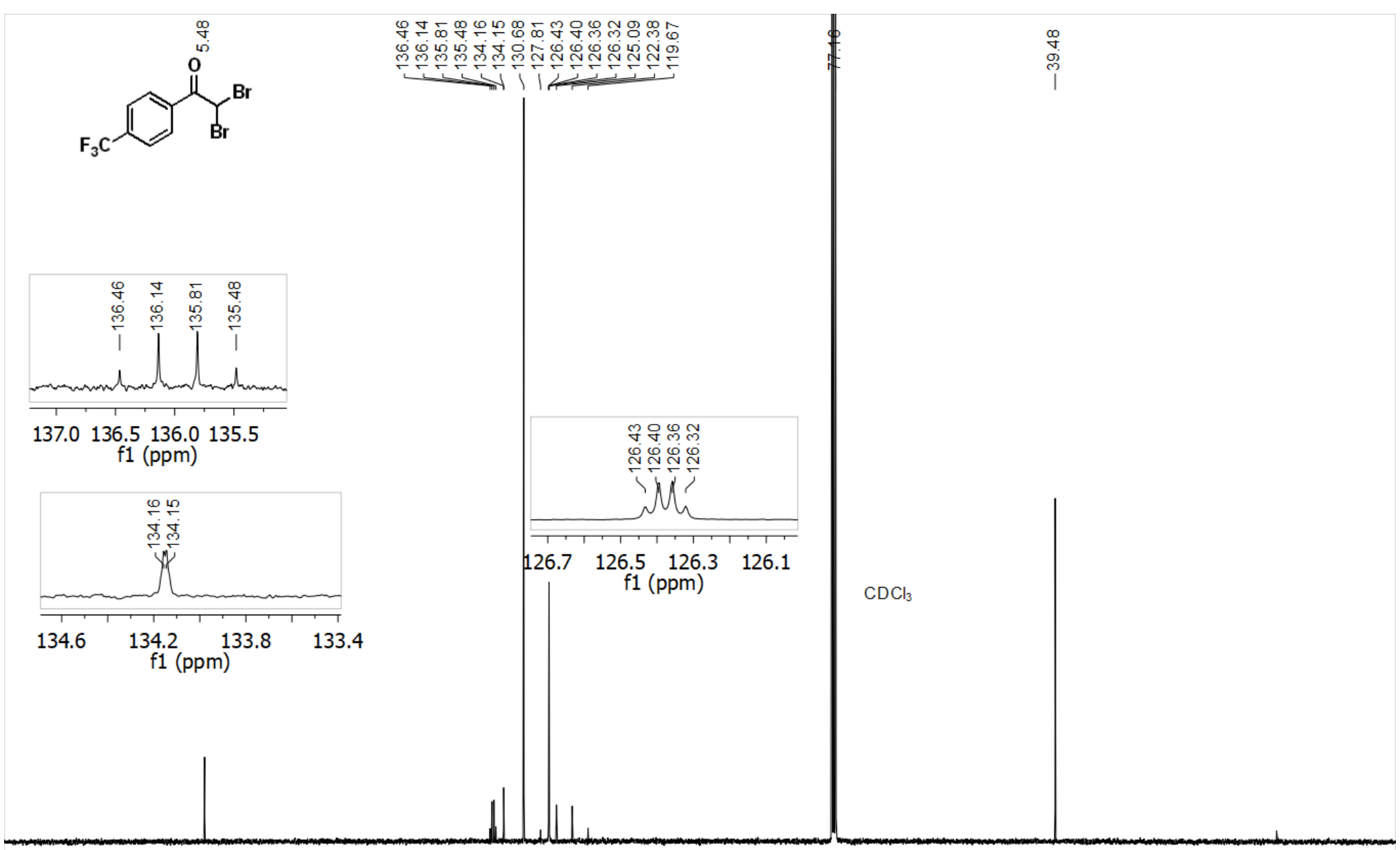

$\begin{array}{lllllllllllllllllllllll}210 & 200 & 190 & 180 & 170 & 160 & 150 & 140 & 130 & 120 & 110 & 100 & 90 & 80 & 70 & 60 & 50 & 40 & 30 & 20 & 10 & 0 & -10\end{array}$ 


\section{GC and MS of 9c 2,2-dibromo-1-(4-(trifluoromethyl)phenyl)ethan-1-one}

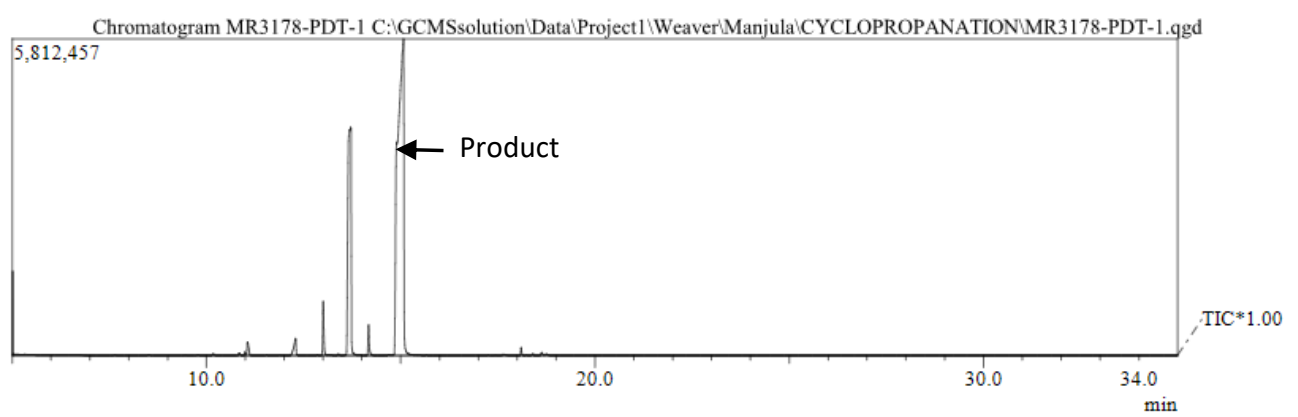

Spectrum

Line\#:1 R.Time:14.9(Scan\#:1194)

RawMode-Single 14.9(1194) BasePeak:173(1408385)

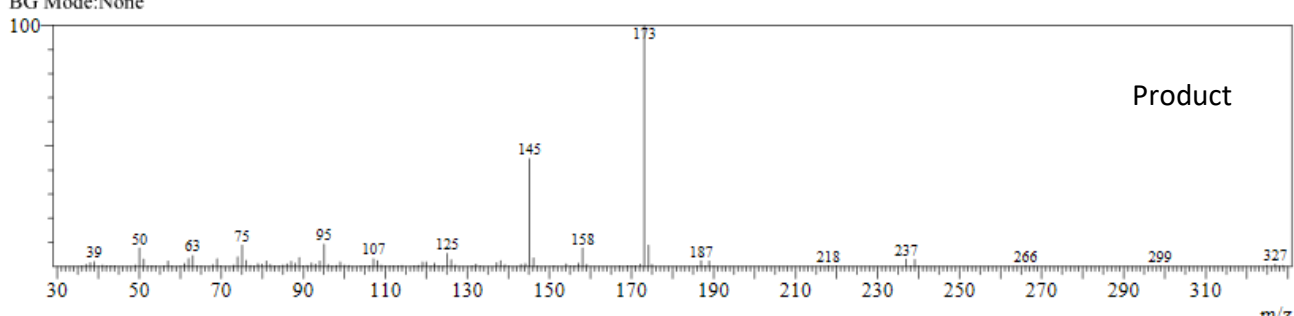

Linett:2 R.Time:13.7(Scan\#:1044

RawMode-Single 13.7(1044) BasePeak:173(1278081)

BG Mode: None

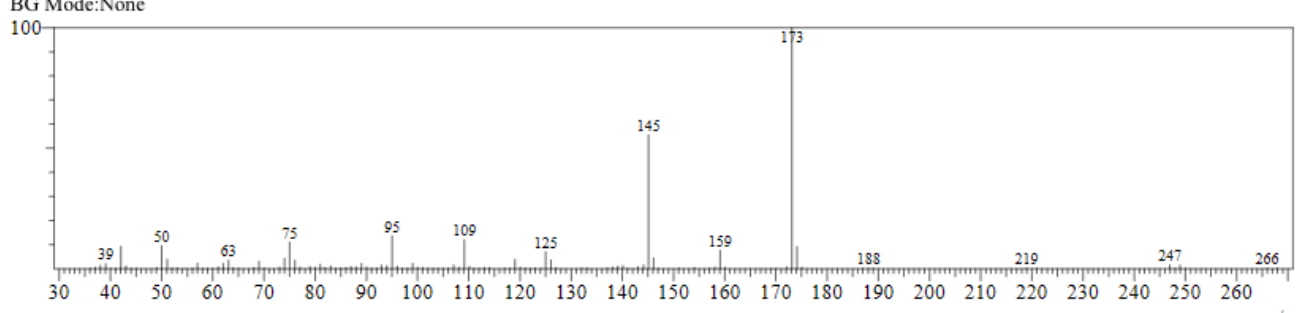




\section{GC and MS of 10c ((1-Bromoethyl)sulfonyl)benzene}

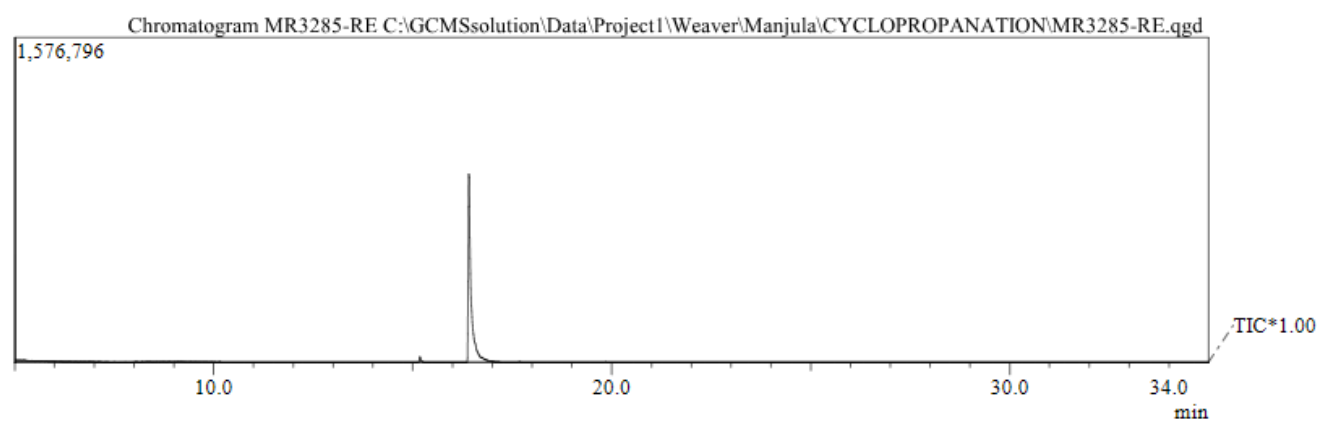

Spectrum

Line\#:1 R.Time: 16.1 (Scan\#: 1330)
MassPeaks:79

MassPeaks:79
RawMode:Single 16.1(1330) BasePeak:77(530170)
BG Mode:None

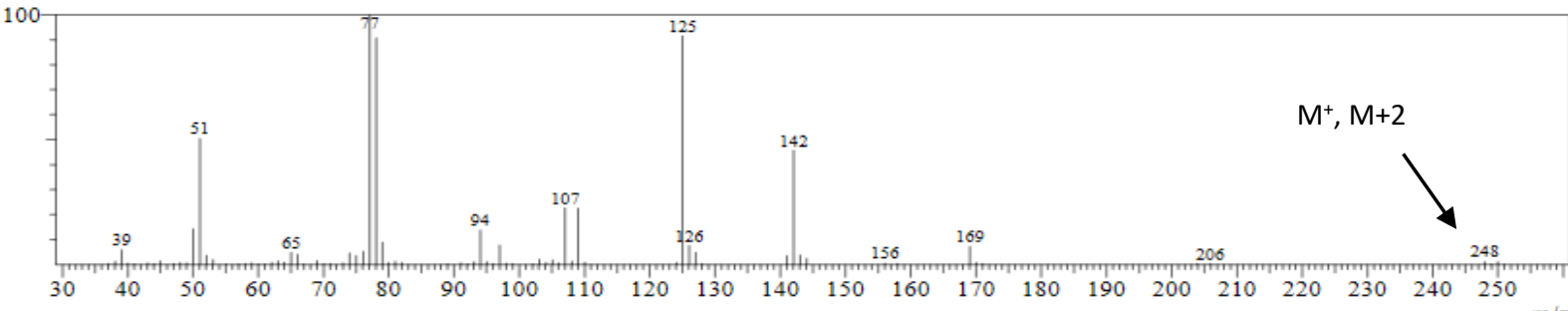

Line\#:2 R.Time:16.1(Scan\#:1333)

RawMode:Single 16.1(1333) BasePeak:77(744030)

BG Mode: None

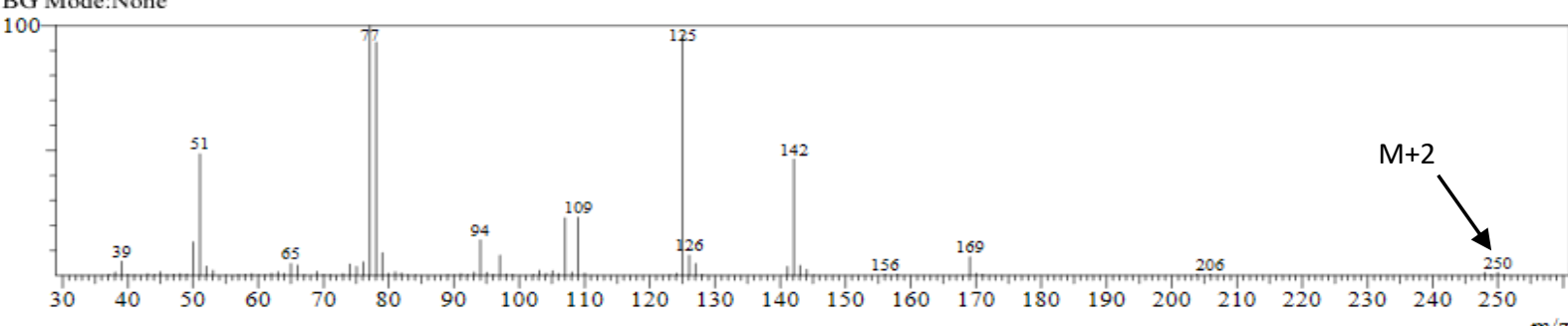


${ }^{1} \mathrm{H}$ NMR (400 MHz, $\left.\mathrm{CDCl}_{3}\right)$ spectrum of 11c ((Bromo(phenyl)methyl)sulfonyl)benzene

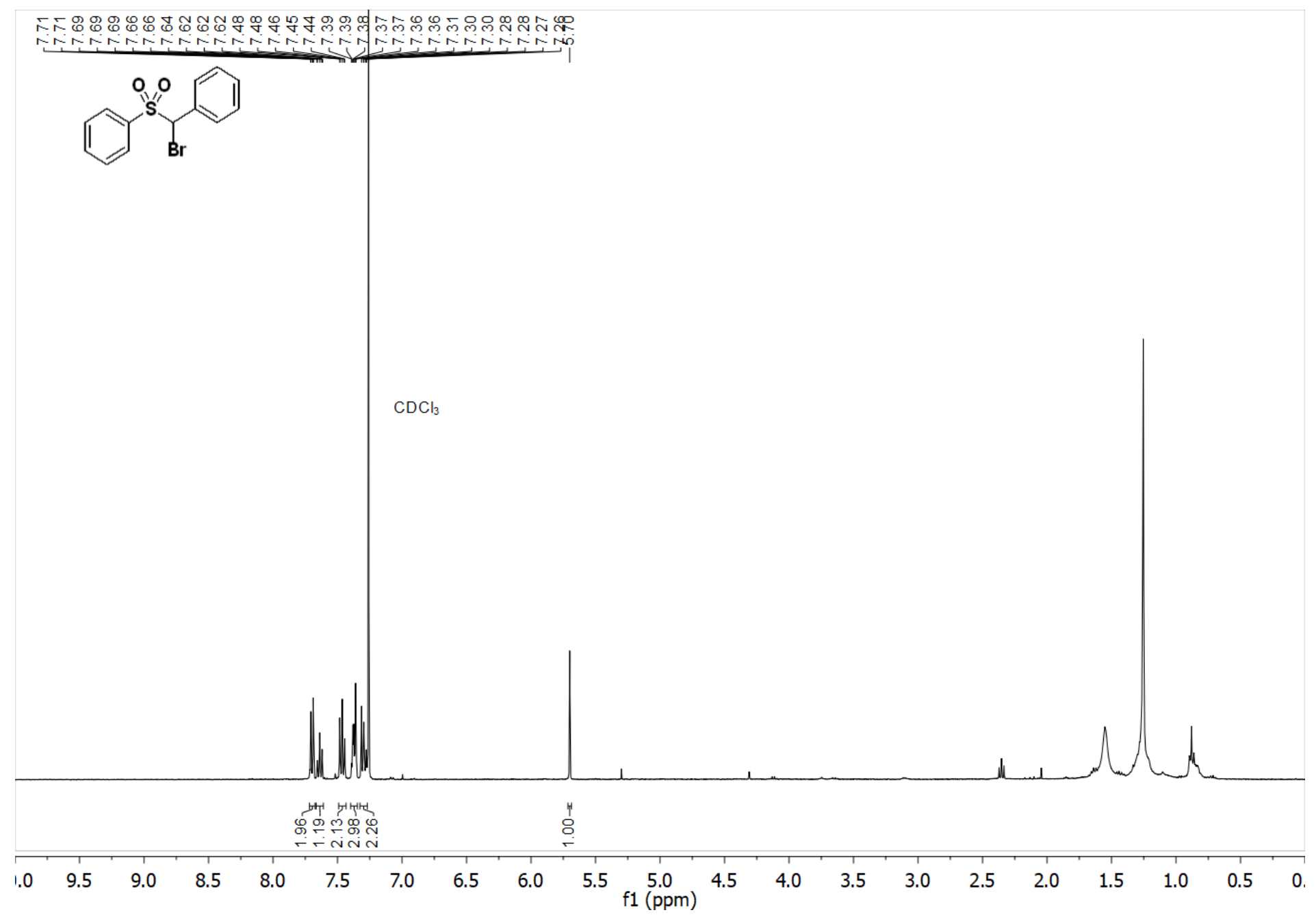


${ }^{13} \mathrm{C}$ NMR (101 MHz, $\left.\mathrm{CDCl}_{3}\right)$ spectrum of 11c ((Bromo(phenyl)methyl)sulfonyl)benzene

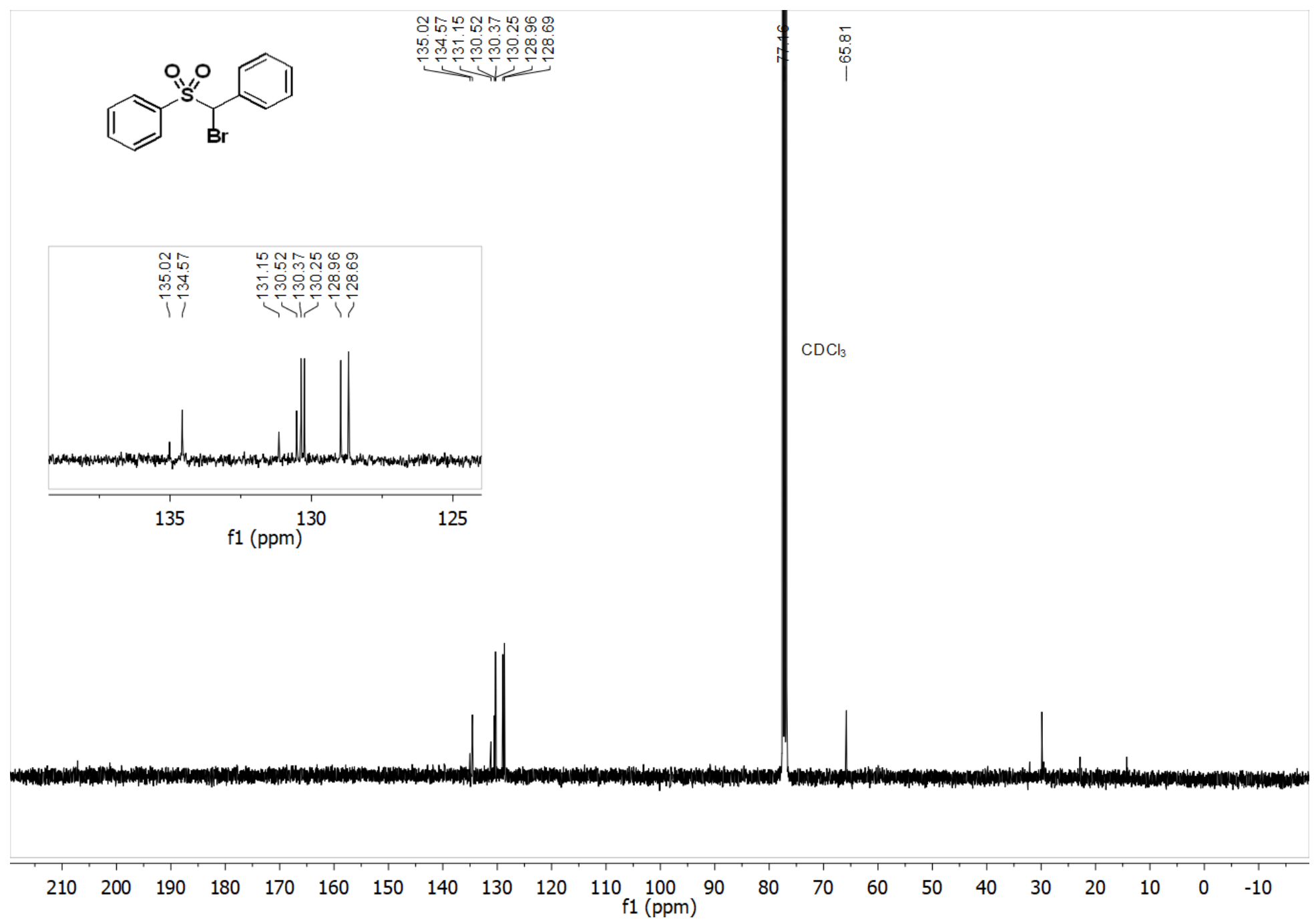




\section{GC and MS of 12c 6-Bromo-2,2-dimethylcyclohexan-1-one}

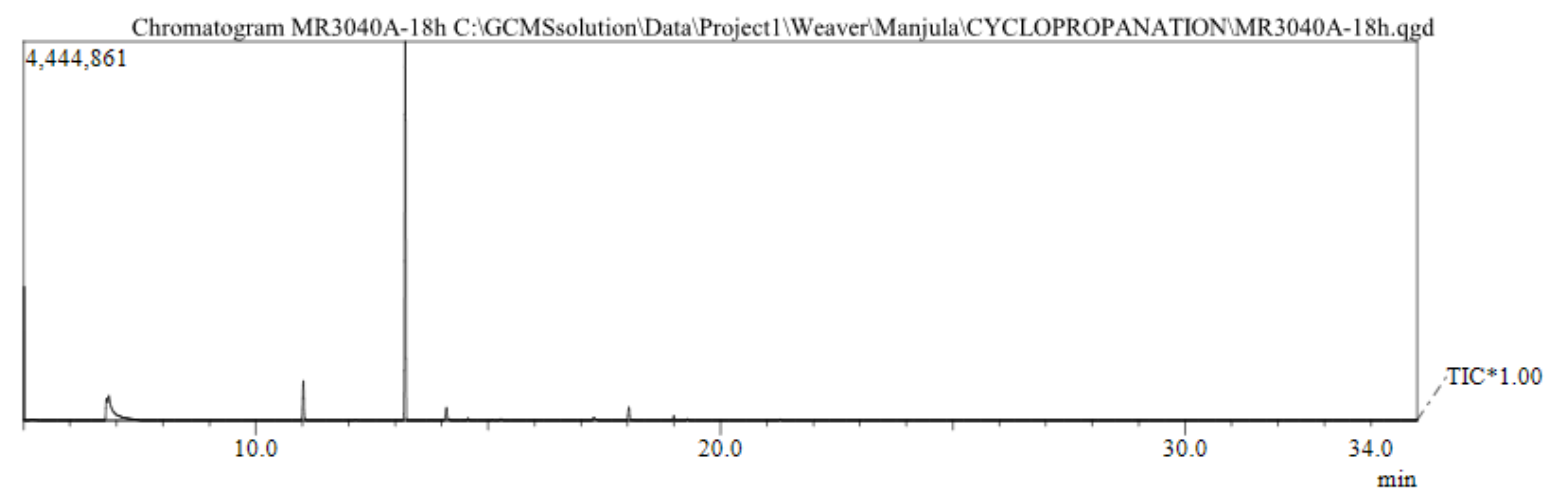

Spectrum

Line\#:1 R.Time:13.2(Scan\#:989)

MassPeaks:52

RawMode:Single 13.2(989) BasePeak:69(120745)

BG Mode:None

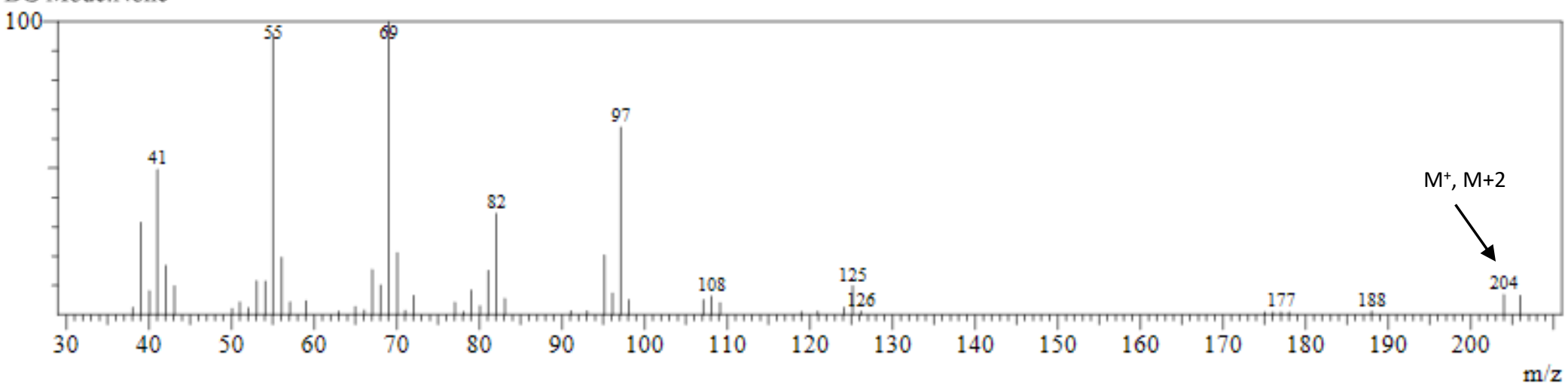


${ }^{1} \mathrm{H}$ NMR (400 MHz, $\mathrm{CDCl}_{3}$ ) spectrum of 13c (Bromomethyl)benzene

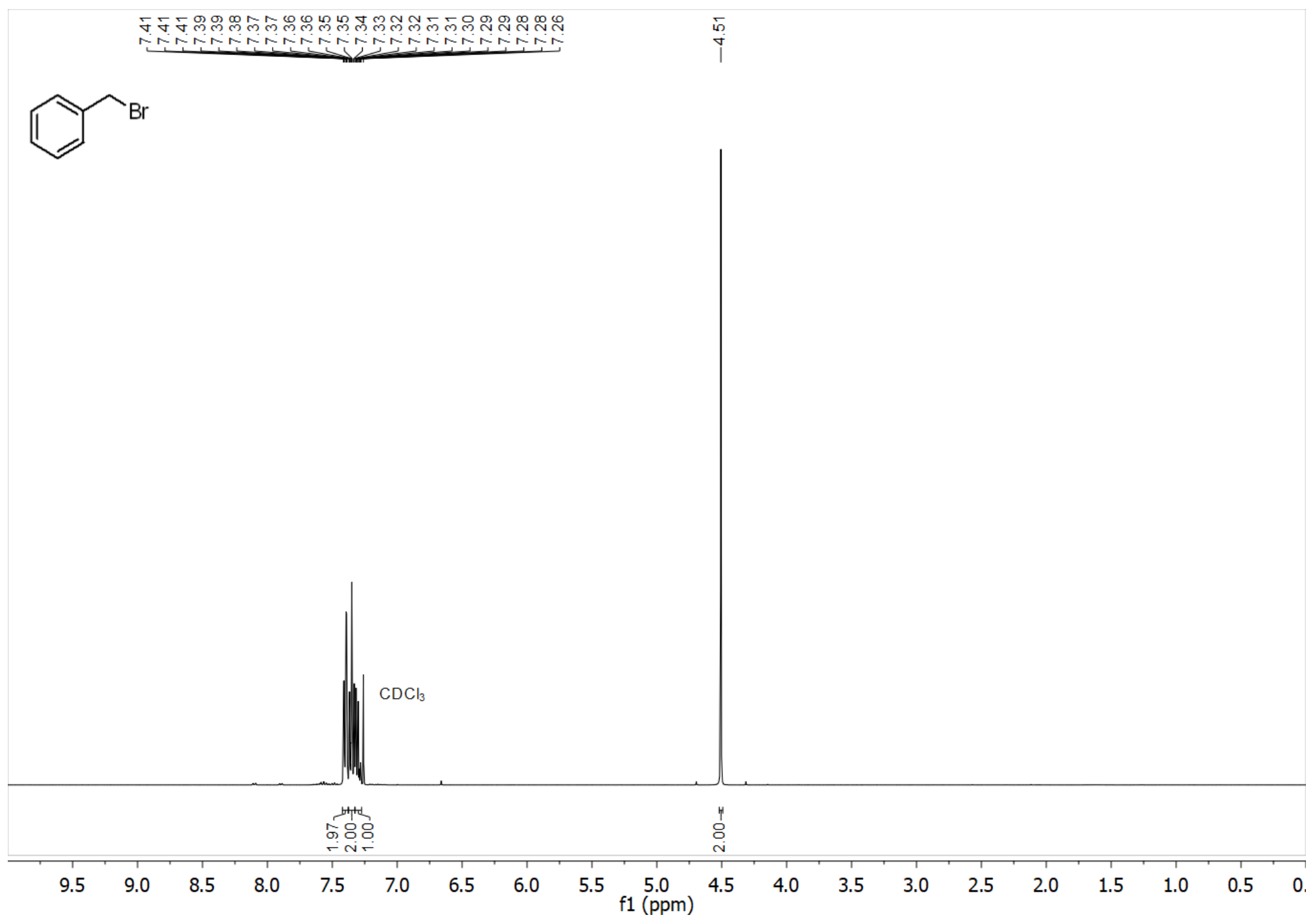


${ }^{13} \mathrm{C}$ NMR (101 MHz, $\mathrm{CDCl}_{3}$ ) spectrum of 13c (Bromomethyl)benzene

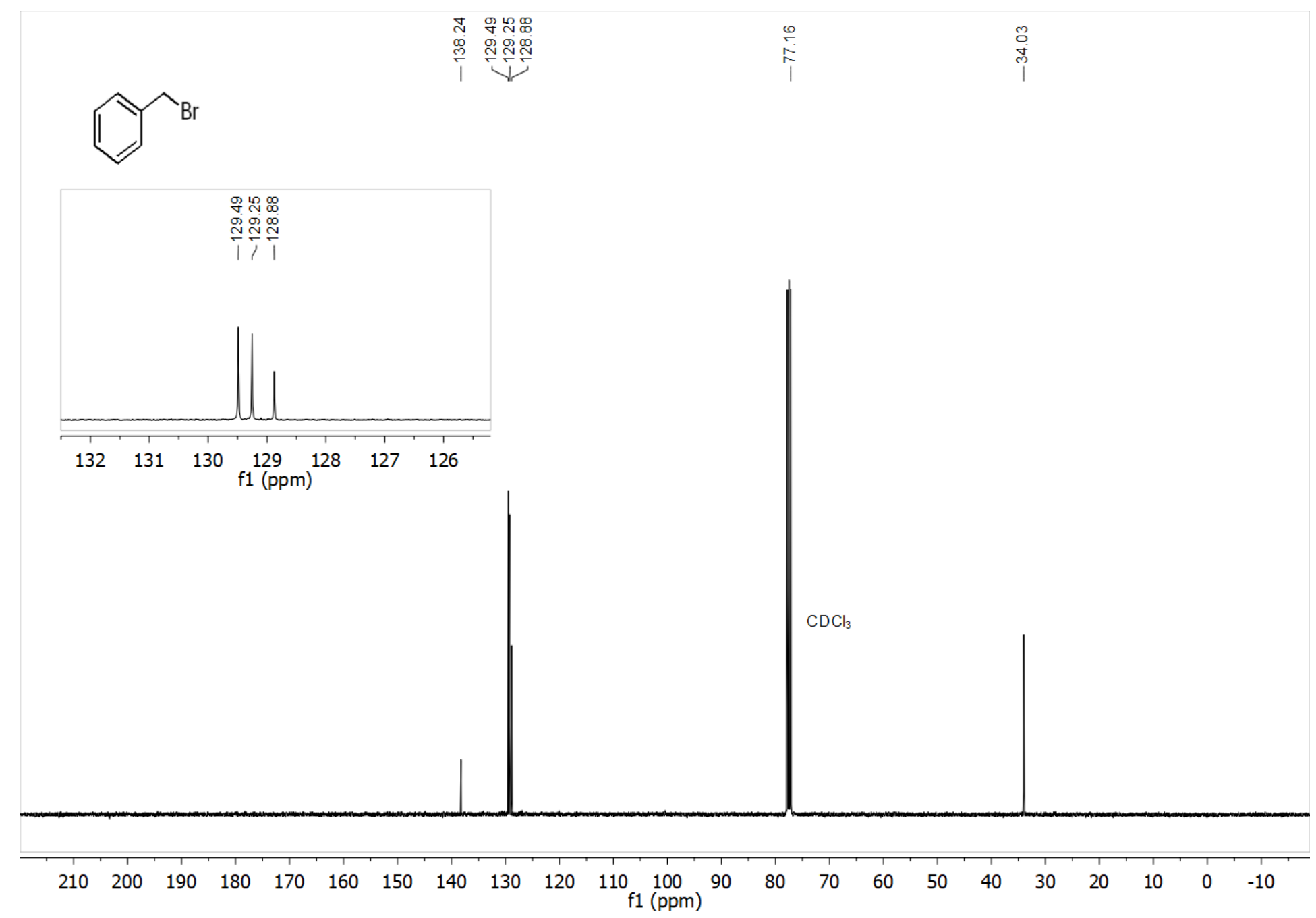


${ }^{1} \mathrm{H}$ NMR (400 MHz, $\left.\mathrm{CDCl}_{3}\right)$ spectrum of 14c ethyl 2-chloro-2-((2,6-difluorophenyl)sulfonyl)acetate

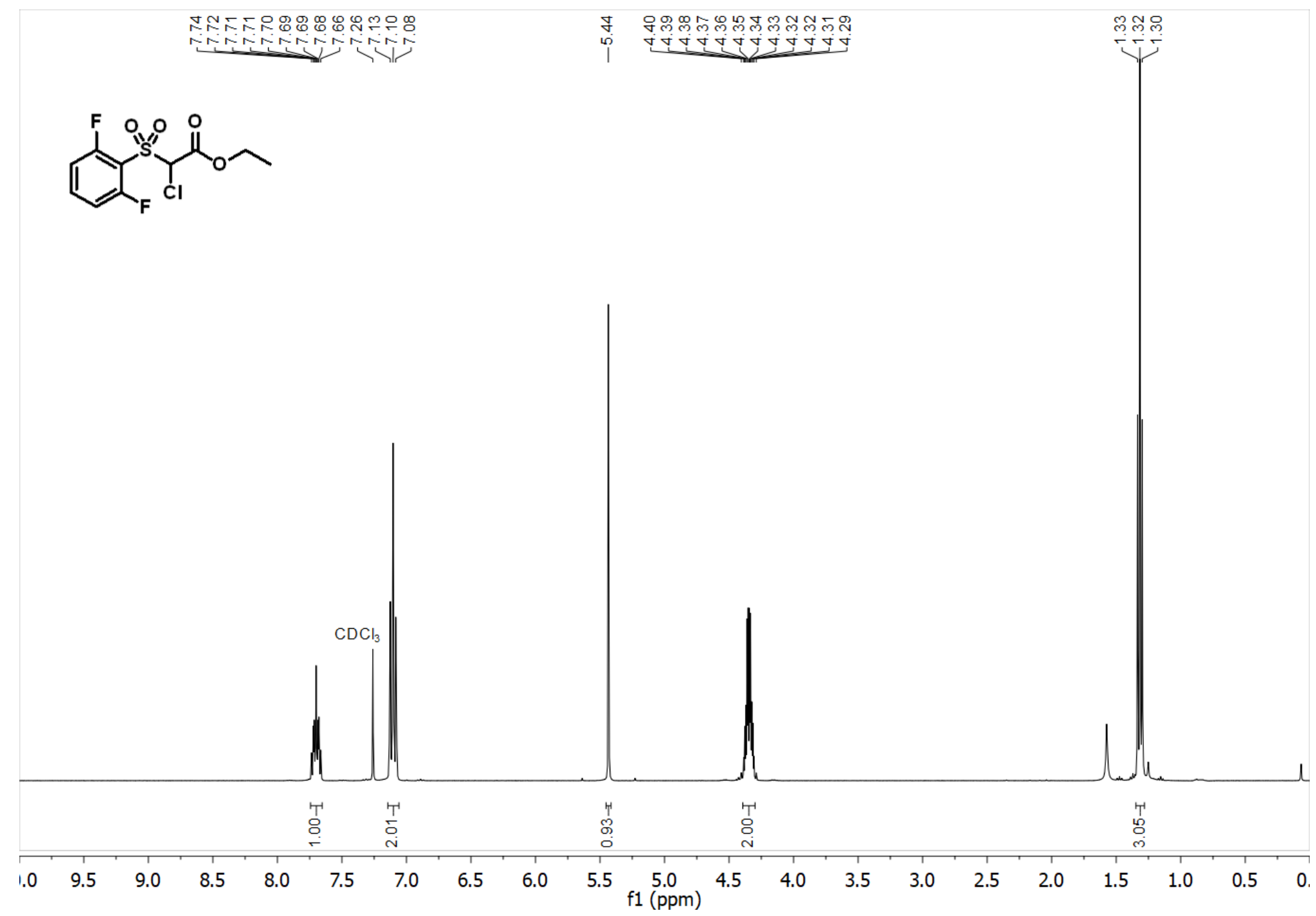


${ }^{19}$ F NMR (376 MHz, CDCl $)$ spectrum of 14c ethyl 2-chloro-2-((2,6-difluorophenyl)sulfonyl)acetate

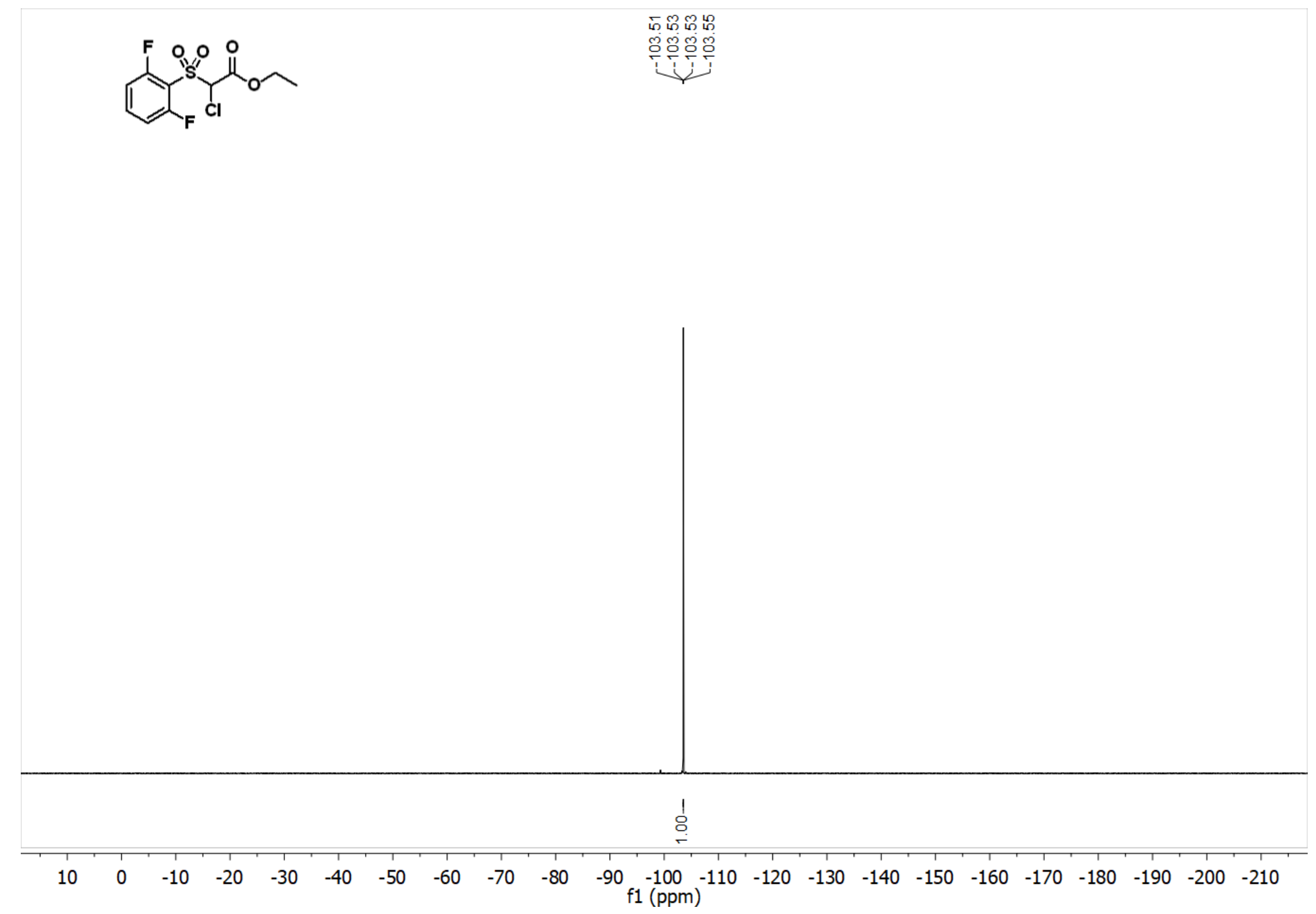


${ }^{13} \mathrm{C}$ NMR (101 MHz, $\left.\mathrm{CDCl}_{3}\right)$ spectrum of 14c ethyl 2-chloro-2-((2,6-difluorophenyl)sulfonyl)acetate

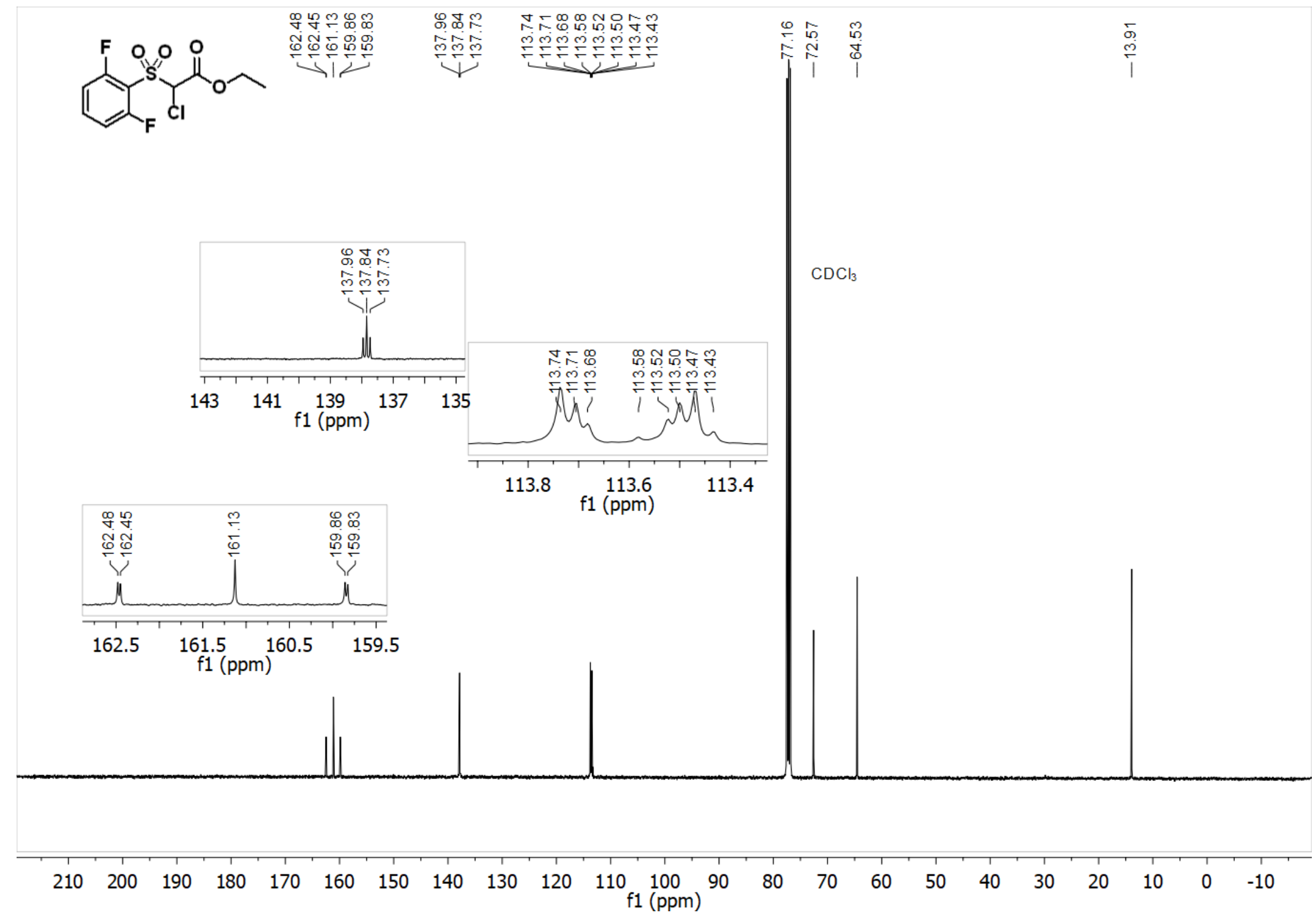


GC and MS of 14c ethyl 2-chloro-2-((2,6-difluorophenyl)sulfonyl)acetate

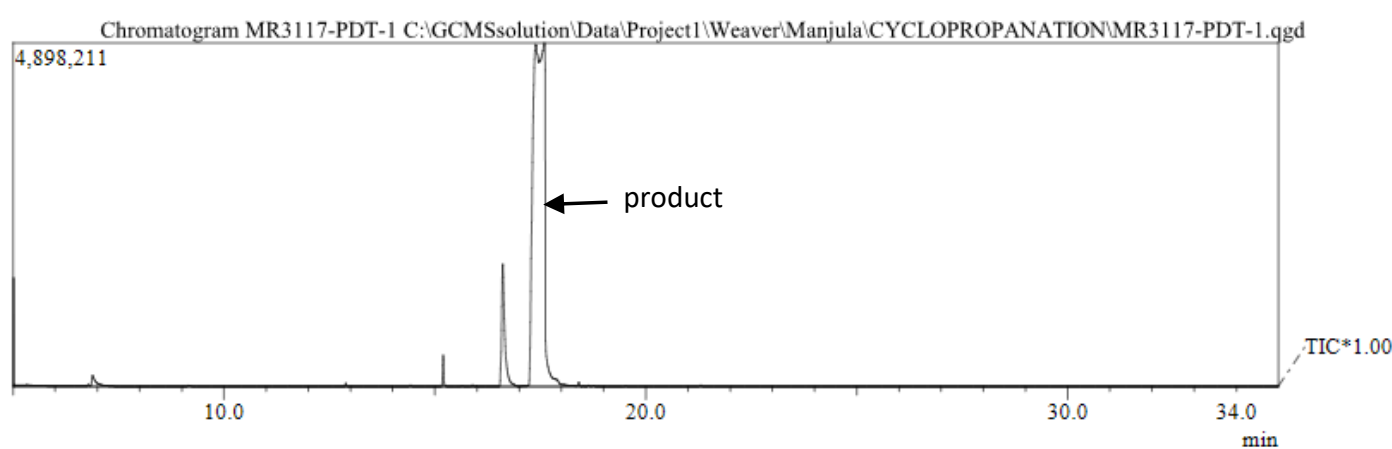

Spectrum

Line\#: 1 R.Time: 17.5 (Scan\#:1498)
MassPeaks: 133

RawMode:Single 17.5(1498) BasePeak:177(626318)

RawMode:Single 17

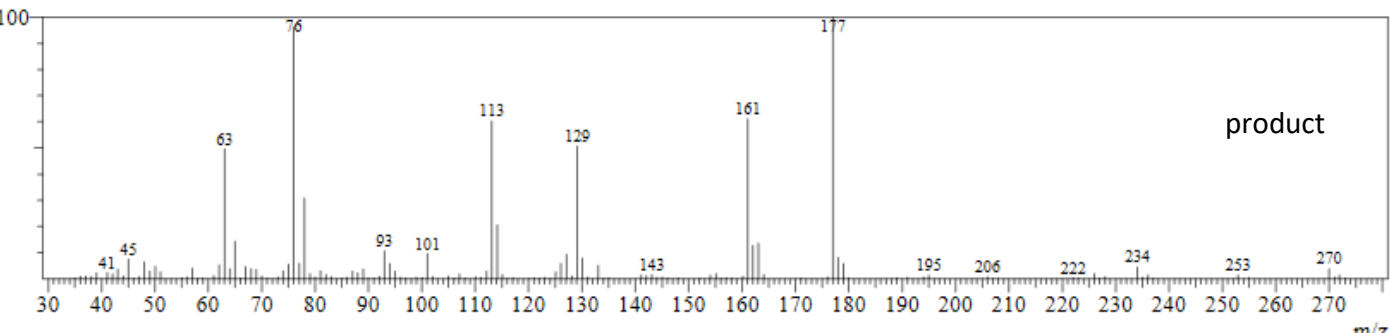

Line\#t:2 R.Time: 16.6(Scan\#:1398)

MassPeaks: : 11 ingle 16.6(1398) BasePeak:127(193636)

BG Mode: None

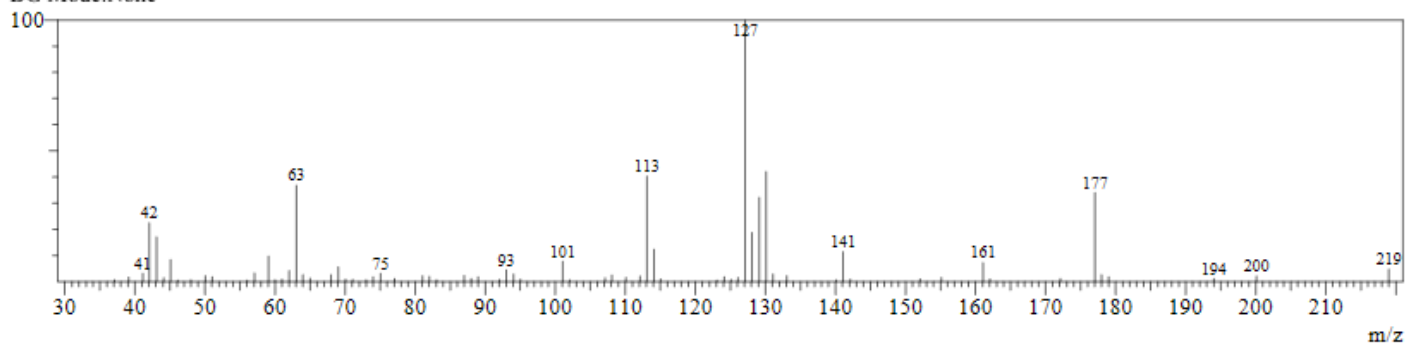


${ }^{1} \mathrm{H}$ NMR (400 $\mathrm{MHz}, \mathrm{CDCl}_{3}$ ) spectrum of $15 \mathrm{c}$ ethyl 2,2-dichloroacetate

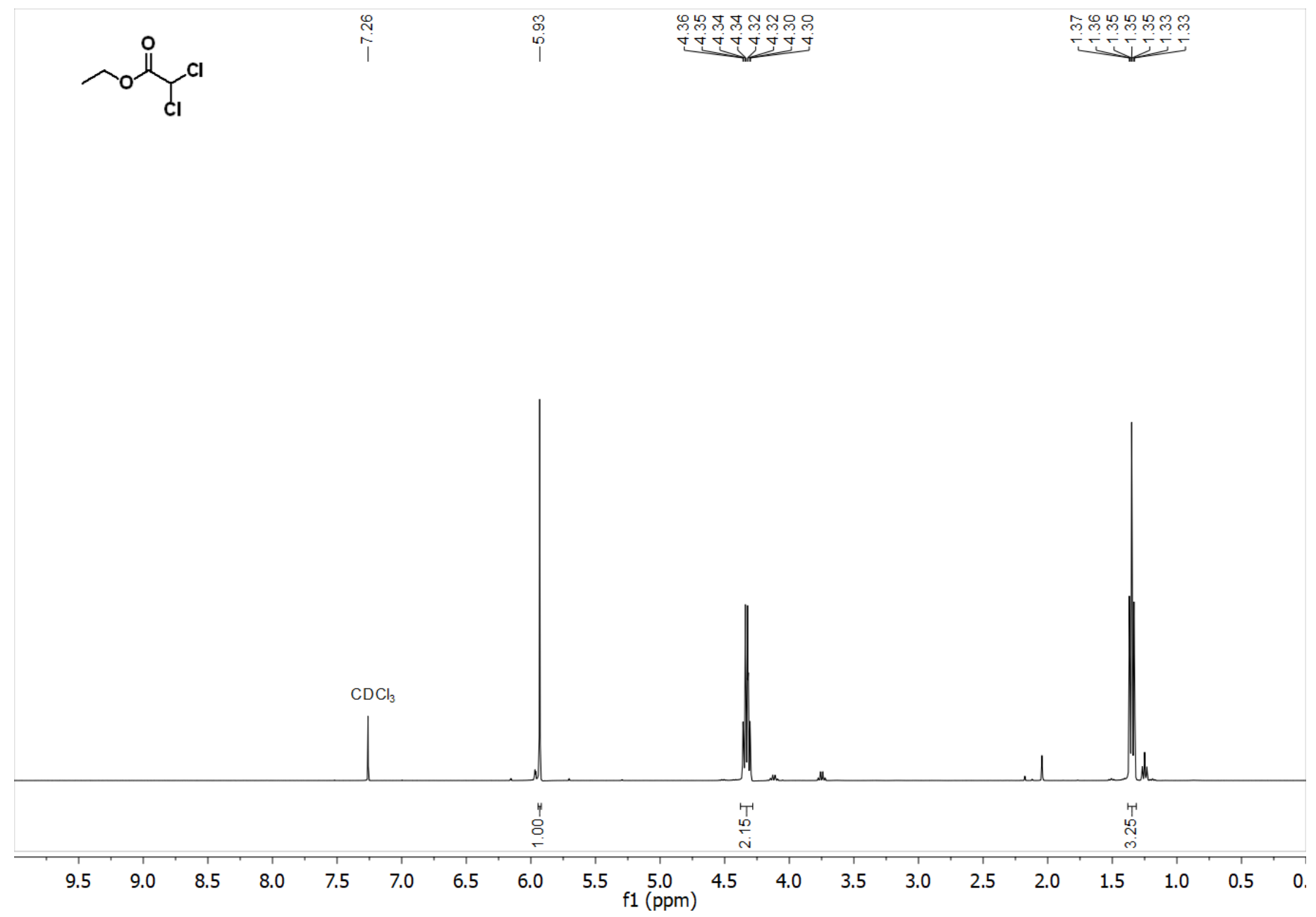


${ }^{13} \mathrm{C}$ NMR (101 MHz, $\left.\mathrm{CDCl}_{3}\right)$ spectrum of 15c ethyl 2,2-dichloroacetate

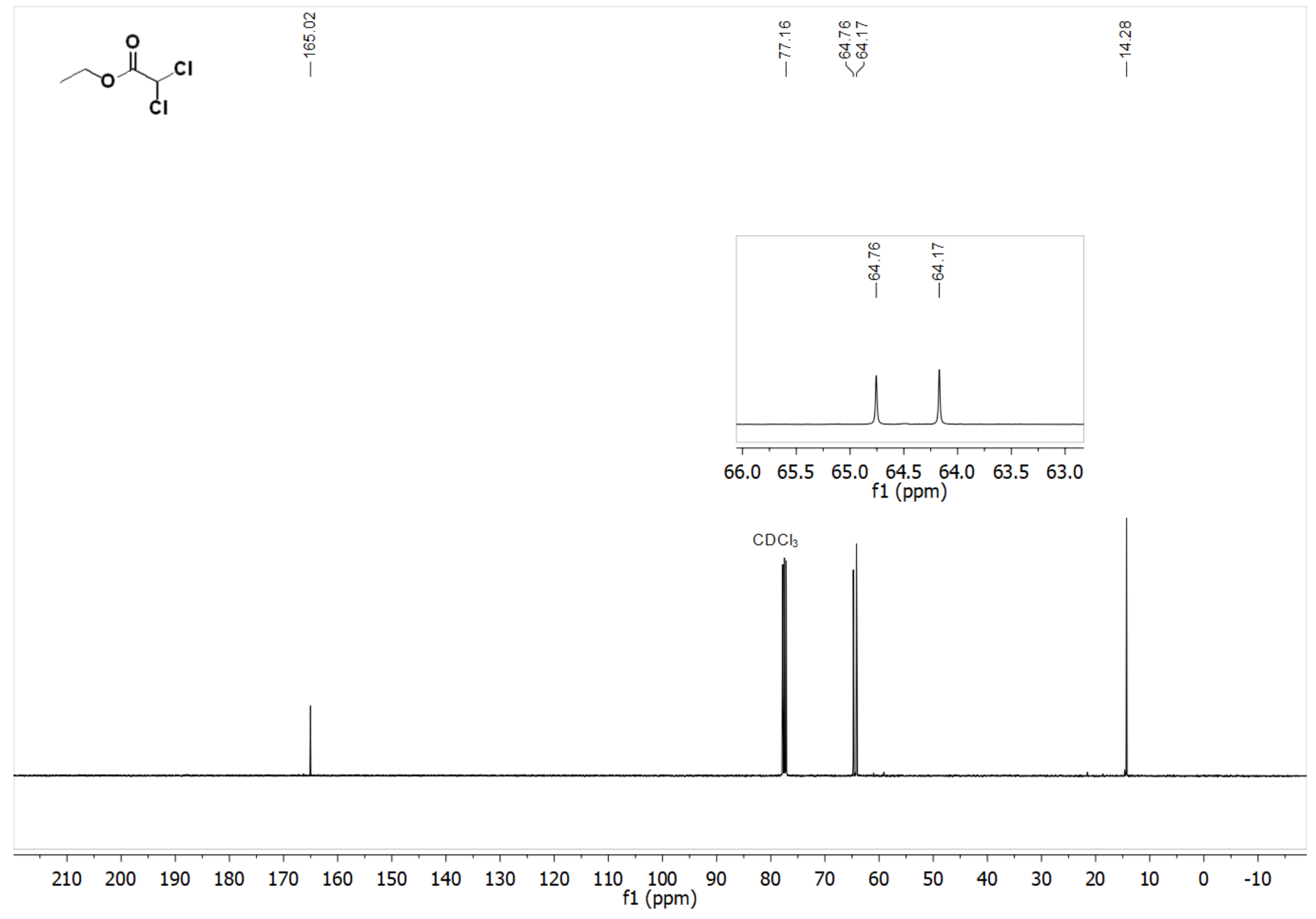


${ }^{1} \mathrm{H}$ NMR (400 MHz, $\mathrm{CDCl}_{3}$ ) spectrum of 16c benzyl 2,2-dichloroacetate

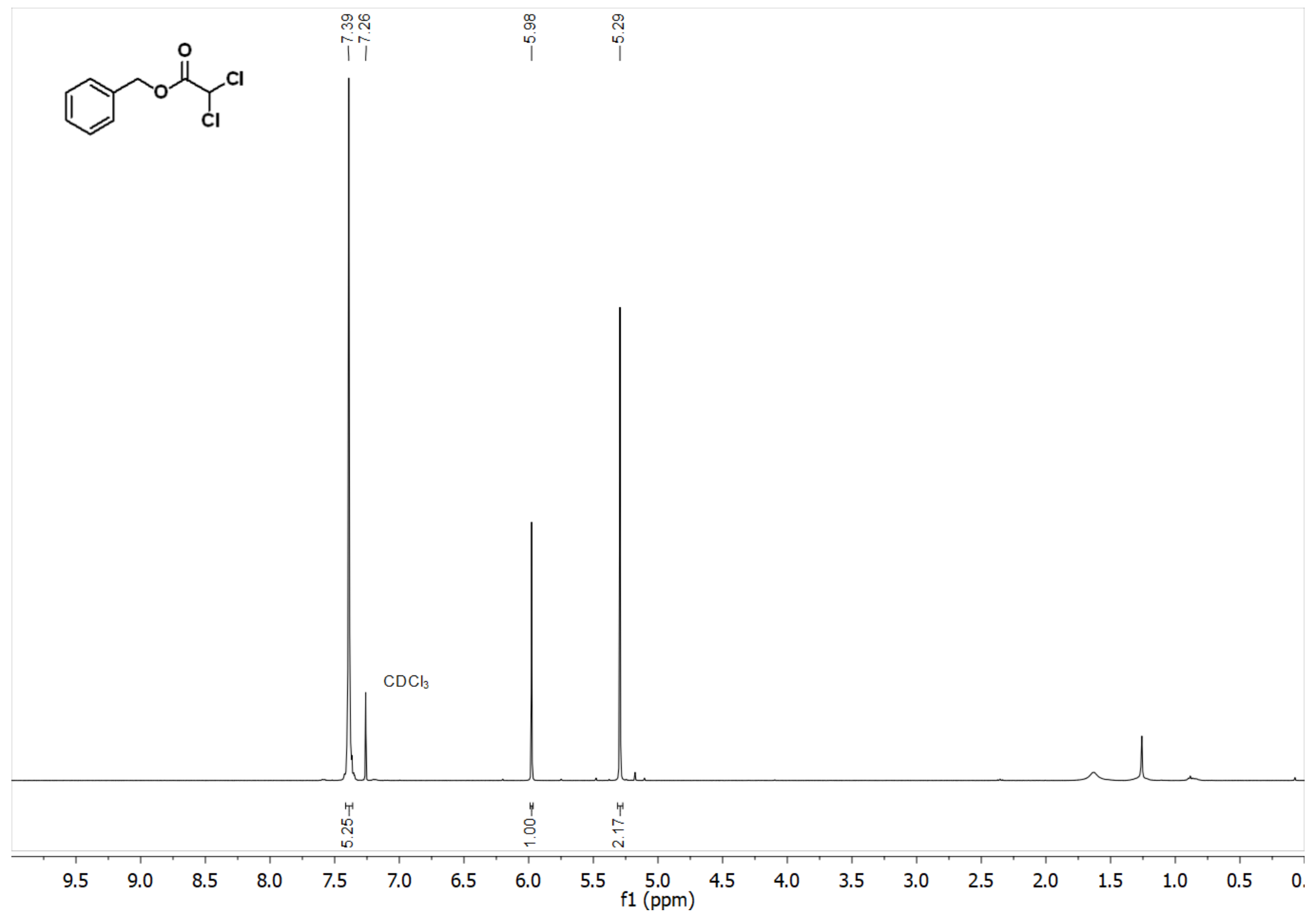


${ }^{13} \mathrm{C}$ NMR (101 MHz, $\mathrm{CDCl}_{3}$ ) spectrum of $16 \mathrm{c}$ benzyl 2,2-dichloroacetate

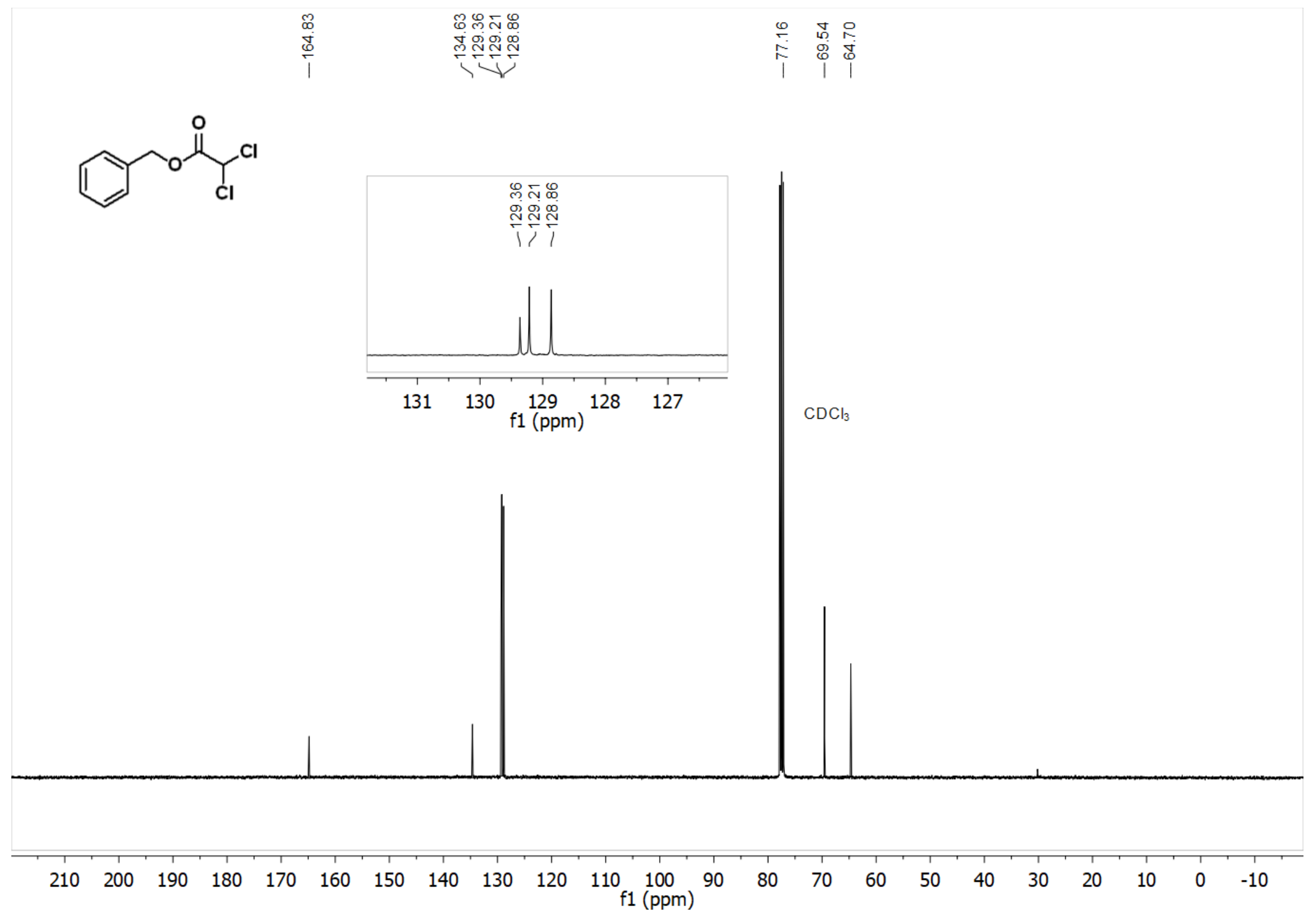




\section{GC and MS of 16c benzyl 2,2-dichloroacetate}

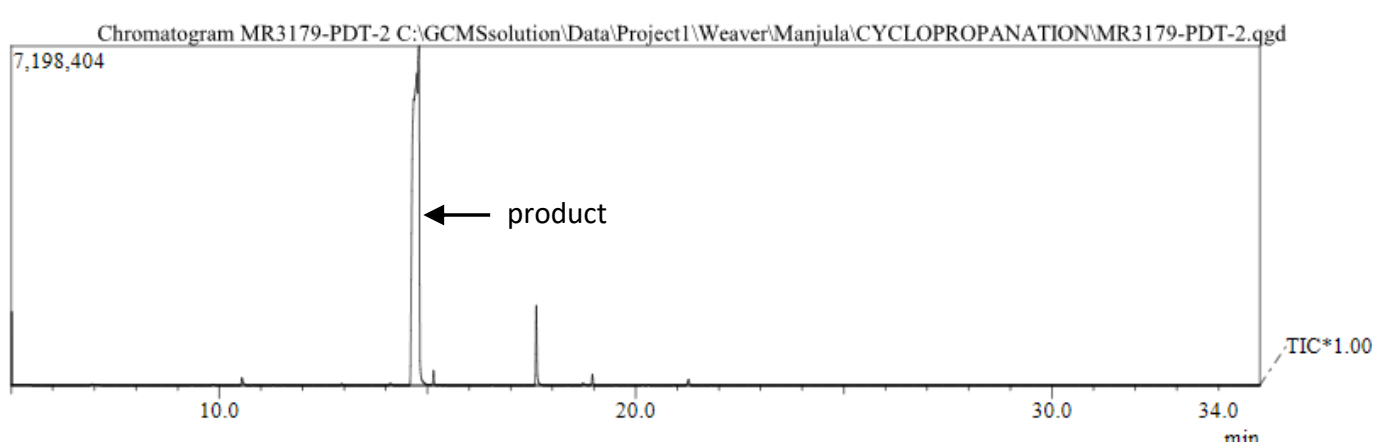

Spectrum

Line\#:1 R.Time:14.7(Scan\#:1163)

RawMode:Single 14.7(1163) BasePeak:91(2023471)

BG Mode: None

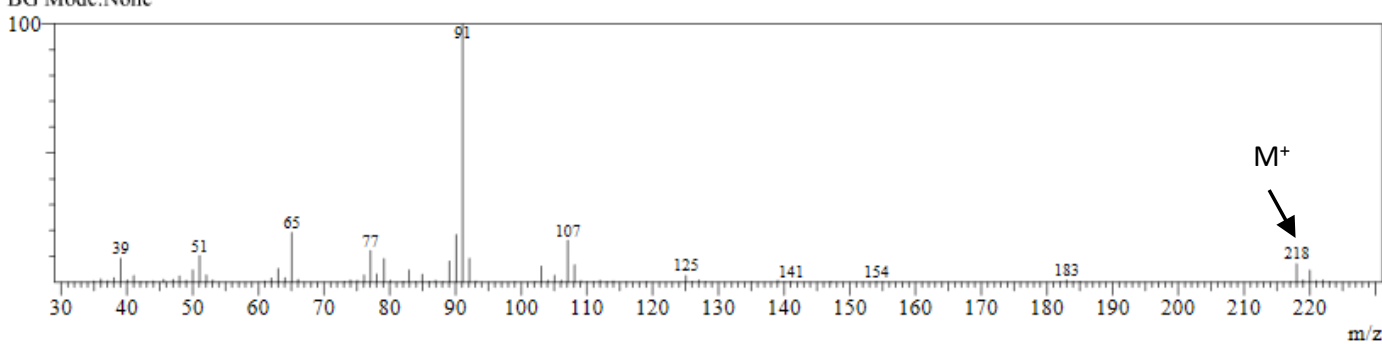

Linetf:2 R.Time:17.6(Scan\#:1518)

RawMode'Single 17.6(1518) BasePeak:91(33849)

BG Mode: None

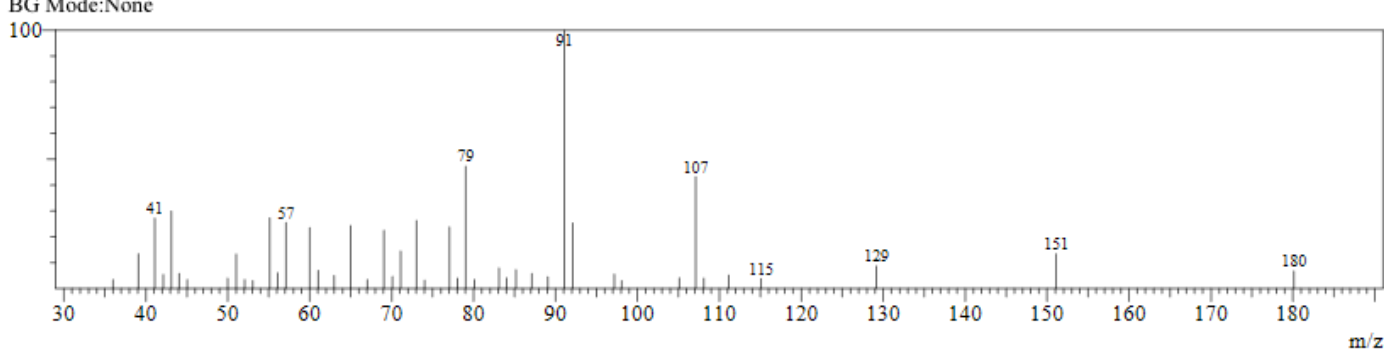

